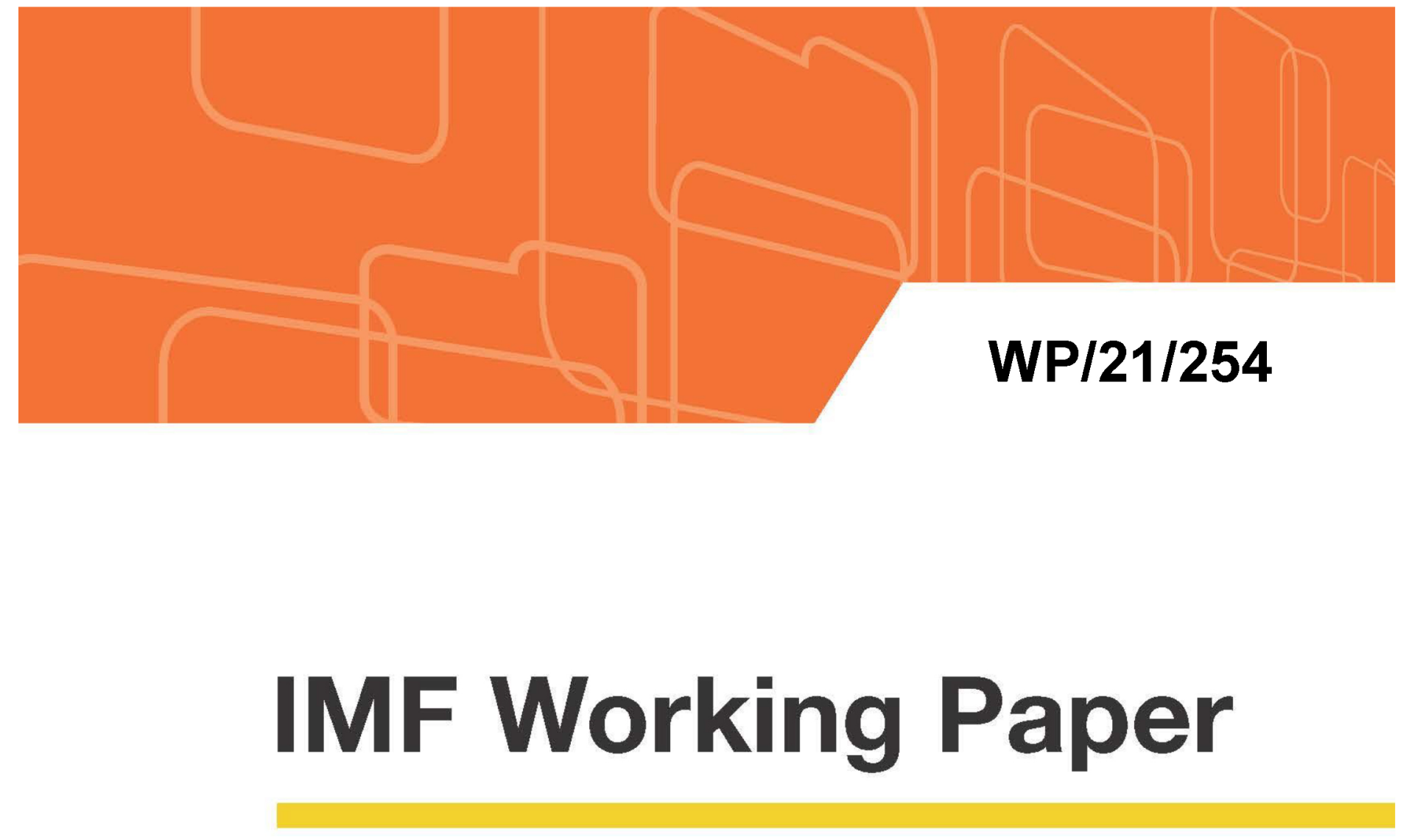

\title{
Safe Asset Demand, Global Capital Flows and Wealth Concentration
}

by Taehoon Kim

IMF Working Papers describe research in progress by the author(s) and are published to elicit comments and to encourage debate. The views expressed in IMF Working Papers are those of the author(s) and do not necessarily represent the views of the IMF, its Executive Board, or IMF management.

$$
\text { I N T E R N A T I O N A L M O N E T A R Y F U N D }
$$




\title{
IMF Working Paper
}

Research Department

\section{Safe Asset Demand, Global Capital Flows and Wealth Concentration \\ Prepared by Taehoon Kim}

Authorized for distribution by Deniz Igan

October 2021

\begin{abstract}
IMF Working Papers describe research in progress by the author(s) and are published to elicit comments and to encourage debate. The views expressed in IMF Working Papers are those of the author(s) and do not necessarily represent the views of the IMF, its Executive Board, or IMF management.
\end{abstract}

\begin{abstract}
The US economy is often referred to as the "banker to the world," due to its unique role in supplying global reserve assets and funding foreign risky investment. This paper develops a general equilibrium model to analyze and quantify the contribution of th is role to rising wealth concentration among American households. I highlight the following points: 1) financial globalization raises wealth inequality in a financially-developed economy initially due to foreign capital pressing up domestic asset prices; 2) much of this increase is transitory and can be reversed as future expected returns on domestic assets fall; and 3) despite the low-interest-rate environment, newly accessed foreign capital provides incentives for affluent households to reallocate wealth toward risky assets while impoverished households increase their debt. Wealth concentration ensues only if this rebalancing effect is large enough to counteract diminished return on domestic assets. Quantitative analysis suggests that global financial inte gration alone can account for a third to a half of the observed increase in the current top one percent wealth share in the US, but indicates a possible reversal in the future.
\end{abstract}

JEL Classification Numbers: F36, F41, E21, E44

Keywords: Global capital flows, Financial integration, Safe asset, Wealth inequality Authors' E-Mail Addresses: tkim@imf.org 


\section{Contents}

1 Introduction $\quad \underline{3}$

2 Core Model $\quad \underline{10}$

2.1 Setup ................................

2.2 Effect of Financial Globalization $\ldots \ldots \ldots \ldots \ldots$

2.3 Back-of-the-Envelope Calculation . . . . . . . . . . . . . 17

3 Closed Economy $\quad \underline{19}$

3.1 Model Extension . . . . . . . . . . . . . . . . . . 20

3.2 Market Clearing Conditions . . . . . . . . . . . . . $\underline{22}$

3.3 Comparative Statics . . . . . . . . . . . . . . . . . . 22

4 Financial Globalization $\quad \underline{24}$

4.1 Security Market Liberalization . . . . . . . . . . . . . . . $\underline{24}$

4.2 FDI Liberalization . . . . . . . . . . . . . . . . . $\ldots$

4.3 Cross-country implications . . . . . . . . . . . . . . . 27

5 Taking the Model to the Data $\underline{28}$

5.1 Quantitative Extension . . . . . . . . . . . . . . . 29

5.2 Numerical Method . . . . . . . . . . . . . . . . . . $\underline{30}$

5.3 Calibration Strategy . . . . . . . . . . . . . . . .

6 Quantitative Analysis $\quad \underline{36}$

6.1 Model Fit . . . . . . . . . . . . . . . . . $\underline{36}$

6.2 Result 1: Transitional Dynamics . . . . . . . . . . . . . . $\underline{36}$

6.3 Result 2: Reversal of the Trend . . . . . . . . . . . . . . . . $\underline{39}$

6.4 Result 3: Factor Decomposition . . . . . . . . . . . . . . 41

7 Conclusion $\quad \underline{43}$

A Detailed Proofs $\quad \underline{48}$

A.1 Proof of Proposition $1 \ldots \ldots \ldots \ldots \ldots$ 


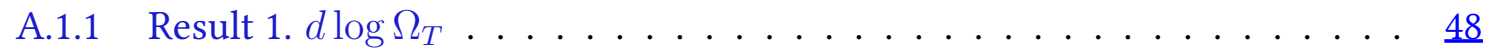

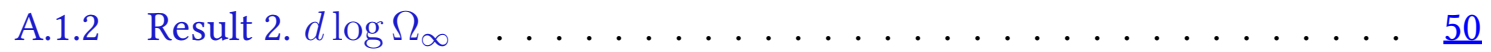

A.2 More Details on Dynamics … . . . . . . . . . . .

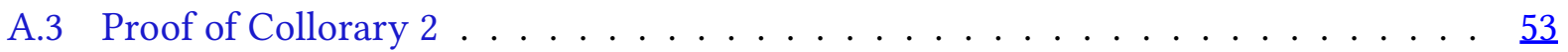

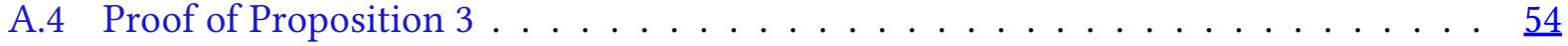

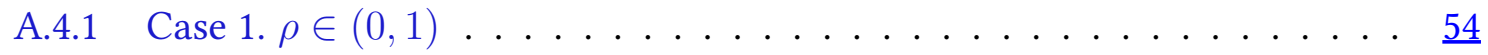

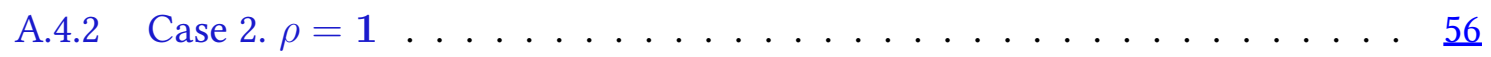

A.5 More Details on Foreign Direct Investment . . . . . . . . . . . . 57

A.6 Proof of Proposition $4 \ldots \ldots \ldots \ldots \ldots \ldots$

A.7 More Details on the Money Premium . . . . . . . . . . . . . . 62

B HJB Equations $\quad \underline{63}$

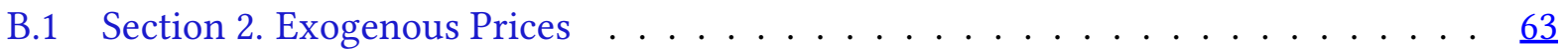

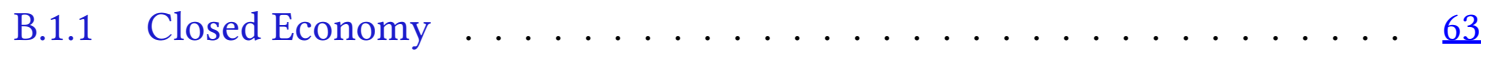

B.1.2 Open Economy . . . . . . . . . . . . . . . . . . . . . . . 64

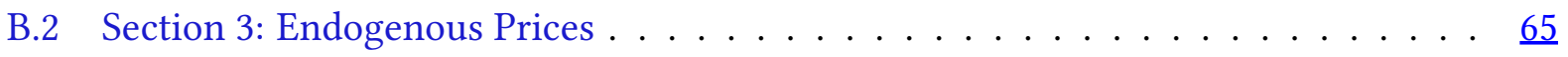

B.2.1 Closed Economy $\ldots \ldots \ldots \ldots \ldots \ldots \ldots \ldots$

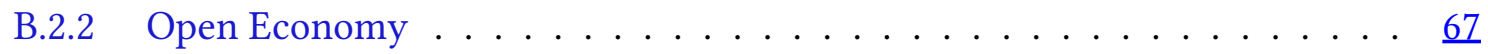

C Quantitative Analysis

C.1 Closed Economy . . . . . . . . . . . . . . . . . . . . . . . . . . . $\underline{69}$

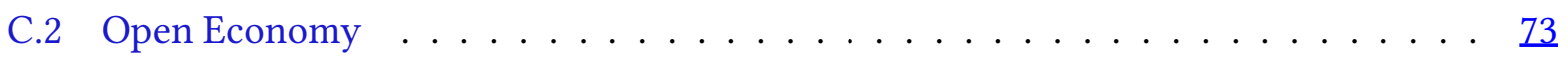

D Additional Details $\underline{77}$

D.1 Estimation of the Risk Premium . . . . . . . . . . . . . . .

D.2 Kolmogorov Forward Equation $($ Section 2$) \ldots \ldots \ldots \ldots \ldots$

D.3 Convergence of the Wealth Distribution . . . . . . . . . . . . . . 79

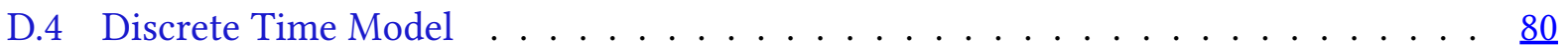




\section{Introduction $^{1}$}

The United States is often referred to as the "banker to the world," due to its unique role in supplying global reserve assets and funding foreign risky investment (Kindleberger 1965, Gourinchas and Rey 2007). The rapid advancement of financial globalization in recent decades has allowed US economic entities to seek funding from foreign investors, created new investment opportunities, and changed the market value of domestic assets owned by American households. However, despite the US being the centerpiece of global financial architecture, little research has studied the effect of capital flows on the domestic household wealth distribution.

This paper takes a first stab at the mechanism. Using new methods for modeling heterogeneous agent economies, I show that the liberalization of financial flows between the central and peripheral economies potentially accounts for $34 \%$ to $55 \%$ of the observed increase in the current top one percent wealth share in the US. Yet, the model also implies that the trend in rising wealth concentration could reverse over the course of the twenty-first century.

The key factor here is a contrast between (a) the low interest rate and the inflated market value of US domestic assets due to capital inflows and (b) the expansion of new risky investment outflows such as global equity, and the foreign direct investment (FDI) of multinational firms. The future trajectory of wealth concentration depends on the relative sizes of these two forces as they dictate household investment, debt raising, and domestic asset valuation. The main contribution of this paper is to use a tractable modeling framework to elucidate the linkage of global financial flows to wealth concentration. I also offer a new angle on the rising wealth inequality in America, which is most often seen simply as a permanent trend.

This study is motivated by three major changes in the American capital market, which have drawn much attention among economists in international finance and macroeconomics:

- Financial globalization: Capital account liberalization has integrated global financial markets to a remarkable degree since the 1980s. The sum of foreign assets and liabilities in the US scaled by GDP-a de facto measure of financial integration-surged from $48.3 \%$ in 1980 to $324 \%$ in 2017. As of 2017, foreign portfolio equity and FDI account for $40.3 \%$ of the total value of equity held by American households (see Figure 1a). Foreign investors own $30.0 \%$ of US corporate bonds outstanding and $44.5 \%$ of US treasuries (US Department of the Treasury 2018).

\footnotetext{
${ }^{1}$ This paper previously circulated under the title "The World's Banker: On the Rise in US Wealth Inequality." I am grateful to my advisors, Gita Gopinath, Pol Antràs, Kenneth Rogoff, and Jeremy Stein, for their thoughtful advice. I would also like to thank John Campbell, Vu Chau, Thummim Cho, Xiang Ding, Emmanuel Farhi, Xavier Gabaix, Jesus Fernandez-Villaverde, Elhanan Helpman, Yosub Jung, Casey Kearney, Divya Kirti, Spencer Kwon, Andrew Lilley, Matteo Maggiori, Michael-David Mangini, Ben Moll, Giselle Montamat, Elisa Rubbo, Gea Hyun Shin, Hillary Stein, Ludwig Straub, Maria Voronina, Brian Wheaton, and Paul Willen for their feedback. All errors are my own.
} 
- Banker to the world: The US is the world's dominant supplier of global reserve assets and fixed income securities. Its cross-border asset positions, by contrast, are mainly composed of equity and FDI (see Figure 1b). Because of this two-way capital flow, the US is often described as the "banker to the world" or even the "venture capitalist to the world." (e.g. Gourinchas and Rey 2007, Gourinchas and Rey 2010)

- Wealth concentration \& household balance sheet: Wealth distribution and household balance sheet in the US have been shifted asymmetrically across wealth groups. In terms of the distribution shape, the estimated wealth share of the top one percent of households, by wealth, rose from 24.3\% to $41.8 \%$ from 1980 to 2011. (Saez and Zucman 2016) In terms of the balance sheet, those same households have substantially increased their exposure to equity, even though equity earnings yield has declined (see Figure 1c). The bottom 90 percent has not increased its share in equity as much, while its household debt has surged (see Figure 1d).

These facts naturally lead us to ask the following questions: how does financial globalization affect the return on capital owned by the wealthiest magnates, such as George Soros and Phil Knight ${ }^{2}$, while promoting debt among the middle class? To what extent is wealth inequality driven by foreign investors pressing up US domestic asset prices? Is the increased wealth concentration permanent, or rather transitory? In this paper, I develop a unified model to answer these questions quantitatively.

Three modeling ingredients deserve comment. First, I assume that households have decreasing relative risk aversion. ${ }^{3}$ This implies that affluent households invest more heavily in risky assets than impoverished households do. More importantly - and somewhat subtly-the decreasing relative risk aversion makes affluent households readjust their balance sheet more elastically whenever there is a change in risk compensation; impoverished households are relatively stuck in safe assets or in debt.

Second, safe assets are short-term assets such as bank deposits whereas risky assets are longterm assets such as equities. An unanticipated drop in interest rates thus generates capital gains for equity holders, while deposit holders receive only contemporaneous yields.

\footnotetext{
${ }^{2}$ George Soros is the founder of Soros Fund Management, which invests in foreign currency, equity, and fixed income markets across the globe. Phil Knight is a cofounder of Nike, Inc. As of 2017, foreign direct investment outside North America accounts for $68.8 \%$ of Nike's long-term physical assets i.e., Property, Plant and Equipment.

${ }^{3}$ I consider a standard HARA (hyperbolic absolute risk aversion) utility that exhibits decreasing relative risk aversion. In the paper, decreasing relative risk aversion is defined only in this narrow class of utility functions. The functional form has been used in various contexts including portfolio choice models (e.g., Litzenberger and Rubinstein 1976) and habit formation models (e.g. Campbell and Cochrane 1999). See Ogachi and Zhang (2001) and the related literature for micro-level evidence that supports decreasing relative risk aversion for portfolio choice.
} 
Figure 1: Financial Globalization and Household Balance Sheet

(a) Foreign Equity as Share of Total Equity Holdings

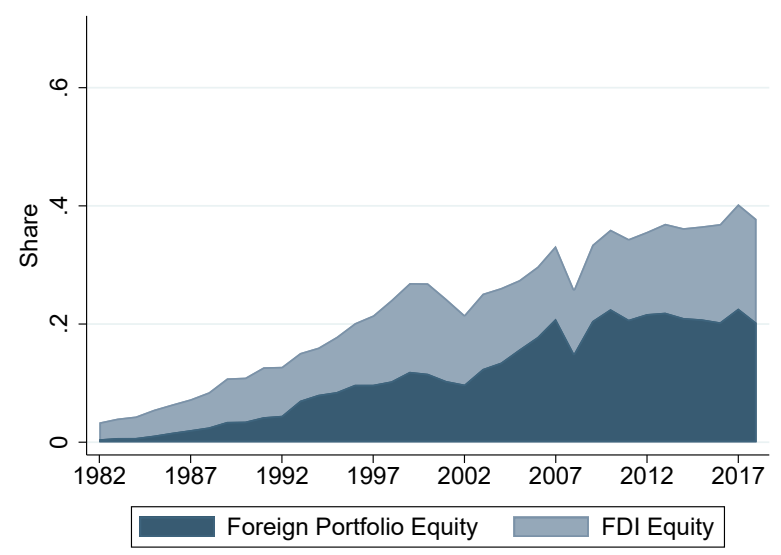

(c) Asset Allocation by Wealth Group
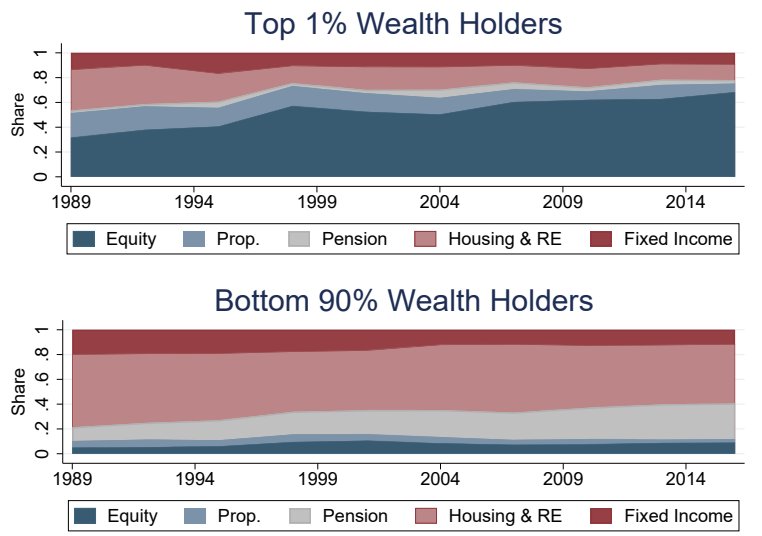

(b) External Balance Sheet, 2017

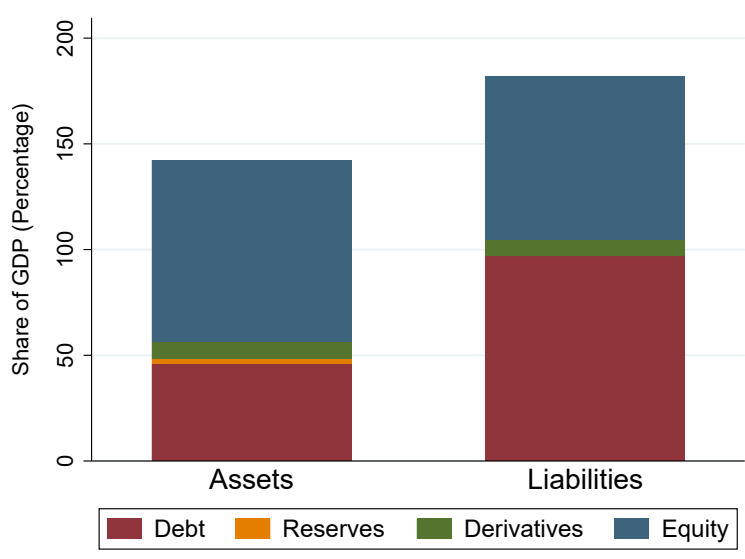

(d) Debt-to-income Ratio

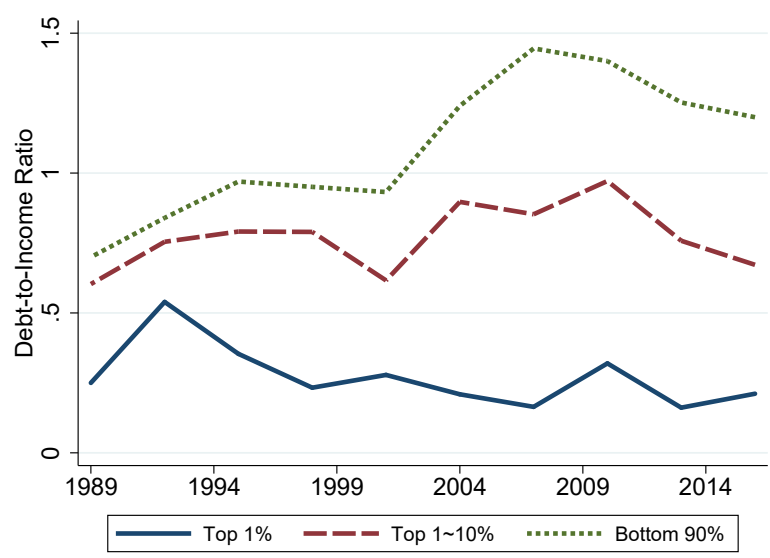

Notes. Panel (a): The numerators are the estimated values of foreign portfolio equity and direct investment equity reported in IIP Table 1.2., from the Bureau of Economic Analysis. The denominator is the estimated total value of equity held by US residents reported in the Fedfis Financial Account (Series Code: FL153081005). Panel (b): IIP Table 1.2., Bureau of Economic Analysis. Panel (c): Survey of Consumer Finances. "Prop." represents proprietorship and partnership assets, while "RE" represents real estate. Panel (d): Survey of Consumer Finances. Mortgage and non-mortgage debts are all considered. 
Third, banks ${ }^{4}$ in peripheral countries have limited abilities to create riskless debt, due to the inferior banking system relative to the financial center country (i.e., the most financially-developed country). The supply of safe assets is thus limited in those regions. Besides, since equity financing involves a transaction cost beyond the risk premium, these banks end up facing a higher overall cost of capital. The total investment is thus restrained. Essentially, the financial center country such as the US is endowed with a comparative advantage in manufacturing safe assets, and with absolute advantages in both safe and risky assets. The center country therefore exports safe assets, imports risky assets and, becomes a net debtor after crossborder investment barriers are lifted.

With this structure in place, I first show that global integration increases wealth concentration in the financial center country, initially due to foreign capital pressing up domestic asset prices (i.e., the Revaluation Effect). The market value of domestic equity appreciates immediately as its required rate of return has fallen. Affluent households reap more capital gains because their exposure to domestic equities is higher prior to the shock. In the model, the required expected return on domestic equity consists of the risk-free interest rate plus the domestic risk premium. After global financial markets are integrated, the overall required return for US domestic equity is decreased by the excess demand for US assets from foreign countries. The domestic equity price immediately reflects this change, generating capital gains for wealthy households who subsequently earn a lower expected return.

A more important point, however, is that this effect is transitory. The inflated top wealth share gradually disappears and, in the distant future, it can even be reversed (i.e., the Declinein-return Effect). The basic principle of finance is the inverse relation between price and return. Whatever prompts asset-price inflation will, in turn, lower future expected returns on existing assets. The short-run effect of capital gains dissipates gradually; within a generation, households smooth their consumption in the lower-interest-rate environment. Between generations, wealth inheritance is imperfect. In the new stationary state, the top wealth share is eventually suppressed by the lower future expected return on existing domestic assets.

What might generate a persistent concentration of wealth, in the case of financial globalization, is asymmetric balance sheet readjustment amongst household groups in the new environment (i.e., the Rebalancing Effect). After capital gains are realized, households in the financial center country face a lower risk-free interest rate with the entry of foreign investors. At the same time, they gain access to new foreign risky assets, whether in the form of global equity or of the FDI outflow of multinational firms. Thus, the new investment portfolio, combining foreign and domestic risky assets, offers a higher risk-to-reward ratio than the pure domestic counterpart in

\footnotetext{
${ }^{4}$ Banks here can be more accurately thought of as any consolidated entity, a category encompassing private sector companies, financial intermediaries, and government.
} 
autarky. The tilted expansion of the investment frontier offers households incentives to reallocate wealth to risky assets. Affluent households increase exposure to risky assets more elastically than impoverished households, due to decreasing risk aversion. The average return on wealth between the two household groups diverges. Wealth concentration ensues in the financial center country if this rebalancing effect is large enough to counteract diminished returns on domestic assets.

I first illustrate these key points with a simple setup. The model is then extended to include additional features-such as household debt, entrepreneurial income, and FDI-to gain a full understanding of the distributional effects of financial globalization. These components reinforce the main idea: indebted households take on more debt as the interest rate falls. The increased household debt lowers the net worth of the bottom household group, which in turn raises the top wealth share in the financial center country. Entrepreneurial income rises as entrepreneurs face a lower cost of capital. The market-equivalent value of entrepreneurial equity is further increased by a lower required return in the financial market. Lastly, FDI outflow of domestic firms allows for more expansion of risky assets. It strengthens incentives-particularly for rich households-to reallocate wealth to risky assets. All in all, global integration provides an environment conducive to wealth concentration in the financial center country ${ }^{5}$ although, as before, the long-run trajectory still depends on the relative magnitudes of (a) the decrease in domestic interest rates and (b) the expansion of foreign assets.

Finally, I take the model to the data. Quantitatively, to what extent does financial globalization explain the recent change in US wealth distribution? How much of that change is permanent? I estimate the model's key parameters from various sources of data-ranging from the Fed's Survey of Consumer Finances to the BEA's National Economic Accounts-to assess the quantitative magnitude of the effect of financial globalization. The national accounts data are used to construct a time series of average realized returns on various asset classes, including cross-border assets and liabilities of the US economy. Each asset class is linked with its fundamentals-such as dividends, earnings, and rents at the macro-economy level-so as to estimate their risk premia, Sharpe ratios (i.e., risk premium divided by its standard deviation), and capital gains. With these estimates, I apply solution methods developed by the heterogeneous-agent macro literature (Ahn et al. 2018, Fernández-Villaverde et al. 2018 and Kaplan et al. 2018) to conduct a full-blown quantitative analysis.

The effect is quantitatively sizable; in the calibrated model, a global integration shock alone accounts for $34 \%$ to $55 \%$ of the observed increase in the top one percent's wealth share in the United States since $1989 .{ }^{6}$ At least over the past three decades, the portfolio rebalancing effect

\footnotetext{
${ }^{5}$ Distribution effects in outside countries are less clear. Section 4.3 discusses cross-country implications.

${ }^{6}$ I choose 1989 as the benchmark year for the pre-globalization economy due to data availability, such as Survey
} 
appears to outweigh diminished returns on domestic assets in light of the estimates in the data. Yet, the model leaves room for a reversal. The recent decline of yields on US domestic assets suggests that a reversal of the trend in rising wealth inequality is not impossible in the upcoming future. I provide back-of-the envelope calculations of when this would be the case and a full quantitative analysis to support this claim. Later on, I decompose the contributions of several factors to rising wealth concentration. For the top one percent's wealth share, widened wage inequality has a smaller impact than global financial integration. This is because, in the calibrated model, a major source of income for the wealthy is capital, not labor.

By shedding light on the architecture of global finance, this study offers a novel argument for why, amongst the developed economies, the US has experienced a particularly large increase in wealth concentration. The US is often referred to as the global banker, due to its exclusive role as liquidity provider in international financial markets (Gourinchas and Rey 2007, Gourinchas and Rey 2010, Eichengreen 2011). My paper suggests that this unique function of the US economy played a prominent role in transforming domestic financial prices during the period of rapid global integration, thereby fostering wealth concentration amongst American households. It also provides theoretical underpinnings for cross-country studies finding that capital account liberalization was followed by increased income inequality ${ }^{7}$ (Jaumotte et al. 2008, Furceri and Loungani 2015, Furceri et al. 2017), although the focus of this paper is more on wealth inequality and on the US economy. While most of the literature explores trade liberalization and wage inequality ${ }^{8}$, I emphasize the importance of capital income and the financial side of globalization.

Methodologically, this paper contributes to the literature by proposing a tractable model for studying macro-finance implications of global financial flows. It has been widely documented that a higher foreign demand for US debt securities can account for a decline in safe yields over the past decades (e.g. Caballero et al. 2008, Mendoza et al. 2009). Yet, less attention has been paid to the relationship between foreign factors and other financial variables, such as risk premium, Sharpe ratio, required expected return, corporate profits, and the portfolio frontier, which are all essential to understanding the distribution of capital income. Even studies that incorporate one or two of these elements require heavy numerical computation (Dou and Verdelhan 2015, Maggiori 2017). The model in this paper is more versatile. It allows for comparative statics with simple equilibrium solutions as well as a full quantitative analysis with numerical simulations. These modeling tools can potentially be used to understand time-varying changes in returns on various assets (Jordà et al. 2017), especially in the international context.

of Consumer Finances. See Section 5 for more details.

${ }^{7}$ In particular, Jaumotte et al. (2008) shows that financial globalization and FDI are associated with an increase in inequality, much more so than is trade liberalization. Cross-country implications of my model are revisited in Section 4.3.

${ }^{8}$ See Helpman (2018) for the most up-to-date review on globalization and inequality. 
Lastly, this study adds a new angle to the literature on heterogeneous-agent macroeconomics. I treat capital income more carefully than existing studies on wealth inequality. I also elaborate on the underlying mechanism behind a structural change in capital income. Since Piketty (2014) was published, capital income has gained much attention as a crucial driver for rising wealth inequality in advanced economies. Many studies concur (e.g. Hungerford 2011, Bach et al. 2018, Fagereng et al. 2018). Yet, the standard models in the literature simply abstract capital income into the rental rate $r$ of physical capital (Aiyagari 1994), the risk-free interest rate (Bewley 1983, Huggett 1993), or the profits of non-public firms (Quadrini 2000, Cagetti and De Nardi 2006) with little modeling of financing instruments such as tranching, pooling, and portfolio diversification. More recent studies emphasize return heterogeneity (Hubmer et al. 2018, Kacperczyk et al. $2018^{9}$ ). This paper also relates to the literature on trade liberalization and wealth dynamics. (Chesnokova 2007, Antràs and Caballero 2010) For modeling tools, I embed global financial markets to a model of Pareto Inequality which orginates back to Champernowne (1953). ${ }^{10}$ Unlike these studies, I shed light on determinants of financial variables - including risk premium, Sharpe ratio, capital gains, and portfolio frontier-and how changes in these variables transform wealth distribution over different time horizons. This framework can be applied to structural changes other than financial globalization, such as financial innovation and capital tax reform.

The rest of the paper is organized as follows. Section 2 presents a stripped-down version of the model to present my core predictions. Section 3 develops general equilibrium foundations. Section 4 discusses distributional effects of security market liberalization and foreign direct investment as well as the cross-country implications. Section 5 takes the model to the data, confirming that empirical patterns are consistent with the main predictions of the model. Estimates for the key parameters are also presented. Section 6 uses a calibrated model to assess to the extent to which financial globalization can account for the observed increased in wealth concentration in the United States. Section 7 concludes.

\footnotetext{
${ }^{9}$ Kacperczyk et al. (2018) agree on the importance of endogenous portfolio choices in driving wealth inequality in a closed economy, although their study focuses on the advancement of information acquisition technology and does not consider the revaluation gain channel.

${ }^{10}$ The literature on Pareto-inequality models has a long history and numerous applications. See Gabaix (2009), Jones (2015) and Benhabib and Bisin (2018) and for recent surveys of studies.
} 


\section{Core Model}

To illustrate the mechanism, I begin by considering the simplest case of financial globalization: the set of investment opportunities available to households is fixed, and then transformed by global integration of financial markets. The interest rates on these assets are exogenously given and then changed. I characterize the immediate and persistent effects of this shock on the household wealth distribution. The model is extended step by step in later sections: from market clearing conditions to labor income and household debt.

\subsection{Setup}

Households Consider a closed economy populated by a continuum of households. The measure of households is normalized to unity. Household $i$ is endowed with initial wealth drawn from a probability density function, $g_{0}$. Time is continuous. In a closed economy, each household has access to two types of investments: a risk-free asset and a domestic risky asset. The riskfree asset yields $r^{*} d t$ with certainty. The domestic risky asset yields $\left(r^{*}+\sigma_{1} s_{1}^{*}\right) d t+\sigma_{1} d z_{1 t}$, where $\sigma_{1} s_{1}^{*}$ represents the risk premium and $d z_{1 t}$ represents the increment of a Wiener process. To conceptualize the price of risk, I decompose the risk premium into two parts: the standard deviation of returns, $\sigma_{1}$, and the Sharpe ratio (=an asset's risk premium divided by its standard deviation) of the domestic risky asset, $s_{1}^{*}$. By definition, $s_{1}^{*}$ can be viewed as a reward for taking one unit of domestic risk. The domestic risky asset is indexed by 1 . An asterisk in the superscript is used to indicate an autarky price.

The portfolio frontier spanned by the two basis assets, $\left\{r^{*},\left(s_{1}^{*}, \sigma_{1}\right)\right\}$, plays a central role in households' saving decisions. ${ }^{11}$ For the moment, assume that the portfolio frontier is exogenously given, so the values of $r^{*}$ and $s_{1}^{*}$ stay constant over time. We will consider a general equilibrium foundation in the next section.

Given the constant portfolio frontier, $\left\{r^{*},\left(s_{1}^{*}, \sigma_{1}\right)\right\}$, household $i$ maximizes lifetime utility by choosing consumption flow, $c_{i t}$, and the share of savings in the domestic risky asset, $\theta_{1 i t}$. Let $\delta$ denote the time discount rate. Household $i$ born at time 0 seeks to maximize

$$
\max _{\theta_{1 i t}, c_{i t}} \mathbb{E}_{0}\left[\int_{0}^{\infty} e^{-(\delta+m) t} \log \left(c_{i t}-\kappa\right) d t\right]
$$

\footnotetext{
${ }^{11}$ The Mutual Fund Theorem (e.g. Merton 1971) implies that $\left\{r^{*},\left(s_{1}^{*}, \sigma_{1}\right)\right\}$ embodies 1 risk-free asset and $N$ risky assets without loss of generality.
} 
The budget constraint is given by

$$
d a_{i t}=\left[\left(r^{*}+\sigma_{1} s_{1}^{*} \theta_{1 i t}\right) a_{i t}-c_{i t}\right] d t+\sigma_{1} \theta_{1 i t} a_{i t} d z_{1 t}
$$

In the core model, financial assets are the only sources of income for households. The two parameters, $m$ and $\kappa$, in the household's problem deserve further comments.

First, $m$ is intended to capture the death probability. As in the perpetual youth model (Yaari 1965, Blanchard 1985), a fraction $m$ of households die and lose their wealth at every instantaneous time. These households are replaced by offsprings whose wealth endowments are re-drawn from the initial density distribution, $g_{0}$. Wealth dispersion of the newborn households, $g_{0}$, differs from wealth dispersion of the deceased households, $g_{t} .{ }^{12}$ The discrepancy between the two distributions implies that wealth of parents is not fully transferred to wealth of their children. A large value of $m$ intensifies the imperfect wealth inheritance.

Second, $\kappa>0$ in the flow utility captures decreasing relative risk aversion. ${ }^{13}$ This assumption implies that wealthy households not only invest in the risky asset more heavily than impoverished households, but they are also more responsive to a change in risk compensation. This property can be seen most clearly from solutions of a household's problem (Merton 1971)

$$
c_{i t}=\underbrace{(\delta+m) a_{i t}+\left(r^{*}-\delta-m\right) \underline{a}}_{\text {Consumption Flow }} \quad \theta_{1 i t}=\underbrace{\frac{s_{1}^{*}}{\sigma_{1}}\left(1-\frac{\underline{a}}{a_{i t}}\right)}_{\text {Share of Risky Savings }}
$$

where $\underline{a} \equiv \frac{\kappa}{r^{*}}$ denotes the wealth cutoff. All households choose to retain wealth above this cutoff to avoid negative consumption (i.e., $a_{i t} \geq \underline{a}$ ). Expression (3) shows that the share of savings invested in the domestic risky asset increases with individual wealth, $a_{i t}$, and falls to zero when $a_{i t}=\underline{a}$. Furthermore, $\frac{\partial^{2} \theta_{1 i t}}{\partial a_{i t} \partial s_{1}^{*}}>0$ implies that wealthy households respond to a change in $s_{1}^{*}$ more elastically.

There are several ways to interpret $\underline{a}$. The cutoff can be viewed as the minimum level of wealth that should be retained every period. Households whose wealth is near this threshold invest more heavily in the safe asset to meet the subsistence consumption level, $\kappa$, without any uncertainty. On the other hand, households with a sufficiently large stock of wealth are relatively free of this concern so they invest more heavily in the domestic risky asset. Note that (i) household debt and

\footnotetext{
${ }^{12}$ Every $k$ 'th moment of $g_{0}$ is assumed to be finite, which implies that $g_{0}$ does not have excessively thick tails. Examples of such distributions include normal, and lognormal distributions. Also, I impose $\int_{-\infty}^{\infty} g_{0}(a) d a \leq$ $\int_{-\infty}^{\infty} g_{t}(a) d a$. The strict inequality can be interpreted as a deadweight loss.

${ }^{13}$ The flow utility in the objective function belongs to the class of HARA (hyperbolic absolute risk aversion) utility functions. This functional form has been used in various studies such as portfolio choice models (e.g., Litzenberger and Rubinstein 1976). In my paper, decreasing relative risk aversion is defined only in this narrow class of utility functions.
} 
(ii) private equity are missing in the core model. I will discuss them in later sections.

Asset Price Another important assumption is that the domestic risky asset is a long-term asset, much like equity. The safe asset is assumed to be a short-term asset, much like bank deposit. To capture this aspect, let $n_{i t}$ denote the number of domestic risky asset shares invested by household $i$, and $p_{t}$ denote the price per share. Each share is a contract that transfers $\sigma_{1} d z_{1 \tau}$ to its holder. The contract pledges constant future dividend $x d t$ for all $\tau \geq t$. Given an exogenous market price $\left\{r^{*},\left(s_{1}^{*}, \sigma_{1}\right)\right\}$, the expected return on the risky asset in the budget constraint (2) can be decomposed into

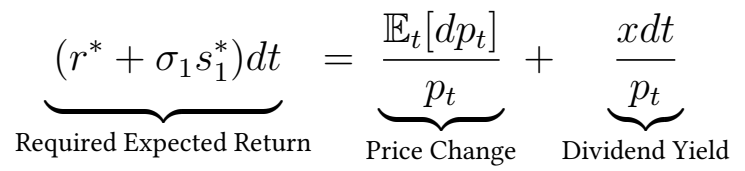

For tractability, I focus on the case where $x=r^{*}+\sigma_{1} s_{1}^{*}$ and $p_{t}=1$ for all $t .{ }^{14}$ The price of the domestic risky asset stays constant as long as there is no unanticipated change in the economy. The savings in the domestic risky asset can then be written as $\theta_{1 i t} a_{i t} \equiv n_{i t}$. Conversely, an unanticipated change in the required expected return generates capital gains or losses for risky asset holders. Suppose, for example, the market required return drops unexpectedly to $r+\sigma_{1} s_{1}$ at time $T$, with $x$ being fixed. Then the price of the domestic risky asset should rise immediately to $\frac{r^{*}+\sigma_{1} s_{1}^{*}}{r+\sigma_{1} s_{1}}>1$ to satisfy (4). The price remains constant thereafter. The safe asset, on the other hand, does not pledge future cash flows beyond contemporaneous yield $r^{*}$. No capital gains or losses are generated even if there is a change in $r^{*}$

Wealth Distribution Lastly, let me define a measure of wealth concentration in the economy. We focus on a trajectory of aggregate shocks in which $d z_{1 t}=0$ for all $t$. Yet, households consider ex ante volatility, $\operatorname{Var}\left[\sigma_{1} d z_{1 t}\right]=\sigma_{1}^{2} d t$, in financial markets. ${ }^{15}$

The c.d.f. and p.d.f. of the wealth distribution, $G_{t}(a)$ and $g_{t}(a)$, are defined over this zero trajectory, so they evolve deterministically. We can characterize the evolution of $g_{t}$ by the below

\footnotetext{
${ }^{14}$ In other words, each share of the domestic risky asset pays variable cash flow $\sigma_{1} d z_{1 t}$ and fixed dividend $x d t$ at each instantaneous time. Given this, we can rewrite the budget constraint, (2), as $\left[\left(r^{*}+\sigma_{1} s_{1}^{*} a_{i t}\right) a_{i t}-c_{i t}\right] d t+$ $\sigma_{1} \theta_{1 i t} a_{i t} d z_{1 t} \equiv\left[r^{*}\left(1-\theta_{1 i t}\right) a_{i t}+x \theta_{1 i t} a_{i t}-c_{i t}\right] d t+n_{i t}\left(\sigma_{1} d z_{1 t}+d p_{t}\right)$.

${ }^{15}$ Similar approaches have been taken in previous studies, such as Fernández-Villaverde et al. (2018), Ahn et al. (2018) and Kaplan et al. (2018) to establish tractability. The notion of stationary state in my model corresponds to the stochastic steady state defined by Fernández-Villaverde et al. (2018).
} 
differential equation: ${ }^{16}$

$$
\frac{d}{d t} g_{t}(a)=-\underbrace{m g_{t}(a)}_{\text {(i) Death }}+\underbrace{m g_{0}(a)}_{\text {(ii) Newborn }}-\frac{d}{d a}[\underbrace{\left\{\left(r^{*}+\sigma_{1} s_{1}^{*} \theta_{1}(a)\right) a-c(a)\right\}}_{\text {(iii) Savings }} g_{t}(a)]
$$

Here, $\theta_{1}(a)$ and $c(a)$ indicate portfolio and consumption choices of a household whose wealth level is $a$. The differential equation in (5) is often referred to as the Kolmogorov Forward Equation (KFE) in the heterogeneous-agent model literature. The intuition for the KFE is as follows: the first term on the right hand side represents the wealth distribution of households who drop out due to death. The second term is the wealth endowment distribution of new-born households. The last term represents a change in the wealth distribution driven by savings of individual households. See Appendix D.2 and D.3 for the derivation of the KFE and its convergence property.

It is worth noting that, as time passes by, $g_{t}$ gradually converges to the stationary wealth distribution, $g_{\infty}$. In principle, a stationary wealth distribution is defined as a wealth distribution that stays constant over the course of time, i.e. $\frac{d}{d t} g_{\infty}(a)=0$, as the economy moves along the zero trajectory. Given any initial distribution, the long-term wealth distribution of the economy coincides with $g_{\infty}$. So one can think of $g_{\infty}$ as the distribution of wealth that will eventually arise in the distant future.

With this apparatus, I shed light on two measures of wealth inequality, $\Omega_{t}$ and $\Omega_{\infty}$, to characterize the short-run and long-run effects of financial globalization respectively.

Definition 1. Let $\Omega_{t}$ denote the top one percent's wealth share in $g_{t}$. Also, let $\Omega_{\infty}$ denote the top one percent's wealth share in the stationary state, which is approximated by the Pareto exponent ${ }^{17}$ of $g_{\infty}$. In other words,

$$
\Omega_{t}=\frac{\int_{G_{t}^{-1}(0.99)}^{\infty} a g_{t}(a) d a}{\int_{-\infty}^{\infty} a g_{t}(a) d a} \quad \text { and } \quad \Omega_{\infty} \equiv 100^{\frac{1}{\xi}-1}
$$

where the Pareto exponent, $\xi$, is defined as a constant stemming from $\lim _{a \rightarrow \infty} \frac{g_{\infty}(\tau a)}{g_{\infty}(a)}=\tau^{-(1+\xi)}$. Note that the approximation is exact (i.e., $\lim _{t \rightarrow \infty} \Omega_{t}=\Omega_{\infty}$ ) if $g_{\infty}$ coincides with a Pareto distribution.

These measures, $\Omega_{t}$ and $\Omega_{\infty}$, are used to investigate the short-run and long-run effects of financial globalization on wealth concentration respectively. The top $1 \%$ bracket is chosen for illustration, and can be replaced with any $n \%$ without loss of generality. Suppose now that global

\footnotetext{
${ }^{16}$ One may notice that the equation has no quadratic term that typically appears in a Kolmogorov Forward Equation. This is because the model has no idiosyncratic return and the wealth distribution is only defined along the zero trajectory.

${ }^{17}$ The approximation method yields analytically tractable results. See Jones (2015) and Gabaix et al. (2016) for other studies using this conversion.
} 
capital markets are integrated unexpectedly at time $T$. One can use $d \log \Omega_{T}$ to capture an immediate increase in the top one percent wealth share, and $d \log \Omega_{\infty}$ to capture a long-run increase.

\subsection{Effect of Financial Globalization}

I next investigate the effect of financial globalization. Prior to global integration, all households face the portfolio frontier spanned by $\left\{r^{*},\left(s_{1}^{*}, \sigma_{1}\right)\right\}$ : there are a single risk-free asset whose return is given by $r^{*}$, and a domestic risky asset whose risk premium is given by $\sigma_{1} s_{1}^{*}$. What financial globalization does is to transform the set of investment opportunities (=the portfolio frontier) available to households from the left to the right.

$$
\left\{r^{*},\left(s_{1}^{*}, \sigma_{1}\right)\right\} \Rightarrow\left\{r,\left(s_{1}, \sigma_{1}\right),\left(s_{2}, \sigma_{2}\right)\right\}
$$

The correlation between $d z_{1 t}$ and $d z_{2 t}$ is given by $\rho \in[0,1)$. There are two changes. First, the risk-free interest rate, and the Sharpe ratio of the domestic risky asset both take new values. Second, households gain new access to a foreign risky asset, which is indexed by 2 .

The key idea here is that financial globalization leads to a biased technological change in the US capital market due to the asymmetry in global financial markets. For expositional purposes, think of the US as a small open economy for the moment, and consider the following example. After global markets are integrated at time $T$, the financial center country undergoes a change in the portfolio frontier such that

$$
\begin{array}{lll}
\text { (a) } r<r^{*} & (b) s_{1}=s_{1}^{*} \quad(c) \sigma_{2}>0
\end{array}
$$

That is, households begin to face a lower risk-free interest rate, $r$, possibly because foreign investors willingly purchase US safe assets at a lower interest rate than domestic households do. For the moment, the Sharpe ratio of the domestic risky asset is assumed to be unchanged in the financial center country. Lastly, $\sigma_{2}>0$ implies that newly-added foreign assets are risky assets. As we show later, $s_{1}$ could differ from $s_{1}^{*}$ in general equilibrium depending on the risk profile of the outside world. In later sections I will formally characterize under what circumstances global integration results in these changes and how this relates to the asymmetry between the financial center country and peripheral economies.

The first question we ask is the following: given (6), how does financial globalization transform the evolution of the wealth distribution in the short run and in the long run? Essentially, 
global integration leads households' budget constraints to become

$$
\begin{aligned}
\underbrace{d a_{i t}}_{\text {Change in Wealth }}= & \left(\left(r+\left[\begin{array}{ll}
\theta_{1 i t} & \theta_{2 i t}
\end{array}\right]\left[\begin{array}{l}
\sigma_{1} s_{1} \\
\sigma_{2} s_{2}
\end{array}\right]+m\right) a_{i t}-c_{i t}\right) d t \\
& +a_{i t} \theta_{1 i t} \sigma_{1} d z_{1 t}+a_{i t} \theta_{2 i t} \sigma_{2} d z_{2 t}
\end{aligned}
$$

from time $T$ onward. To avoid pathological situations, I make two assumptions. First, I only consider cases where the optimal choices of $\theta_{1 i t}$ and $\theta_{2 i t}$ are non-negative. Second, the wealth cutoff, $\underline{a}$, is assumed constant. This prevents households at the bottom from suddenly falling into negative consumption (i.e. negative infinite utility) due to an unanticipated drop in $r{ }^{18}$ Under this setup, Proposition 1 below characterizes short-term and long-term changes in the top wealth share upon global financial integration.

Proposition 1. The short-term and long-term effects of financial globalization on the top one percent wealth share can be summarized as follows: ${ }^{19}$

$$
\begin{aligned}
& d \log \Omega_{T}=-\underbrace{\phi_{1} d \log \left(r+\sigma_{1} s_{1}\right)}_{\text {(i) Revaluation Effect }} \\
& d \log \Omega_{\infty}=\underbrace{\phi_{2} d \log \left(r+\sigma_{1} s_{1}\right)}_{\text {(ii) Decline-in-return Effect }}+\underbrace{\phi_{3} d \log s_{2}-\phi_{4} d \log \rho}_{\text {(iii) Rebalancing Effect }}
\end{aligned}
$$

where $\phi_{1}, \phi_{2}, \phi_{3}$, and $\phi_{4}$ are all positive coefficients.

Proof. See Appendix A.1

Corollary 1. Financial globalization widens wealth inequality immediately by generating capital gains. Wealth inequality is increased permanently only if $s_{2}$ and $1 / \rho$ are sufficiently large.

The core message of Proposition 1 can be summarized with three points. First, financial globalization raises wealth inequality in the short term through domestic asset price inflation (i.e., the Revaluation Effect). Recall that the discount rate for the domestic risky asset consists of the risk-free rate plus the risk premium. An unanticipated integration of global capital markets lowers the market required return, $r+\sigma_{1} s_{1}$, while the pledged future cash flow, $x d t=\left(r+\sigma_{1} s_{1}^{*}\right) d t$, remains unchanged. The price of the domestic risky asset, $p_{T}$, rises immediately in response to

\footnotetext{
${ }^{18}$ The constant wealth cutoff is equivalent to assuming that the subsistence level of consumption is variable and proportional to $\underline{a}$ (i.e., $\kappa=r \underline{a}$ after the shock, and $r^{*} \underline{a}$ before the shock). As in habit formation models (e.g. Campbell and Cochrane 1999), I treat $\kappa$ as a variable rather than a constant parameter. Alternatively, one can avoid the negative infinite utility issue by assuming that the wealth distribution $g_{t}(\cdot)$ prior to $T$ has no mass below $\underline{a}=\frac{\kappa}{r}$.

${ }^{19}$ Note here that, for illustration, I take differentiation with respect to $\left(r+\sigma_{1} s_{1}\right)$ instead of $r$ and $s_{1}$ separately. The latter would yield different coefficients for $r$ and $s_{1}$.
} 
Figure 2: Capital Allocation Line

(a) Closed Economy

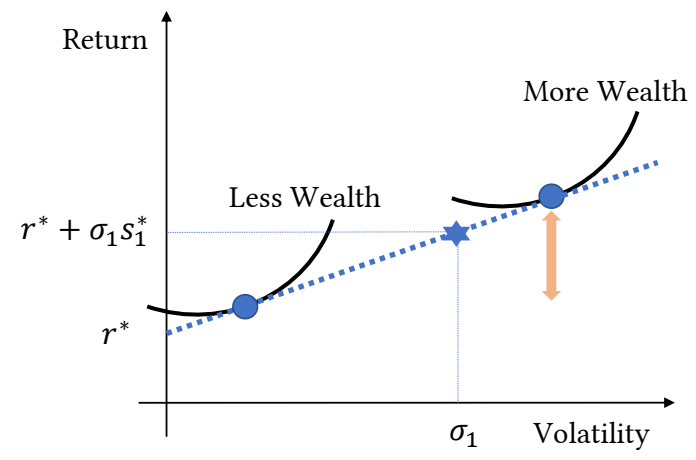

(b) Open Economy

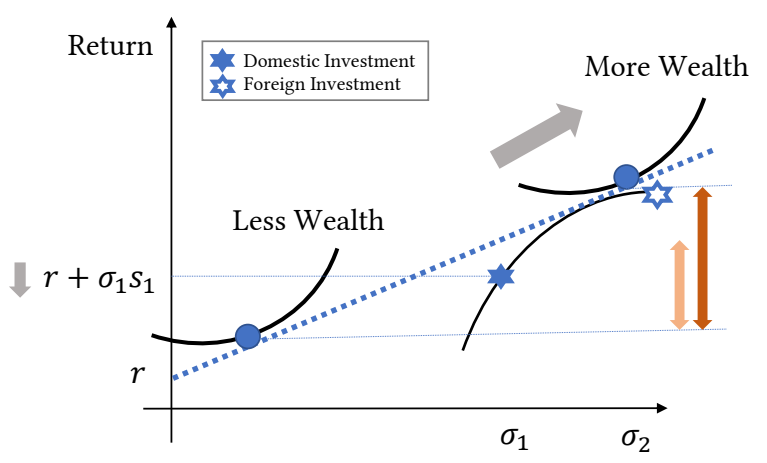

this change. Since affluent households have a larger exposure to the domestic risky asset prior to financial globalization, the top one percent's wealth share, $\Omega_{T}$, rises immediately. The effect is greater when the required expected return drops more acutely, as is shown in (7).

Second, this increase is only transitory and - in the new stationary state - the concentration of wealth is eventually suppressed by the lower expected return on the domestic assets. (i.e., the Decline-in-return Effect). The basic tenet of finance is the inverse relation between price and return. The low discount factor that offers affluent households capital gains, in turn, lowers the future expected return on the domestic risky asset. The effect of capital gains wears off gradually through consumption smoothing within a generation. Wealth inheritance is imperfect between generations. In the end, a wealth distribution in an open economy converges to

$$
g(a)=\mathcal{C}(a)(a-\underline{a})^{-1-\frac{m}{r+R^{\prime} \Sigma^{-1} R-\delta}}
$$

where $\mathcal{C}(a)$ is a function of $a, R \equiv\left[\sigma_{1} s_{1} ; \sigma_{2} s_{2}\right]$ and $\Sigma \equiv\left[\sigma_{1}^{2}, \rho \sigma_{1} \sigma_{2} ; \rho \sigma_{1} \sigma_{2}, \sigma_{2}^{2}\right]$. The stationary wealth distribution has a thick right tail, and the Pareto exponent ${ }^{20}$ is given by $\frac{1}{\xi} \equiv \frac{r+R^{\prime} \Sigma^{-1} R-\delta}{m}$. This expression shows that the lower expected returns on the domestic assets, $d r=d\left(r+\sigma_{1} s_{1}\right)<$ 0 , exert a downward force on wealth concentration. Indeed, this is precisely the reason why term (i) and (ii) have opposite signs in Proposition 1. Without any countervailing forces, wealth concentration in the financial center country would first increase, and then revert back to a lower number, even lower than the initial state.

After all, what might generate a persistent increase in wealth concentration is the asymmetric portfolio reallocation between different household groups (i.e. the Rebalancing Effect). Afflunent households increase their investment share in risky assets more elastically, while impoverished

\footnotetext{
${ }^{20}$ The existence of all $k$ 'th moments of $g_{0}$ (i.e. $g_{0}$ has a thin tail) ensures that $\mathcal{C}$ does not distort the exponent as $a$ goes to infinity. Examples of such thin tail distributions include log-normal distribution. The proof of Proposition 1 in Appendix A.1 offers more details.
} 
households are relatively stuck in the safe asset. Figure 2 illustrates the mechanism with a diagram from the static Capital Asset Pricing Model (Sharpe 1964). The key factor here is the slope of the capital allocation line - the dotted line connecting the risk-free to risky assets in the diagram. Households choose their portfolio such that their indifference curves between risk and expected return are tangent to the capital allocation line. In a closed economy, wealthy households choose a riskier portfolio due to the decreasing relative risk aversion assumption. In an open economy, the expected return on the domestic risky asset, $r+\sigma_{1} s_{1}$, falls. Yet, an expansion of the portfolio frontier (indicated by the curve connecting stars) increases the slope of the capital allocation line. This provides incentives for households to reallocate their wealth more towards the risky domestic and foreign assets. Affluent households respond to this change more elastically than impoverished households due to decreasing relative risk aversion. Thus, capital return inequality between the households is widened further by financial globalization.

This rebalancing effect exerts an upward force to support $\Omega_{\infty}$ in the long run. The expression in (8) suggests that the rebalancing effect is larger when a newly-accessed foreign risky asset has a higher reward-to-risk ratio, $s_{2}$, and a lower correlation with domestic assets, $\rho$. Financial globalization leads to persistent wealth concentration only if these forces are strong enough to counteract diminished returns on the domestic assets. Corollary 1 formalizes this intuition.

Two simplifying assumptions deserve comments. First, the core model does not feature household debt. All households choose to retain positive net worth throughout their lifespans. In section 5, I extend the model such that some households have negative net worth. Numerical simulations show that indebted households begin to take on more debts as $r$ drops upon financial globalization. Net worth of households in the bottom decile falls, which raises the top one percent's wealth share more than the illustrative model suggests. Second, every household has unrestricted access to risky investment. In practice, entrepreneurial households might hold a large share of stock in certain companies and some of these holdings are private equity. In the next section, I do extend the model to allow for private equity. The extension only strengthens the main results; global integration of capital markets increases entrepreneurial income and inflates its market-equivalent valuation.

\subsection{Back-of-the-Envelope Calculation}

One can use this core setup- before turning to a full-blown quantitative model - to roughly gauge the magnitude of the effect of financial globalization. The aim of this back-of-the-envelope calculation is to quantitatively disentangle the basic forces that transform the distribution of 
wealth. As the first step, let me invoke the formula for the stationary wealth distribution

$$
g_{\infty}(a)=\mathcal{C}(a)(a-\underline{a})^{-1-\frac{m}{\tilde{r}+\tilde{s}^{2}-\delta}}
$$

In a closed economy, the interest rates are given by $\tilde{r}=r^{*}$ and $\tilde{s}=s_{1}^{*}$. In an open economy, $\tilde{r}=r$ and $\tilde{s}=\sqrt{\left[\sigma_{1} s_{1}, \sigma_{2} s_{2}\right] \Sigma^{-1}\left[\sigma_{1} s_{1}, \sigma_{2} s_{2}\right]^{\prime}}$. The latter indicates the Sharpe ratio of the open economy portfolio consisting of the domestic and foreign risky assets. As explained earlier, one can approximate the top one percent's wealth share with the Pareto exponent of the stationary wealth distribution, i.e., $\Omega_{\infty}=100^{-1-\frac{m}{\tilde{r}+\tilde{s}^{2}-\delta}}$

The next step is to calculate a change in wealth concentration by calibrating the parameters of the core model. I pick 1989 as the benchmark year for the pre-globalization period. ${ }^{21}$ I set $r^{*}=0.027, s_{1}^{*}=0.029$, and $\delta=0.05 . r^{*}$ is calibrated from the 1-year treasury yield after inflation around 1989. $s_{1}^{*}$ stems from the estimated Sharpe ratio for the domestic portfolio, which I will revisit in Section 5.3. $\delta$ is the standard value for the discount rate. The remaining parameter in the Pareto exponent is $m$, which represents the imperfection of wealth inheritance between generations. I leave $m$ as a free parameter; the value of $m$ is chosen to fit the top one percent's wealth share in year 1989 from the Survey of Consumer Finances (SCF). Finally, I calibrate the average portfolio weights for the top 1 percent, the 1-9 percent and the bottom 90 percent households from the SCF.

The core part of this exercise is to change the values of $\tilde{r}$ and $\tilde{s}$ to measure the effect of a financial globalization shock on the top one percent's wealth share. Table 1 presents three scenarios. In scenario (1), the risk-free interest falls to 0.01 and the Sharpe ratio of the market portfolio rises 0.327 . The top $1 \%$ wealth share immediately increases by $1.8 \% \mathrm{p}$ due to capital gains. The share continues to increase because, in this scenario, the portfolio rebalancing effect outweighs the decline in return on the domestic assets. The model-implied increase, $8.8 \% \mathrm{p}$, is comparable in size to the actual increase in the data. By contrast, in scenario (2), the Sharpe ratio does not increase as much, ${ }^{22}$ so the model exhibits an inverse-U shape transitional dynamics. Along this transitional dynamics, the top one percent wealth share first rises due to the revaluation effect, but eventually reverts back. The new stationary state ends up having a lower wealth inequality than the initial state. A similar pattern arises in scenario (3), where the risk-free interest falls zero. One can also see that the current trend in rising wealth concentration can reverse in the future if

\footnotetext{
${ }^{21}$ The year 1989 is chosen as the benchmark year due to data availability, such as Survey of Consumer Finances, which will be later used for a full-blown quantitative analysis. I use the same year for the back-of-the-envelope calculation to maintain consistency.

${ }^{22}$ One may notice that the back-of-the-envelope calculation is highly sensitive to a change in the Sharpe ratio. The sensitivity is alleviated if the utility function is replaced by one with a higher risk aversion than log utility. For example, one may assume $u\left(c_{i t}\right)=\frac{\left(c_{i t}-\kappa\right)^{1-\gamma}}{1-\gamma}$ and $\gamma=3$. In this case, the Sharpe ratio should rise to 0.37 to generate the same magnitude as in Scenario (1).
} 
Table 1: Back-of-the-envelope Calculation

\begin{tabular}{lccc}
\hline \hline & \multicolumn{3}{c}{ Scenarios } \\
Common Parameters & $(1)$ & $(2)$ & $(3)$ \\
\hline Real risk-free interest (Autarky) & 0.027 & $\cdot$ & $\cdot$ \\
Sharpe ratio (Autarky) & 0.29 & $\cdot$ & $\cdot$ \\
$m$ & 0.085 & $\cdot$ & $\cdot$ \\
$\delta$ & 0.05 & $\cdot$ & $\cdot$ \\
Portfolio weight in equity & $0.5,0.35,0.15$ & $\cdot$ & $\cdot$ \\
by wealth groups & & & \\
& & & \\
Shock from financial globalization & 0.01 & 0.01 & 0 \\
\hline Real risk-free interest (Open) & 0.327 & 0.31 & 0.327 \\
Sharpe ratio (Open) & & & \\
& & & \\
Results: Top 1\% wealth share & $27.3 \%$ & $27.3 \%$ & $27.3 \%$ \\
\hline Autarky (= Data, 1989) & $+1.8 \% \mathrm{p}$ & $+3.1 \% \mathrm{p}$ & $+7.5 \% \mathrm{p}$ \\
Open (after capital gains) & $+8.8 \% \mathrm{p}$ & $-6.5 \% \mathrm{p}$ & $-5.5 \% \mathrm{p}$ \\
Open (stationary state) & & & \\
& $+8.7 \% \mathrm{p}$ & $+8.7 \% \mathrm{p}$ & $+8.7 \% \mathrm{p}$ \\
\hline
\end{tabular}

Notes: This table displays back-of-the-envelope calculations for changes in wealth concentration under different scenarios. A period mark indicates that the value is identical to the left column. In column (1), the values, 0.5, 0.35, and 0.19 , represent portfolio weights in equity by the top $1 \%$, the top $1-9 \%$ and the bottom $90 \%$ household groups. Data here refers to the top wealth shares estimated by the Survey of Consumer Finances.

the expansion of foreign investment no longer increases the Sharpe ratio as much (i.e., scenario $(1) \Rightarrow$ scenario (3)), or the expected return on domestic assets falls too sharply (i.e., scenario (1) $\Rightarrow$ scenario (2)).

\section{Closed Economy}

Next, I turn to market clearing conditions. The portfolio frontier is now determined jointly by (a) saving decisions of households and (b) funding decisions of banks. The core element here is that a country's banking system constitutes a source of comparative advantage in global financial markets. To model this feature, I specify the supply side of assets (in the banking sector) and the market clearing conditions. I first consider a closed-economy setup and then move on to an open economy. The aim of this analysis is to disentangle the basic forces that determine the market interest rates. In later sections, I shall explain how this whole structure can be embedded into quantitative analysis. 


\subsection{Model Extension}

Households The household side remains largely unchanged. Let $\left\{r_{t}^{*},\left(s_{1 t}^{*}, \sigma_{1}\right)\right\}$ denote an equilibrium portfolio frontier in autarky at period $t$. Households take these price processes as given. Their saving decisions constitute the demand side of financial assets. Define $\mathbb{S}_{t} \equiv A_{t} \equiv \int a_{i t} d i$ and $\mathbb{S}_{1 t} \equiv \int \theta_{1 i t} a_{i t} d i$. Here, $\mathbb{S}_{t}$ represents the total savings invested by households, while $\mathbb{S}_{1 t}$ represents the savings in the domestic risky asset. Using $\theta_{1 i t}=\frac{s_{1 t}^{*}}{\sigma_{1}}\left(1-\frac{a}{a_{i t}}\right),{ }^{23}$ we can rewrite the closed economy saving curves as

$$
\mathbb{S}_{t}=A_{t}, \quad \mathbb{S}_{1 t}=\frac{s_{1}^{*}}{\sigma_{1}}\left(A_{t}-\kappa\right)
$$

Aggregate savings the in domestic risky asset increases with the Sharpe ratio. These two savings curves, along with the investment curves that will be defined momentarily, are used to pin down the equilibrium portfolio frontier in financial markets.

Banks Financial assets are manufactured by the representative bank - a consolidated entity encompassing private companies, financial intermediaries and the government. Every period, the bank generates

$$
d \pi_{t}=\Phi\left(K_{t}\right) d t+\bar{\sigma} K_{t} d z_{1 t}
$$

by investing $K_{t}$ units of capital within the boundary of a country. Production involves raw output volatility $\bar{\sigma}$ in proportion to the investment level. The production function, $\Phi\left(K_{t}\right)$, exhibits diminishing marginal returns. ${ }^{24}$

Funding decisions of the bank constitute the supply side of assets. The bank creates assets by converting its future cash flow into risk-free and risky tranches. The bank is a price taker and there is no adjustment cost in changing $K_{t}$. Thus, they simply maximize contemporaneous profit $^{25}$

$$
\underbrace{V_{t}^{*} d t}_{\text {Private Equity Income }} \equiv \max _{K_{t}, D_{t}, E_{t}}\{d \pi_{t}-\underbrace{r_{t}^{*} D_{t} d t}_{\text {Debt Income }}-\underbrace{\left(r_{t}^{*}+\sigma_{1} s_{1 t}^{*}+\tau\right) E_{t} d t}_{\text {Public Equity Income }}-\underbrace{\sigma_{1} E_{t} d z_{1 t}}_{\text {Public Equity Volatility }}\}
$$

\footnotetext{
${ }^{23}$ As in the core model, I assume that $\underline{a}$ is given as constant to avoid the negative infinite utility issue associated with an unanticipated structural change. (See footnote 18) Also, it will later turn out that $\left(r_{t}, s_{1 t}\right)$ is a function of the aggregate state variable $A_{t}$ in equilibrium, which itself follows a stochastic process. Unlike Merton (1971), this feature adds extra complexity to the Hamiltonian-Jacobi-Bellman equation. See Appendix B for more details.

${ }^{24}$ That is, $\Phi^{\prime}>0, \Phi^{\prime \prime}<0, \lim _{K \rightarrow 0} \Phi^{\prime}(K)=-\infty$ and $\lim _{K \rightarrow \infty} \Phi^{\prime}(K)=0$. In this sense, my model is a variant of Cox et al. (1985), which assumes constant return to capital (i.e. $\Phi\left(K_{t}\right)=\alpha K_{t}$ and $d K_{t}=\alpha K_{t}+\bar{\sigma}_{1} K_{t} d z$ )

${ }^{25}$ Appendix D.4 studies the associated decision makings in a discrete time framework over the interval $[t, t+h]$, and the model here corresponds to the limit case when $h$ converges to 0 .
} 
subject to the constraints

$$
K_{t} \equiv D_{t}+E_{t}, \quad \sigma_{1}=\bar{\sigma} K_{t} / E_{t}, \quad D_{t} \leq \lambda K_{t}
$$

where $D_{t}$ is the value of debt, $E_{t}$ is the value of equity and $\sigma_{1}$ is the standard deviation of returns per unit of equity outstanding.

Let me first elaborate on the objective function. $V_{t}^{*} d t$ represents the excess profit that stems from the gap between the average physical rate of returns and the average cost of capital. I simply assume that $V_{t}^{*} d t$ is not distributed to households as there is a separate entrepreneur of the bank who monopolizes technology. The entrepreneur is in effect a hand-to-mouth agent who consumes $V_{t}^{*} d t$ immediately. The bank relies on outside capital. Debt holders receive the risk-free rate. Equity holders are compensated with the risk premium in proportion to the risk per unit of equity. Equity financing involves a deadweight transaction cost, $\tau$, besides the risk premium, so the bank has incentives to rely on debt as a cheaper means of capital raising. Appendix A.7 provides more explanation about the relation between $\tau$ and the money premium in the banking literature.

Turning to the balance sheet conditions, the first constraint in (12) implies that the value of assets should be equal to the value of debt and equity outstanding. The next constraint implies that the issuance of debt-like securities scales up the risk per unit of equity. Essentially, risky asset holders bear all the risk. Lastly, the maximum leverage is limited up to $\lambda K_{t}$. $\lambda$ indicates a country's capacity to create safe assets by tranching. Later on, I will assume that peripheral countries have a lower value of $\lambda$ than the financial center country, which implies that the ability to manufacture safe assets is not identical across economies. Besides, because of $\tau$, firms in peripheral countries end up facing a higher overall cost of capital. The total investment is restrained. Essentially, the financial center country is endowed with a comparative advantage in manufacturing safe assets and absolute advantages in both types of assets, relative to the outside world.

We can derive the aggregate supply curves of the domestic assets from the funding decisions of the bank: $\mathbb{I}_{t}=K_{t}$ and $\mathbb{I}_{1 t}=E_{t}$, with $\sigma_{1}=\bar{\sigma} K_{t} / E_{t}$. Solving the bank's optimization problem, it is easy to show ${ }^{26}$

$$
\mathbb{I}_{t}=\Phi^{\prime-1}\left(r_{t}^{*}+\bar{\sigma} s_{1 t}^{*}+\tau-\tau \lambda\right), \quad \mathbb{I}_{1 t}=(1-\lambda) \mathbb{I}_{t}
$$

The volatility per share is $\sigma_{1}=\frac{\bar{\sigma}}{1-\lambda}$. A quick inspection shows that both of these curves are

\footnotetext{
${ }^{26}$ The total investment, $K_{t}$, is simply pinned down by the first order condition, $\Phi^{\prime}\left(K_{t}\right)=r+\bar{\sigma} s_{1}+\tau(1-\lambda)$. The issuance of equity is pinned down by the binding constraint, $E_{t}=(1-\lambda) K_{t}$, as equity financing involves extra costs besides the risk premium.
} 
downward sloping in terms of the market funding cost, $r_{t}+\bar{\sigma} s_{1 t}$, and the Sharpe ratio of the country's risky asset, $s_{1 t}^{*}$. Figure 3 displays these two downward-sloping investment curves in tandem with the saving curves.

\subsection{Market Clearing Conditions}

A closed economy equilibrium is defined as a path of price vectors that clear local financial markets. So each country has its own interest rates before the integration of global financial markets. Formally speaking, I make the following definition.

Definition 2. A closed economy equilibrium is a stochastic process, $\left\{r_{t}^{*},\left(s_{1 t}^{*}, \sigma_{1}\right)\right\}_{t \geq 0}$, which clears local financial markets: $\mathbb{S}_{t}=\mathbb{I}_{t}$ and $\mathbb{S}_{1 t}=\mathbb{I}_{1 t}$ for all $t$.

Given this setup, we can solve for the equilibrium values of $r^{*}$ and $s_{1}^{*}$ by using the two market clearing conditions. Merging (10) and (13), we can write the solutions as

$$
\begin{aligned}
& s_{1}^{*}(A)=\bar{\sigma} A /(A-\underline{a}) \\
& r^{*}(A)=\Phi^{\prime}(A)-\bar{\sigma}^{2} A /(A-\underline{a})-\tau+\tau \lambda
\end{aligned}
$$

when the aggregate wealth stock is given by $A_{t}=A$. Notice that the market clearing interest rates can be expressed as a function of the total wealth stock. Essentially, $A_{t}$ acts as the state variable of the economy. I henceforth use the notation $r_{t}^{*} \equiv r^{*}\left(A_{t}\right)$ and $s_{1 t}^{*} \equiv s_{1}^{*}\left(A_{t}\right)$. After all, $A_{t}$ evolves according to a stochastic process that will be discussed shortly, and so do the interest rates. The (long-term) domestic risky asset is modeled as a contingent security that pledges future dividend $x_{t} \equiv r^{*}\left(A_{t}\right)+s_{1}^{*}\left(A_{t}\right) \sigma_{1}$ for all $\tau \geq t$ as in Section 2. The dividend stream now depends on the realization of the state variable.

\subsection{Comparative Statics}

Consider two countries: US and FO. In this two-economy world, US represents the financial center country, while FO represents the rest of the world. The key difference ${ }^{27}$ between the central and peripheral economies is their ability to create safe assets in the banking sector. I assume $\lambda^{U S}>\lambda^{F O}$, so US has comparative advantage in manufacturing safe assets. Along with the imperfect correlation between $d z_{1 t}$ and $d z_{2 t}$ (= diversification benefit from the foreign risky asset), the different size of $\lambda^{U S}$ is the minimal building block to provide microfoundation for the

\footnotetext{
${ }^{27}$ Later on, I will also talk about the case where two identical countries are integrated. The only driver for global financial flows in this case is diversification benefit. See Remark 2 in Section 4.
} 
Figure 3: Closed Economy Equilibrium

(a) Total Assets

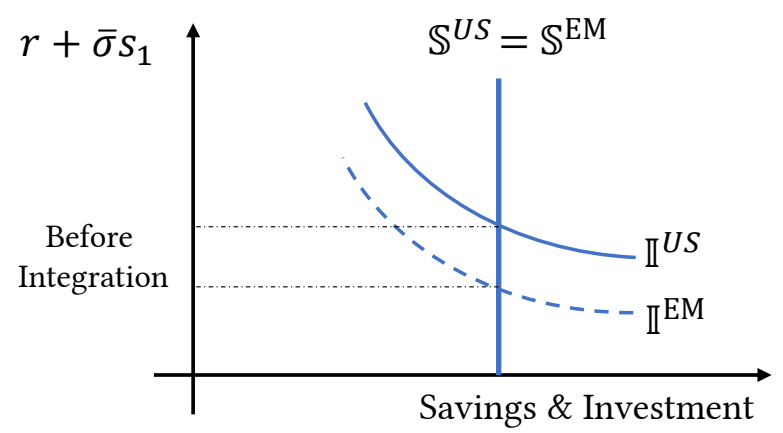

(b) Domestic Risky Assets

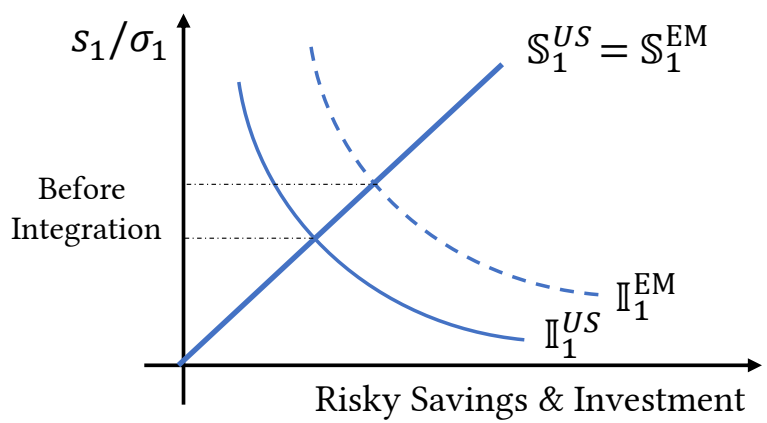

biased change in the portfolio frontier in Section 2. Additionally, one may assume that the output volatility is lower in the financial center country (i.e. $\bar{\sigma}^{U S}<\bar{\sigma}^{F O}$ ), which helps improve a quantitative fit to the data in later sections.

Before turning to dynamics, we can use the solutions in (14) and (15) to conduct comparative static analysis. By log-differentiating the two, it is straightforward to prove the following statement:

Proposition 2. Suppose that US and FO are identical in size (i.e., $A_{1 t}=A_{2 t}=A$ ). Then, in autarky, FO has a lower risk-free rate and a higher Sharpe ratio than US. That is,

$$
\begin{aligned}
& \text { (a) } d \log r^{*}=\underbrace{\phi_{5} d \log \lambda}_{\text {Financial Friction }}-\underbrace{\phi_{6} d \log \bar{\sigma}}_{\text {Output Volatility }} \\
& \text { (b) } d \log s_{1}^{*}=\underbrace{\phi_{7} d \log \bar{\sigma}}_{\text {Output Volatility }}
\end{aligned}
$$

where $\phi_{5}, \phi_{6}$ and $\phi_{7}$ are positive coefficients. Furthermore, FO has a lower required return on risky assets, and a lower excess profit in autarky:

$$
d \log \left(r^{*}+\bar{\sigma} s_{1}^{*}\right)=\underbrace{\phi_{8} d \log \lambda}_{\text {Financial Friction }} \quad d \log \left(V^{*}\right)=\underbrace{\phi_{9} d \log \lambda}_{\text {Financial Friction }}
$$

where $\phi_{8}$ and $\phi_{9}$ are again postive coefficients.

The core message of Figure 3 and the associated proposition is that peripheral economies tend to have an equilibrium in which the risk-free interest rate is low, the expected required return on the risky asset is low, and the Sharpe ratio of the domestic risky asset is high. The pledgeability of future cash flows plays a central role. The production sector's limited ability to promise a fixed return dictates the use of costly fund raising. The supply of safe contractual 
claims is limited, but risky contractual claims are relatively more abundant due to $\bar{\sigma}$. To clear the market, a higher compensation should be offered to those who hold risky assets. The expected return on the domestic risky asset, $r^{*}+\bar{\sigma} s_{1}^{*}$, and the excess profit, $V^{*}$ are also lower when $\lambda$ is small.

Remark 1: Dynamics The earlier results compare two economies with identical sizes of wealth stocks. As time passes by, the wealth stock of each economy grows and the stationary state level of wealth is affected by various parameters including $\lambda$ and $\bar{\sigma}$. In the stationary state, as it turns out, the wealth stock is lower in the FO than in the US. In Appendix A.2, I show that most of the results in Proposition 2 remain intact even when we compare stationary state interest rates of the two economies, provided that $\lambda$ is sufficiently small. The appendix also presents the equilibrium law of motion for wealth stock.

\section{Financial Globalization}

The next step of the analysis is to explore changes in the US portfolio frontier when the two economies, US and FO, become integrated. In this section, I decompose financial globalization into two stages: (i) security market liberalization and (ii) FDI liberalization.

\subsection{Security Market Liberalization}

Security market liberalization allows US households to invest in assets issued by the foreign bank. The interest rates of the existing domestic assets are changed. The foreign risky asset, characterized by $\left(s_{2 t}, \sigma_{2}\right)$, is also added to the portfolio frontier, so US households are given more investment opportunities. To specify the market clearing conditions, define

$$
\mathcal{S}_{1 t}^{k} \equiv \int \theta_{1 i t}^{k} a_{i t}^{k} d i, \quad \mathcal{S}_{2 t}^{k} \equiv \int \theta_{2 i t}^{k} a_{i t}^{k} d i \quad \mathcal{S}_{t}^{k} \equiv \int a_{i t}^{k} d i
$$

for each origin country $k \in\{U S, F O\}$. In the above expressions, $\mathcal{S}_{1 t}^{k}$ represents country $k$ 's savings in the US risky asset, while $\mathcal{S}_{2 t}^{k}$ represents country $k$ 's savings in the FO risky asset. Finally, $\mathcal{S}_{t}^{k}$ is country $k$ 's savings in all types of assets.

I define an open economy equilibrium as a path of the interest rates that clears the entire global financial markets. After security market liberalization, the two economies are coordinated by a common set of interest rates. The market clearing conditions pin down the equilibrium values of $r, s_{1}$ and $s_{2} \cdot{ }^{28}$ When the wealth stocks of the two countries are identical in size, one can

\footnotetext{
${ }^{28}$ In an open economy, $A_{1 t}+A_{2 t}$ acts as the state variable of the economy where $A_{1 t} \equiv \int a_{i t}^{U S} d i$ and $A_{2 t} \equiv$
} 
verify that security market liberalization transforms the portfolio frontier of the US economy as described by Proposition 3, thereby altering the country's wealth distribution.

Definition 3. An open economy equilibrium is a stochastic process, $\left\{r_{t},\left(s_{1 t}, \sigma_{1}\right),\left(s_{2 t}, \sigma_{2}\right)\right\}_{t \geq 0}$, which clears the global financial markets: $\sum_{k \in\{F O, U S\}}\left(\mathbb{S}_{t}^{k}-\mathbb{I}_{t}^{k}\right)=0, \sum_{k \in\{F O, U S\}} \mathbb{S}_{1 t}^{k}=\mathbb{I}_{1 t}^{U S}$ and $\sum_{k \in\{F O, U S\}} \mathbb{S}_{2 t}^{k}=\mathbb{I}_{2 t}^{F O}$.

Proposition 3. (i) After security market liberalization, the US becomes the exporter of safe asset and the net importer of global risky assets. US households face ${ }^{29}$
(a) $r<r^{*}$
(b) $r+\sigma_{1} s_{1}<r^{*}+\sigma s_{1}^{*}$
(c) $V>V^{*}$
(d) $s_{\text {mix }} \geq s_{1}$

where $s_{\text {mix }}$ is the Sharpe ratio of the optimal portfolio combining the foreign and domestic risky assets. (ii) The Shape ratio of the domestic risky asset rises (i.e. $s_{1}>s_{1}^{*}$ ) if and only if $\bar{\sigma}_{1}<\rho \bar{\sigma}_{2}$

Proof. Appendix A.4

Proposition 3(i) states that security market liberalization offers new risky investment opportunities for US households, while simultaneously decreasing the required expected returns on the US domestic assets. Figure 4 illustrates the basic intuition by examining a special case $\rho=1$ (i.e., the foreign and domestic risky assets are perfect substitutes.) The supply of safe assets is limited in the FO. Besides, since equity financing involves a deadweight transaction cost beside the risk premium, the FO bank faces a higher overall cost of capital. The total investment is thus restrained. After security market liberalization, US should sell its assets to FO and become a net debtor to clear the global financial markets. The excess demand from FO -as indicated by the solid horizontal line in Figure 4a- exerts a downward force on $r+\sigma_{1} s_{1}$ and $r$ in the US economy. It is now easy to show the excess profit increases (i.e., $V>V^{*}$ ) as the US bank faces a lower average cost of capital. $s_{\text {mix }} \geq s_{1}$ is also straightforward.

How does financial globalization change the risk premium (or the Sharpe ratio) of the US domestic risky asset? While the core model assumed $s_{1}^{*}=s_{1}$, Proposition 3(ii) gives a sharper prediction. The change in $s_{1}$ depends on the risk profile of the outside world. If FO is significantly riskier, $\bar{\sigma}^{U S}<\rho \bar{\sigma}^{F O}$, US households should bear more risk after security market liberalization, so the domestic Sharpe ratio rises to clear the market. Figure $4 \mathrm{~b}$ illustrates this point when $\rho=$ 1. If this is not the case (e.g. $\bar{\sigma}^{U S}=\bar{\sigma}^{F O}$ and $\rho<1$ ), the domestic Sharpe ratio falls after global integration. This is because diversification from the foreign risky asset helps create a safer portfolio, so a lower value of $s_{1}$ is enough to induce US households to clear the markets.

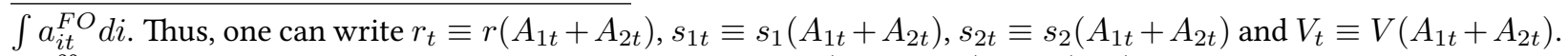

${ }^{29}$ In the statement, $r<r^{*}$ is a simplified expression for $r\left(A_{1 t}+A_{2 t}\right)<r^{*}\left(A_{1 t}\right)$ where $A_{1 t}=A_{2 t}=A$ (i.e., the US and FO are identical in size.) The same notation is applied to the other variables. 
Figure 4: Open Economy Equilibrium

(a) Total Assets

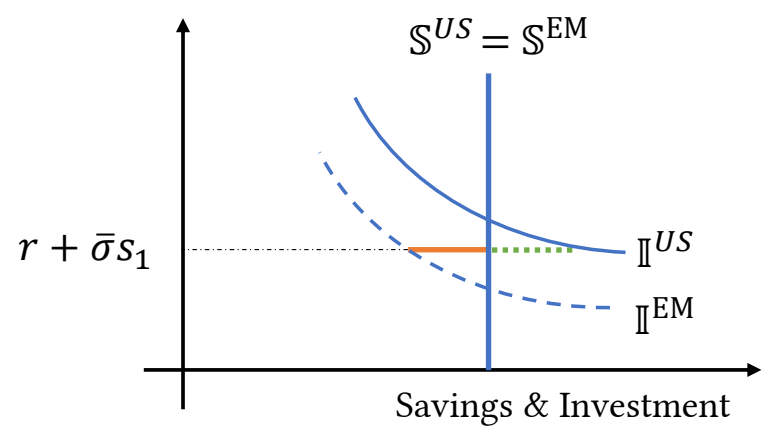

(b) Risky Assets (if $\rho=1$ and $\bar{\sigma}_{1}<\bar{\sigma}_{2}$ )

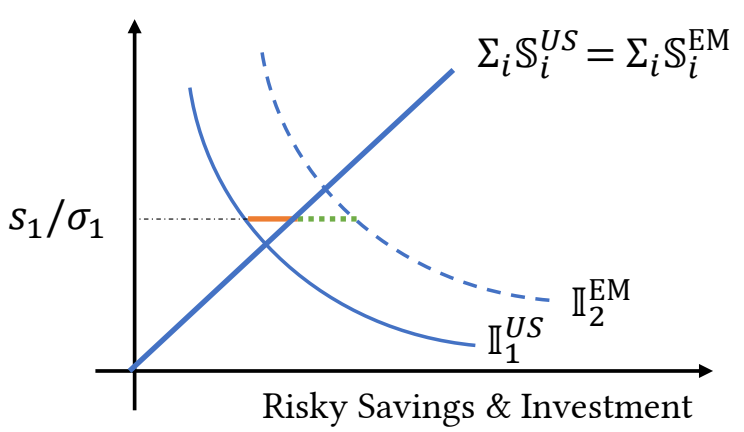

These forces can raise wealth concentration in the US economy through domestic asset price inflation in the short run, and through asymmetric portfolio rebalancing in the long run. The core model in Section 2 confirmed theses channels when the supply of assets is perfectly elastic. This section provides microfoundation for the change. To quantitatively measure the effect on wealth inequality with this general equilibrium setup, one needs to turn to numerical simulations. We will revisit this in Section 5.

\subsection{FDI Liberalization}

In this subsection, I briefly show that FDI provides an additional driver for wealth concentration in the US as it further expands risky investment opportunities available in global economy. ${ }^{30}$ To incorporate foreign direct investment, I embed a simplified model of Holmstrom and Tirole (1997) and Antràs et al. (2009) into my framework. A poor contracting environment in the FO gives rise to the need for US multinational firms as they serve as de facto financial intermediary in global capital markets.

The extended model has three more ingredients. (Appendix A.5 provides a more detailed explanation about the associated optimal contract problem.) First, the entrepreneur in the FO can misbehave in pursuit of private benefits. The misbehavior lowers the expected earning from $\Phi\left(K_{2 t}\right) d t$ to $\pi_{L} \Phi\left(K_{2 t}\right) d t$, where $\pi_{L} \in[0,1)$. The misbehavior gives private benefit to the FO entrepreneur. Second, the US bank can choose to to invest $K_{2 t}^{F D I}$ to create a joint venture with the FO entrepreneur. As a compensation, the US bank receives a designated share of profit. The US bank monitors the FO entrepreneur to make sure that the full profit is reached. Finally, the remaining portion of the investment, $K_{2 t}^{L o c a l} \equiv K_{2 t}-K_{2 t}^{F D I}$, is funded through the local bank in

\footnotetext{
${ }^{30}$ FDI outflow of US multinational firms currently accounts for 43 percent of foreign equity holdings by American households in terms of estimated market value. (Bureau of Economic Analysis, 2017)
} 
the FO. The banks in the two economies raise funds from investors as before, which constitute the supply side of assets.

Given this extension, in Appendix A.5, I compare the three stages of financial globalization: (i) autarky (ii) security market liberalization and (iii) FDI and security market liberalization. For each stage of financial globalization, the equilibrium interest rates are denoted with the superscript (i), (ii), and (iii) respectively. We can then confirm that foreign direct investment provides an additional expansion of the foreign risky asset, thereby exerting an upward force on wealth concentration in the US.

Proposition 4. The liberalization of security markets and FDI transforms the US portfolio frontier such that

$$
\text { (a) } s_{1}^{(i i i)}>s_{1}^{(i i)}>s_{1}^{(i)} \quad(b)\left(V+V^{F D I}\right)^{(i i i)}>V^{(i i i)}>V^{(i)}
$$

if $\bar{\sigma}^{U S}<\rho \bar{\sigma}^{F O}$ and $\pi_{L}$ is sufficiently small. Furthermore, the US becomes the exporter of safe assets, and the net importer of the foreign portfolio and direct investment assets.

Proof. See Appendix A.5.

The intuition for Proposition 4 is as follows. Even after the global security markets are liberalized, the FO entrepreneur still has limited ability to raise funds due to their low pledgeability (i.e., $\pi_{L}<1$ ). Investment in the FO is more limited than investment in the US. What FDI does is to let the US bank become the parent company and monitors the FO subsidiary. By doing so, the joint venture opens up the full potential of investment in the FO. The investment in the FO is essentially riskier than the investment in the US. Thus, a higher value of $s_{1}$ is required when both FDI and security markets are liberalized, to induce US households to bear more risks and clear the markets. The US bank gains an additional excess profit, in the form of $V^{F D I} d t$.

\subsection{Cross-country implications}

One implication of the model is that financial globalization increases wealth concentration most prominently within a financially-developed economy (at least in the short run) by changing the country's equilibrium interest rates. Two channels have been discussed: domestic asset price inflation in the short run and portfolio reallocation in the long run. By shedding light on the global finance architecture, the model offers a novel argument for why the U.S. has experienced a particularly large increase in wealth concentration among developed economies. The US economy is often quoted as the world's banker due to its special role in international financial markets. The 
model suggests that the country's special function would have played a central role in transforming domestic interest rates, thereby increasing wealth inequality among American households.

By contrast, in peripheral economies, the effect depends on specific circumstances. First, suppose that FDI is shut off and the foreign risky asset is a perfect substitute for the domestic risky asset. In this case, whatever happens in the US, the opposite will happen in the FO. Second, if the foreign and domestic risky assets provide diversification benefits for each other, US and FO will both experience the heterogeneous portfolio rebalancing between the rich and the poor. Finally, wealth inequality can be increased in the both regions if FDI plays the most significant role in the process of financial globalization. This is because the liberalization of FDI can expand risky investment opportunities not only for advanced economies but also for emerging markets.

Remark 2: Integration of symmetric countries While capital flow between the central and peripheral economies is an important theme of international finance, the integration of identical countries (as in Obstfeld (1994)) is also a good thought-experiment for obtaining a clearer insight. The only driver for global financial flows in this case is the diversification benefit. Proposition 3(ii) implies that the risk premium of the US domestic risky asset falls, thereby generating capital gains for rich households. This is followed by the heterogeneous portfolio rebalancing between the rich and the poor, which offsets a part of the decline in return on the US domestic assets. A lower value of $\rho$ makes the two effects cancel each other more strongly. Yet it is easy to show that, in this case, the decline-in-return effect always dominates the rebalancing effect. For a persistent increase in wealth inequality, we need an extra-driver such as the asymmetry between the US and peripheral economies.

\section{Taking the Model to the Data}

In this section, I assess whether global financial flows between the central and peripheral economies is likely to be an important factor behind the observed increase in US wealth inequality. I also examine the extent to which the current increase in US wealth concentration can persist in the future. The quantitative analysis proceeds in three steps. First, I extend the baseline model by adding new ingredients, such as labor income and housing wealth. Second, I present the target moments of the model and estimates for the key variables. Lastly, I present results. 


\subsection{Quantitative Extension}

In the extended model, the lifetime utility of households born at time $\tau$ is given by

$$
\mathbb{E}_{\tau}\left[\int_{\tau}^{\infty} e^{-(\delta+m) t} u\left(c_{i t}\right) d t\right]
$$

We can write the the associated budget constraint as, in the case of autarky,

$$
d a_{i t}=[\left(r_{t}^{*}+\theta_{1 i t} \sigma s_{t}^{*}+m\right) a_{i t}+\underbrace{w_{t}^{*} l_{i t}}_{\text {(i) Labor Income }}-c_{i t}+\underbrace{r_{t}^{h} h_{i t}}_{\text {(ii) Housing Return }}) d t+\sigma_{1} \theta_{1 i t} a_{i t} d z_{1 t}
$$

where $w_{t}^{*}$ denotes wage, $l_{i t}$ labor productivity of household $i, h_{i t}$ the value of housing endowment, and $r_{t}^{h}$ return on housing assets. Individual wealth is defined as the sum of net financial assets and non-financial assets i.e. $a_{i t}+h_{i t}$.

Since my main focus is to investigate the effect of financial globalization, modeling ingredients other than financial assets are simplified or taken from previous works in the heterogeneous agent literature. First, I assume that labor productivity consists of two elements: $l_{i t} \equiv \ell_{i}+\epsilon_{i t}$. Here, $\ell_{i}$ represents permanent skill, which is drawn from a lognormal distribution when a household is born. The temporary shock $\epsilon_{i t}$ follows an $\mathrm{AR}(1)$ process $d \epsilon_{i t}=-\beta_{\epsilon} \epsilon_{i t}+q_{i t} d J_{i t}$. The process drifts towards zero at rate $\beta_{\epsilon}$ and jumps arrive at a Poisson arrival rate $\zeta_{\epsilon}$. When a jump occurs $q_{i t}$ is drawn from $N\left(\mu_{\epsilon}, \sigma_{\epsilon}^{2}\right)$. The p.d.f. of the normal distribution is denoted by $\phi(\epsilon)$. This setup long-run and short-run components - is in line with previous works such as Kaplan et al. (2018) and fits well with the actual earning processes in the data.

Second, I simplify the housing problem by assuming that $h_{i t} \equiv \beta_{h 1} a_{i t}+\beta_{h 2}$. That is, home ownership is a function of the expected life-time labor income. $\beta_{h 1}$ and $\beta_{h 1}$ will be calibrated to fit the data. Essentially, housing plays a passive role in the model $-r_{t}^{h}$ is exogenously taken from the data and remains unaffected by financial globalization. Housing is incorporated only to calibrate the size of the main effect. Finally, I use the standard functional forms:

$$
\begin{aligned}
\text { Utility : } & u\left(c_{i t}\right)=\frac{\left(c_{i t}-\kappa\right)^{1-\gamma}-1}{1-\gamma} \\
\text { Technology : } & \Phi\left(K_{t}\right)=Z K_{t}^{\alpha} L_{t}^{1-\alpha} \\
\text { Endowment: } & {\left[\begin{array}{c}
\log a_{i 0} \\
\log \ell_{i}
\end{array}\right] \sim \mathcal{N}\left(\left[\begin{array}{l}
\mu_{a} \\
\mu_{\ell}
\end{array}\right],\left[\begin{array}{cc}
\Sigma_{a a} & \Sigma_{a \ell} \\
\Sigma_{\ell a} & \Sigma_{\ell \ell}
\end{array}\right]\right) }
\end{aligned}
$$

where $L_{t} \equiv \int_{[0,1]} l_{i t} d i$ is the total labor that is shared by a measure 1 of firms. Let $g_{t}(a, \ell, \varepsilon)$ denote a probability density function of households whose asset level is given by $a$, skill by $\ell$ 
and temporary earning shock by $\varepsilon . g_{0}\left(a_{0 i}, \ell, \epsilon\right)$ represents a probability distribution of newborn households. The last line implies that $\int g_{0}\left(a_{0 i}, \ell, \epsilon\right) d \epsilon$ is a bivariate lognormal distribution.

Under this setup, I follow methodologies developed in heterogeneous-agent macroeconomics. ${ }^{31}$ Transitional dynamics of the economy is characterized by a system of two differential equations: the first component is often called the Hamiltonian-Jacobian-Bellman equation, which governs households' saving decisions. Households' saving decisions depend upon $g_{t}$ as well as individual state variables $\left(a_{i t}, \ell_{i}, \varepsilon_{i t}\right)$. Following Ahn et al. (2018), I use $J_{t}(a, \ell, \varepsilon) \equiv J\left(a, \ell, \varepsilon, g_{t}\right)$ to denote the value function associated with the household's problem. The second component is the Kolmogorov Forward Equation which governs the evolution of the wealth distribution. As in the baseline model, we focus on the trajectory in which $d z_{1 t}=d z_{2 t} \equiv 0$ in autarky and $d z_{1 t}=d z_{2 t}=0$ in open economy.

Proposition 5. The wealth distribution evolves according to the following differential equations

$$
\begin{gathered}
(\delta+m) J_{t}=\max _{c, \theta_{1}}\left\{u(c)+\frac{\partial J_{t}}{\partial a} v_{t}(a, \ell, \epsilon)+\frac{1}{2} \frac{\partial^{2} J_{t}}{\partial a^{2}}\left(\sigma_{1} \theta_{1} a\right)^{2}+\frac{\partial J_{t}}{\partial \ell}\left(-\beta \ell_{i t}^{s}\right)\right. \\
\left.+\zeta \int_{-\infty}^{\infty}\left(J_{t}(a, \ell, x)-J_{t}(a, \ell, \epsilon)\right) \phi(x) d x+\frac{1}{d t} \mathbb{E}_{t}\left[d J_{t}\right]\right\} \\
\frac{d}{d t} g_{t}(a, \ell, \epsilon)=-m g_{t}(a, \ell, \epsilon)+m g_{0}(a, \ell, \varepsilon)-\frac{d}{d a}\left[v_{t}(a, \ell, \epsilon) g_{t}(a, \ell, \epsilon)\right] \\
-\zeta g_{t}(a, \ell, \epsilon)+\zeta \phi(\epsilon) \int_{-\infty}^{\infty} g_{t}(a, \ell, x) d x d \ell
\end{gathered}
$$

along with the market clearing conditions. Here, $v_{t}(a, \ell, \varepsilon)$ represents the saving function, ${ }^{32}$ and $\frac{1}{d t} \mathbb{E}_{t}\left[d J_{t}\right]$ is short-hand notation for $\lim _{s \searrow 0} \mathbb{E}_{t}\left[J_{t+s}-J_{s}\right] / s$.

We consider a shock in which US makes a transition from financial autarky to open economy from period $T$ onwards. The aim is to quantify the effect on the wealth distribution. Consider two economies, US and FO. As in the baseline model, the only differences between the two economies are their banking technology, $\lambda^{U S}>\lambda^{F O}$, and output volatility, $\bar{\sigma}^{U S}<\bar{\sigma}^{F O}$.

\subsection{Numerical Method}

I use the differential equations in Proposition 5 to derive transitional dynamics of the wealth distribution. The core challenge in numerically solving these equations is that households' saving decision depends on a realization of the cross-sectional distribution $g_{t}(a, \ell, \varepsilon)$, which is an infinitely dimensional object. One should reduce the dimensionality of the state variable space

\footnotetext{
31 See Ahn et al. (2018) for an introductory guide to this approach. See Kaplan et al. (2018) and FernándezVillaverde et al. (2018) for its applications and variants.

${ }^{32}$ In autarky, $v_{t}=\left(r_{t}^{*}+\theta_{1 i t} \sigma_{1} s_{1 t}^{*}+m\right) a_{i t}+w_{1 t}^{*} l_{i t}-c_{i t}+r_{t}^{h} h_{i t}$
} 
to solve the model. A bounded rationality assumption is one of the solutions to this problem (Krusell and Smith 1998) and has been used widely in the literature. In a similar light, I impose a restriction on households' decision makings regarding portfolio choices.

Assumption 1. In autarky, the functional form of households' portfolio choice, $\theta_{1 i t}$, is given by

$$
\theta_{1 i t}=\frac{s_{1 t}}{\chi_{1} \sigma_{1}}\left(1-\frac{\chi_{2}}{a_{i t}}-\frac{\chi_{3}}{a_{i t} \ell_{i}}\right)
$$

where $\chi_{1}, \chi_{2}$, and $\chi_{3}$ are constants calibrated from data. In open economy, $\frac{s_{1}}{\sigma_{1}}$ is replaced with $\Sigma^{-1}\left[\sigma_{1} s_{1} ; \sigma_{2} s_{2}\right]$. Those whose wealth levels are below $\chi_{2}+\frac{\chi_{3}}{\ell_{i}}$ have $\theta_{i t}=0$.

It is worth noting that the above functional form is an approximation to the actual endogenous portfolio choice by households. In the baseline model, this approximation was exact: $\chi_{1}$ equals the risk-aversion parameter, $\chi_{2}$ equals $\underline{a}$ and $\chi_{3}$ equals 0 . This is what (3) indicates in Section $2 .{ }^{33}$ The portfolio weight in the full quantitative model deviates from this closed-form solution as it embodies labor income. Instead of solving it numerically, I simplify the interaction between labor income and portfolio choice as described by (17) for tractability. Indeed, most studies in the literature on heterogeneous-agent macroeconomics (e.g. Hubmer et al. 2018) assume exogenous portfolio heterogeneity.

There are two advantages of Assumption 1. First, the dimension of the state variables that determine the current equilibrium prices is reduced dramatically; all equilibrium prices, $r_{t}, s_{1 t}$, $s_{2 t}$ and $w_{t}$, are now expressed as a function of a finite number of state variables thanks to its nice aggregation property. One way to see the aggregation property is to look at the total demand for risky assets. For example, in a closed economy where all households have $a_{i t} \geq \chi_{2}+\frac{\chi_{3}}{\ell_{i}}$ (the baseline model was one of these cases), it is easy to show

$$
\int_{i} a_{i t} \theta_{1 i t} d i=\frac{s_{1 t}}{\chi_{1} \sigma_{1}}\left(A_{1 t}-\chi_{2}-\chi_{3} \int_{i} \frac{1}{\ell_{i}} d i\right)
$$

where $A_{1 t}$ denotes $\int_{i} a_{i t}^{U S} d i$. Essentially, the mean of the wealth distribution, instead of the entire distribution, acts as a sufficient statistics for the demand for the risky asset in autarky. Other market clearing conditions are also simplified. (See Appendix C) Second, the fit of $\theta_{1 i t}+\theta_{2 i t}$ to the data is good. Assumption 1 has properties consistent with the fact that (i) wealthier households invest more heavily in equity; (ii) the marginal increase in investment share in equity is diminishing in wealth; and (iii) the investment share in equity converges to an upper bound as the wealth level rises. I confirm these in the later section.

\footnotetext{
${ }^{33}$ The approximation is exact under Epstein-Zin utility with no labor income: $\chi_{1}$ is again the risk aversion parameter and $\chi_{2}=\chi_{3}=0$.
} 
In light of this property, I run a continuous-time analogue of Krusell and Smith (1998). I begin with a guess for the law of motion for the state variable, ${ }^{34}$ which is now presumed to be $A_{1 t}$ in autarky. Through simulations, I verify that the proposed motion is indeed consistent with the model's predictions. The algorithm proceeds in four steps.

(Step 1) Guess the law of motion for the state variable. In actual practice, $d \log A_{1 t}=$ $\left(\psi_{1}-1\right) \log A_{1 t}+\psi_{2}$ works well in autarky. Begin by guessing $\psi_{1}$ and $\psi_{2}$

(Step 2) Under this law of motion, numerically solve the HJB equation and compute individual saving decisions.

(Step 3) Using these saving decisions, compute the evolution of the wealth distribution.

(Step 4) Verify that the proposed law of motion is indeed consistent with Step 3. Return to Step 1 if not consistent.

More detailed explanations about the algorithm, especially when there is household debt, are referred to Appendix C. ${ }^{35}$

\subsection{Calibration Strategy}

Notable target moments Given this setup, I calibrate the model to fit data. I use year 1989 as the benchmark year for financial autarky due to data availability. ${ }^{36}$ Among other parameters, the ones below deserve further comments.

$$
\left\{\lambda^{U S}, \bar{\sigma}^{U S}, \lambda^{F O}, \bar{\sigma}^{F O}, \rho ; \mu_{a}, \Sigma_{a a}, \Sigma_{a l}\right\}
$$

First, I choose $\left\{\lambda^{U S}, \bar{\sigma}^{U S}, \lambda^{F O}, \bar{\sigma}^{F O}, \rho\right\}$ to adjust the equilibrium portfolio frontier in autarky and in open economy, $\left\{r_{t}^{*}, s_{1 t}^{*}, r_{t}, s_{1 t}, s_{2 t}\right\}$, to fall within a reasonable range according to the historical patterns I will explain below. Next, I pick the values of $\mu_{a}, \Sigma_{a a}$, and $\Sigma_{a l}$ to match the modelimplied stationary wealth distribution with the actual wealth distribution in 1989 reported in the Survey of Consumer Finances. The target moments are the top 1\%, the top 5\% and the bottom $90 \%$ wealth shares.

\footnotetext{
${ }^{34}$ As in Krusell and Smith (1998), one implicit assumption is that only a finite moments of the wealth distribution matter in the law of motion for the state variables, and thus for the future equilibrium prices.

${ }^{35}$ For alternative methods, see Ahn et al. (2018) or Fernández-Villaverde et al. (2018). Compared with their works, the numerical approach here provides more transparent interpretations about the law of motion for the state variable (rather than leaving it as a black box). But the range of applications is limited to wealth inequality problems as this framework cannot incorporate TFP shocks.

${ }^{36}$ Since 1989, the Federal Reserve has provided Survey of Consumer Finances that are consistent across years. (The earlier surveys are less comparable.) The data moments, such as top wealth and wage shares, are taken from these datasets. Alternatively, one can look at tax-based estimates on top wealth and wage shares, which allows researchers to trace back to older data series.
} 
One consideration is to generate a modest size of risk premium. It has been well known that the standard neoclassical model performs poorly in matching the risk premium in the data. This paper is no exception. My model has three features that help reconcile this issue partially. First, many households do not own risky assets. Households whose wealth and labor productivity fall short of a threshold in (17) take on debt. By reducing the demand for risky assets and increasing the supply of safe assets, the model-implied risk premium takes on a higher value. The mechanism is similar to Mankiw and Zeldes (1991). Second, $\chi_{1}$ in (17) can be set differently from the elasticity of intertemporal substitution implied by utility function. My model has one more degree of freedom to inhibit investment on the risky assets. Finally, I leave $\bar{\sigma}^{U S}$ and $\bar{\sigma}^{F O}$ as free parameters to match the Sharpe ratios.

Estimation of the interest rates To discipline the model, we investigate a change in the risk-free interest rate, capital gains, and the Sharpe ratio of US domestic and foreign assets. I perform the estimation in two steps. First, I use national accounts data to construct a time series of average realized returns on various asset classes in the U.S. economy. Following Saez and Zucman (2016), ${ }^{37}$ I compute a macroeconomic yield of each asset class by dividing the flow payment reported in Gross National Income by the market value reported in the Fed's Financial Accounts. In the case of equities, for instance, the average dividend yield in 2005 is defined as the ratio between the total dividend paid to households during 2005 and the total value of equity holdings at the end of 2004. I then compute capital gains as an increase in the market value that exceeds the net issuance of equities during the year. Finally, the average return on equities is measured as the average dividend yield plus the average rate of capital gain. A similar methodology can be applied to other asset classes such as fixed income assets, housing and non-corporate business, and also to sub-asset classes such as foreign equity. ${ }^{38}$

Panel (a) of Figure 5 displays the average realized returns on equities, fixed income and 3month treasury bills in the United States, smoothed over twenty years to eliminate cyclical variations. Each line represents the geometric average of real returns over a twenty-year horizon centered on the $\mathrm{x}$ coordinate. What this graph shows is that the average real returns on safe assets have been declining over the past decades, which many studies (e.g. Caballero et al. 2008, Mendoza et al. 2009) associated with the foreign demand for US safe assets. On the other hand, the realized return on equities began to diverge substantially from other safe assets since 1980s as we smooth out the cyclical variation. Fixed income assets exhibit a similar pattern. We should investigate these patterns with care as the realized returns on long-term assets are jointly affected

\footnotetext{
${ }^{37}$ This method has been used in many contexts including Mian et al. (2013), Saez and Zucman (2016) and Piketty et al. (2018) to compute asset returns that are consistent with macroeconomic statistics.

${ }^{38}$ The Fed provides the estimated value of closely held stock by matching it with the market value of publicly traded firms with similar characteristics.
} 
Figure 5: Interest Rates and Returns

(a) 20-year Smoothed Realized Returns

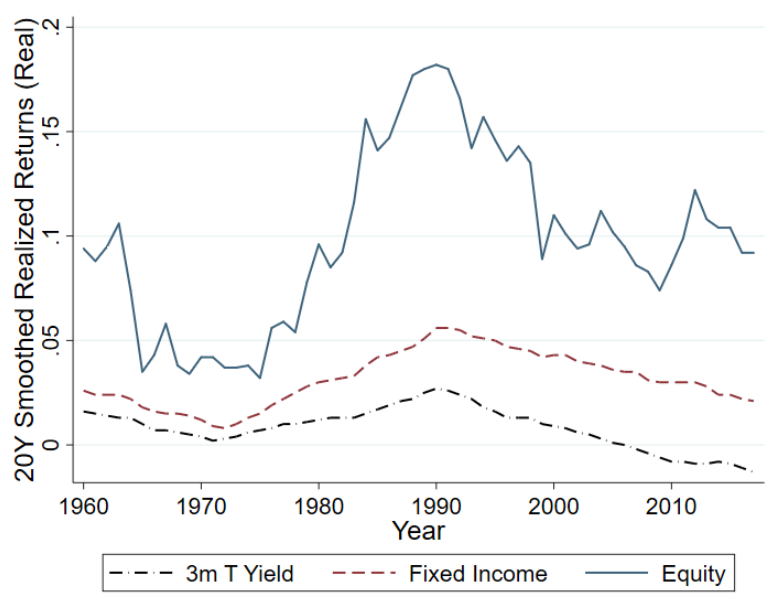

(c) Estimated Capital Gains

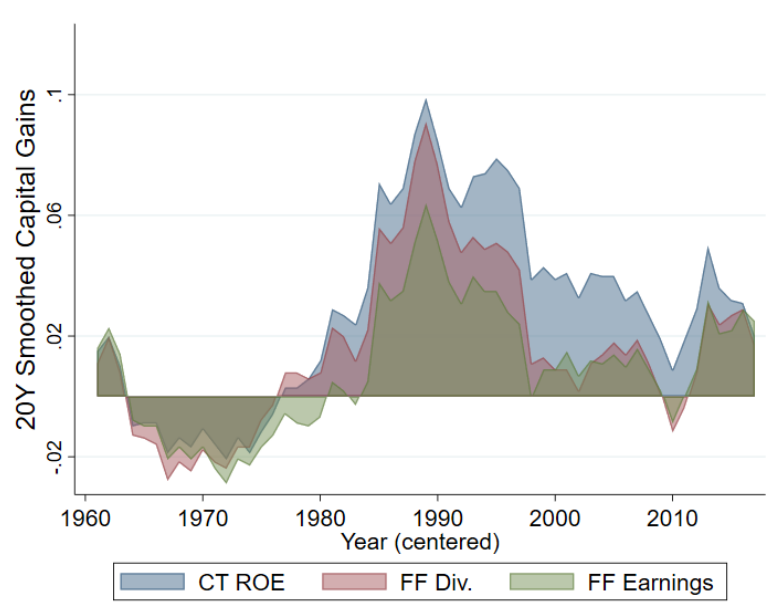

(b) Estimated Risk Premium

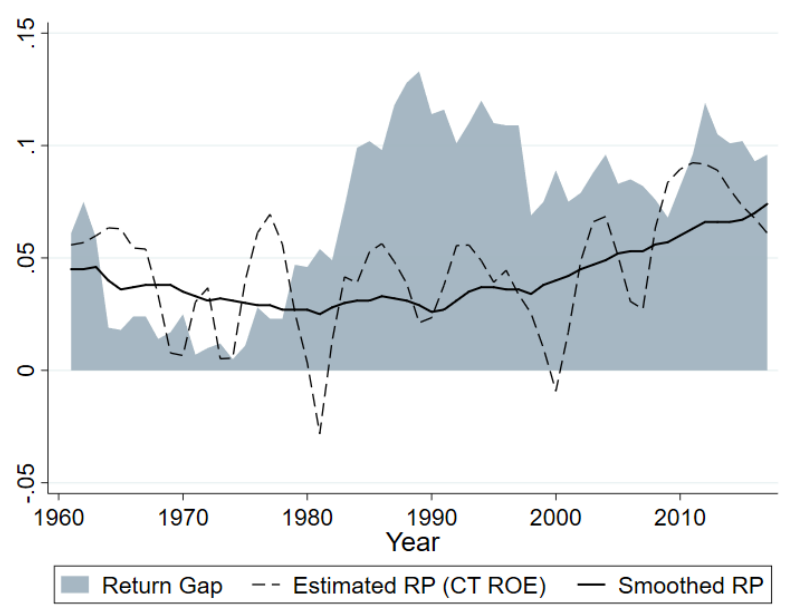

(d) Estimated Sharpe Ratios (1982-2017)

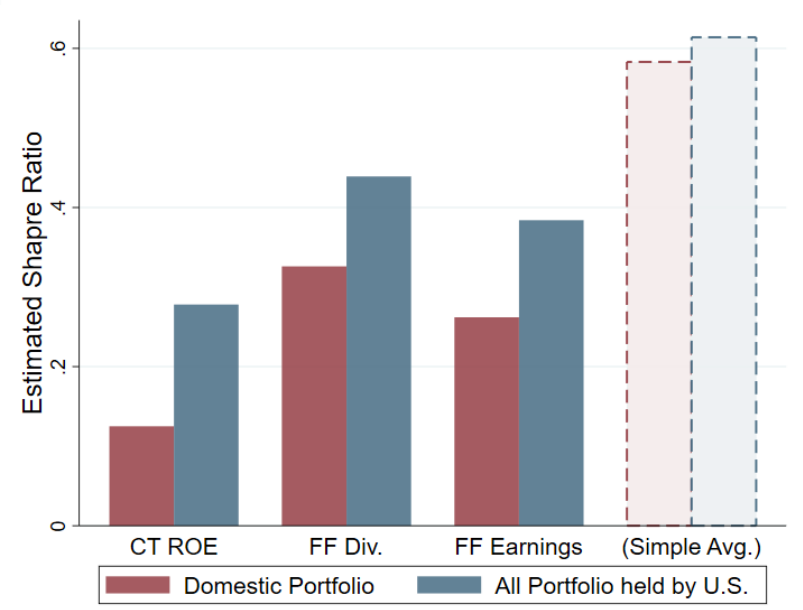

Notes: All returns and gains are measured in real terms. Smoothed returns stand for the geometric average of returns over twenty year period. The right-hand side of the time horizon is shorter in the last ten data points. Due to the data constraint, the Sharpe ratio is only calculated during 1982-2017. Simple average stands for the mean return over the standard deviation of returns, with no consideration of capital gains. CT ROE indicates the estimated risk premium based on accouting return on equity (Campbell 2008 and Campbell and Thompson 2008). FF Div and FF Earnings are based on dividend growth rates and earning growth rates respectively. (Fama and French 2002)

a change in the discount rate and expected cash flows.

The next step of the analysis is to estimate capital gains, expected returns and Sharpe ratio so that we can examine how financial globalization has increased the relative reward for holding risky assets. To this end, I employ a simple estimation method proposed by Fama and French (2002), Campbell (2008) and Campbell and Thompson (2008). The central idea is that fundamentals such as dividends, earnings and profitability can be used for estimating ex ante 
Table 2: Related Statistics for Equity Premium and Shape Ratio

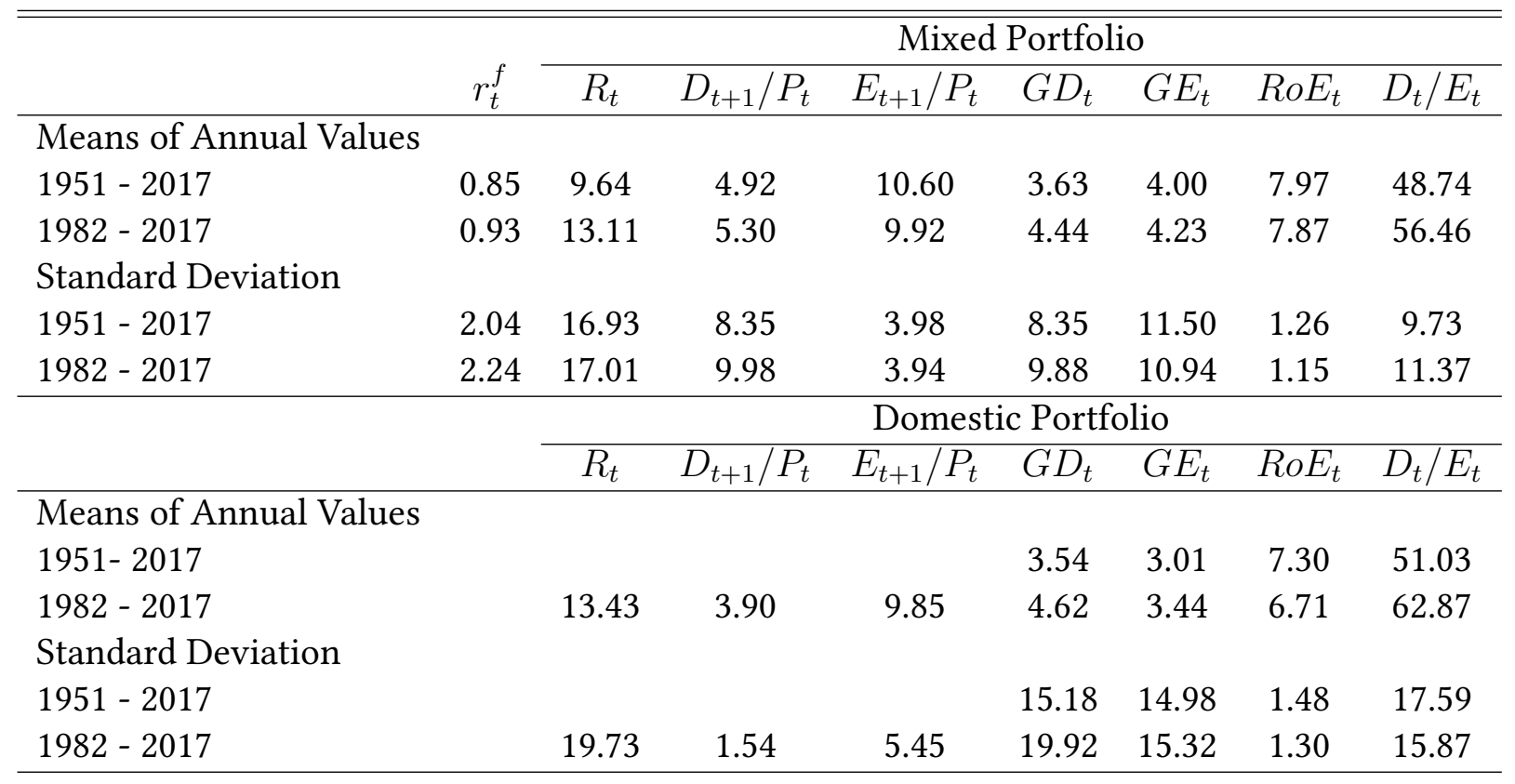

Notes: Some of the series are not available during 1951-1981 due to the data constraint. $r_{t}^{f}$ is the real return on 3 month treasury bills rolled over at each quarter, $G D_{t}$ is the dividend growth rate, $G E_{t}$ is the earning growth rate, and $R o E_{t}$ is accounting return on equity for year $t$. All variables are measured in real terms and expressed as percents.

expected stock returns. The simplest form of these, for example, is dividend yield plus expected dividend growth rate. See Appendix D.1 for more details about these estimation methods

Panel (b) and (c) of Figure 5 suggest that a substantial portion of realized returns on equities can stem from cumulative capital gains over the past decades. In panel (b), the shaded area displays the gap between realized returns on equities and 3-month treasury bills smoothed over twenty years. Some portion of it could be accounted for by the equity premium. The 20-year smoothed equity premium is indicated by the solid line. The upper part of the blue area above the lines therefore indicates the average rate of capital gains.

In Panel (c), I present the 20-year moving averages of capital gains implied by the three different estimations. Regardless of which method I choose, the estimated capital gains account for a significant part of realized returns. This is what the baseline model predicts: as the required expected return on assets has fallen and excess profits have increased, possibly due to globalization, the overall price of equities rises as a consequence of revaluation gains. This is also consistent with the view of Fama and French (2002), who claim that a significant part of the post-war realized returns on the stock index appear to have come from a large capital gain.

Furthermore, panel (d) of Figure 5 provides evidence that the expansion of foreign investment opportunities helped increase the Sharpe ratio of U.S. households' portfolio. I compare two equity 
portfolio, mixed and domestic, indicated by the blue and red bars in Panel (d). The mixed portfolio represents the actual portfolio owned by U.S. households. The underlying dividends and earnings originate from foreign entities as well as domestic firms, which are reported in Gross National Income. On the other hand, the domestic portfolio is based solely on profits generated by domestic investment and therefore reported in Gross Domestic Product. I use estimated market values, dividends, earnings and other fundamentals reported in Fed's Financial Account.

As in Fama and French (2002), I measure the Sharpe ratio of each aggregate portfolio as the estimated risk premium over the sample standard deviation of the realized returns. The blue and red bars present the estimated Sharpe ratios based on the three approaches. The sample period in this exercise is restricted to 1982-2017 due to the data constraint. Panel (d) shows that, indeed, the U.S. households enjoy a higher risk-return trade-off than the one generated in the U.S. domestic sectors. This benefit stems from a higher return on global investment and diversification effect. Table 2 provides related statistics.

\section{Quantitative Analysis}

\subsection{Model Fit}

Table 3 presents the calibrated parameters and their target moments. Figure 6 displays the fit of the model. First, the model is able to generate a Pareto tail in the wealth distribution and the top wealth shares are generally in line with the estimated top wealth share in 1989. Second, the model can match wage inequality and take into account its effect on the top wealth share. Later on, I compare the contribution of financial globalization with that of rising wage inequality. Finally, we can check portfolio choices of different wealth holders as shown in Panel (e) and (f). Affluent households invest more heavily on equity whereas the middle class invest more heavily on safe assets and housing.

\subsection{Result 1: Transitional Dynamics}

Panel (a) and (b) in Figure 7 plot transitional dynamics of the US wealth distribution after global capital flows transform interest rates and portfolio frontier in the economy. These figures confirm the basic logic developed in Section 2. After global capital flows are liberalized, low discount factors lead to capital gains of long-term assets in the financial center country. As can be seen from the figure, indebted households increase their debt level while the upper tail of the wealth distribution becomes thicker. The Pareto exponent of the distribution has increased. Panel (c) and Panel (d) illustrate portfolio shifting behaviors. These diagrams show that, even in a numerical 
Table 3: Calibrated Parameters

\begin{tabular}{|c|c|c|c|c|}
\hline Param. & Description & US & ROW & Source / Target \\
\hline \multicolumn{5}{|c|}{ Preferences } \\
\hline$\delta$ & Discount Rate & 0.05 & . & \multirow{4}{*}{ Survey of Consumer Finances } \\
\hline$\gamma$ & EIS & 2 & . & \\
\hline$c_{1}, c_{2}, c_{3}$ & Portfolio Choice & $2,1,1.5$ & . & \\
\hline$\beta_{h 1}, \beta_{h 2}$ & Housing Endowments & $0.27,2.2$ & . & \\
\hline \multicolumn{5}{|c|}{ Production } \\
\hline$\alpha$ & Capital Share & 0.3 & . & NIPA (2014) \\
\hline$Z$ & Aggregate Productivity & 0.43 & & US Autarky wage normalized to 1 \\
\hline $\bar{\sigma}$ & Aggregate Volatility & 0.125 & 0.15 & Internally Calibrated \\
\hline$\rho$ & Global Correlation & 0.7 & . & Internally Calibrated \\
\hline \multicolumn{5}{|c|}{ Financial Frictions } \\
\hline$\lambda$ & Pledgeability & 0.5 & 0.43 & Internally Calibrated \\
\hline$\tau$ & Additional Equity Cost & 0.065 & . & \\
\hline$\underline{a}$ & Maximum Allowable Debt & -1.9 & . & \\
\hline \multicolumn{5}{|c|}{ Idiosyncratic Shocks } \\
\hline$m$ & Death Rate & 0.025 & . & Avg. Life Span: 40 years \\
\hline$\mu_{\ell}, \Sigma_{\ell \ell}$ & Labor Productivity & $0.3,9$ & . & Internally Calibrated \\
\hline$\lambda_{\epsilon}, \beta_{\epsilon}, \sigma_{\epsilon}$ & Time-varying Productivity & $0.03,0,0$ & & \\
\hline$\mu_{a}, \Sigma_{a a}$ & Inherited Wealth & $0.55,0.49$ & . & Internally Calibrated \\
\hline$\Sigma_{a \ell}$ & Covariance between $a_{0} \& \ell$ & 0.03 & . & Internally Calibrated \\
\hline
\end{tabular}


Figure 6: Model Fit

(a) Wage Distribution

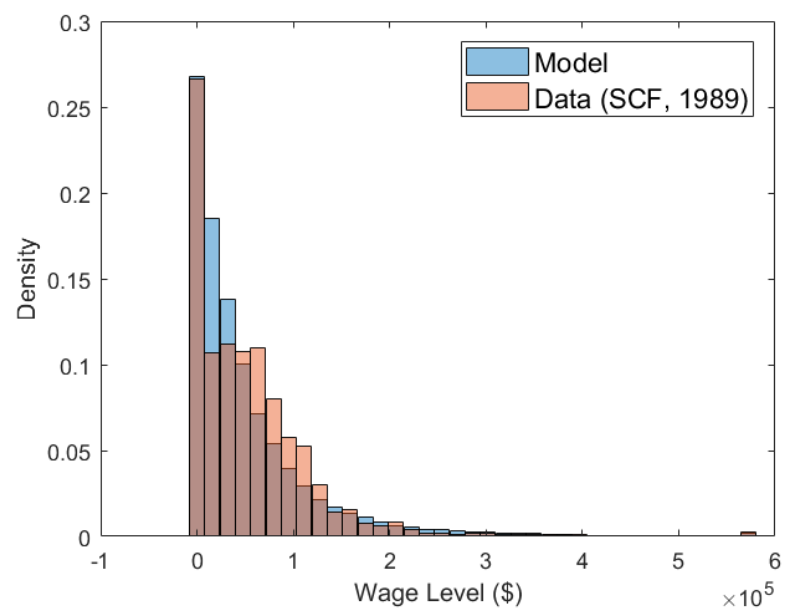

(c) Wealth Distribution

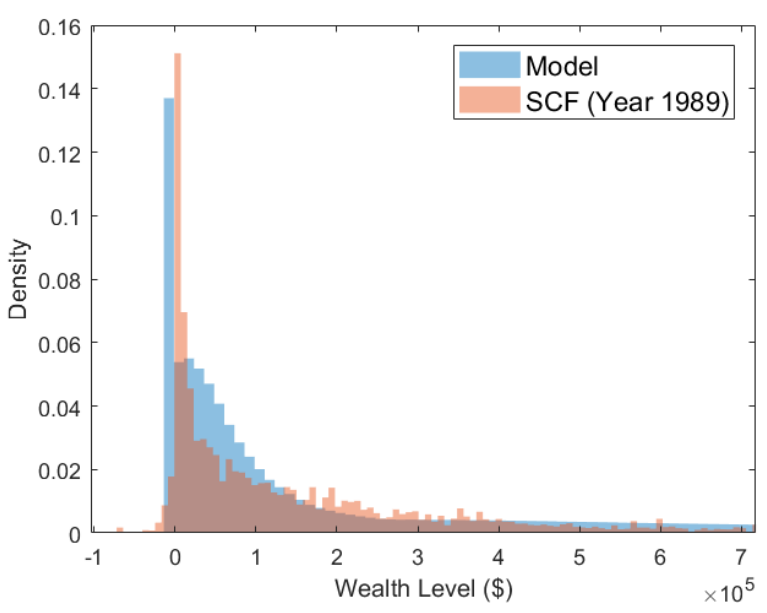

(e) Portfolio Allocation (Model)

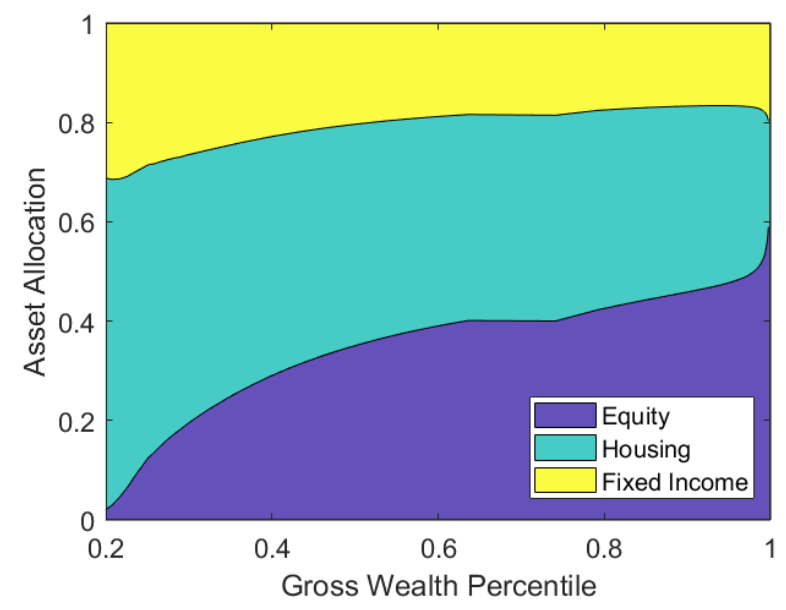

(b) Top Wage Share

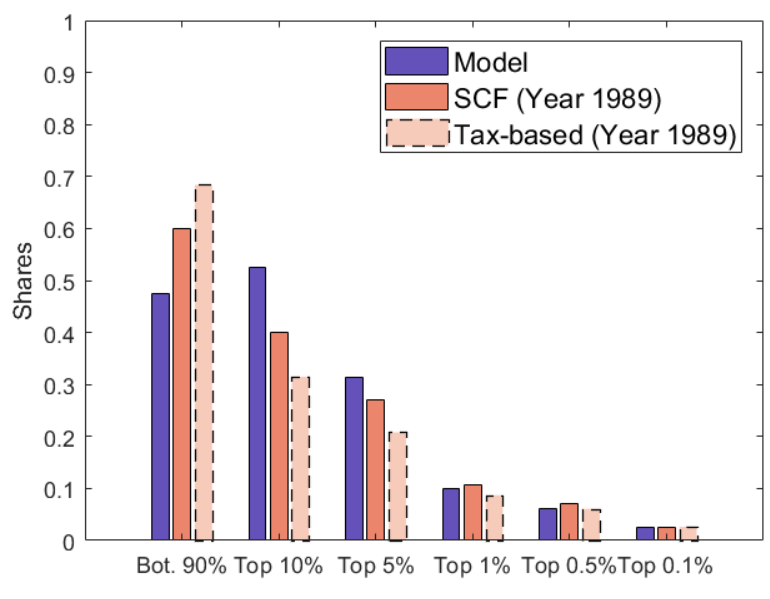

(d) Top Wealth Share

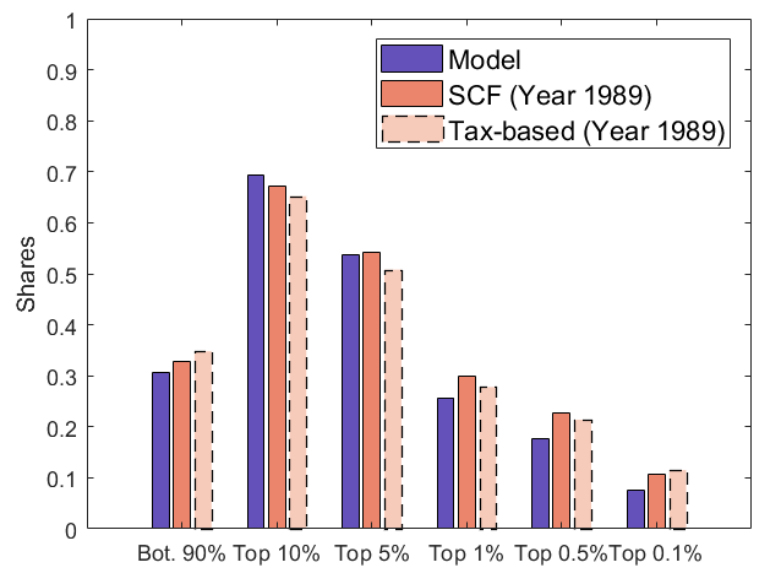

(f) Portfolio Allocation (Model \& Data)

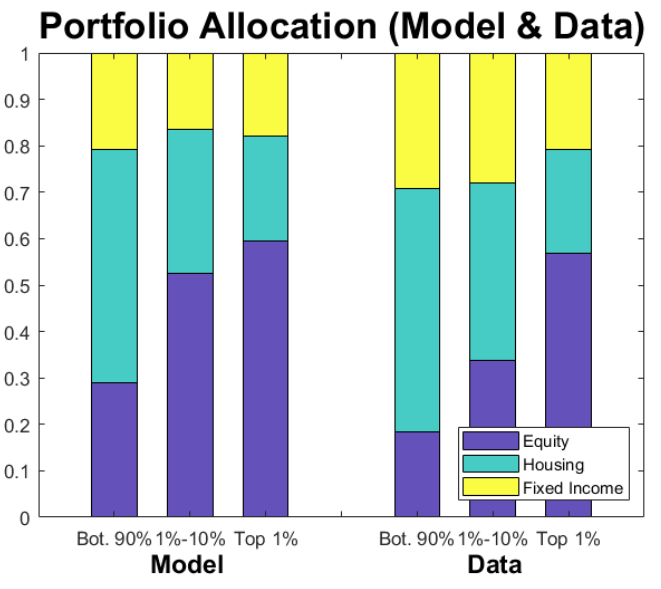


simulation, capital return inequality is widened thanks to a higher slope of the capital allocation line. This portfolio rebalancing effect helps counteract the decline in return on the domestic assets. A higher Sharpe ratio provides incentives for rich households to increase investment share in the risky assets.

Table 4 presents quantitative magnitude of these effects. Over the 30 years, the model generates a $4.8 \%$ p increase in the top one percent wealth share. This accounts for $55 \%=\frac{4.8 \% p}{8.7 \% p}$ of the observed increase in the top one percent wealth share in the Survey of Consumer Finances. If one uses estimates from Saez and Zucman (2016), the calibrated model accounts for $34 \%=\frac{4.8 \% p}{14.1 \% p}$ of the increase in the wealth share. The transitional dynamics can be divided into two steps. Immediately after the globalization shock, the top one percent's wealth share is increased from 0.312 to 0.327 due to capital gains on the existing domestic risky asset. The asymmetric portfolio rebalancing arises, thereby generating a gradual increase in wealth concentration. In the new stationary state, the top wealth share is increased as large as to 0.405 .

\subsection{Result 2: Reversal of the Trend}

A core message of this study is that the long-run trajectory of wealth concentration on the relative magnitudes of (a) the decrease in domestic interest rates and (b) the asymmetric balance sheet reallocation across different wealth holders. The previous analysis suggests that, at least over the past three decades, the effect from (b) appears to outweigh the effect from (a). As in Section 2, the model still leaves room for a possible reversal in the future if financial globalization

Table 4: Transitional Dynamics

\begin{tabular}{lcccc}
\hline \hline Wealth Shares & Bottom 90\% & Top 10\% & Top 5\% & Top 1\% \\
\hline Autarky & 0.351 & 0.649 & 0.537 & 0.312 \\
Data Estimates (1989) & 0.329 & 0.671 & 0.542 & 0.299 \\
& & & & \\
Open (after 0 year) & $-5.8 \% \mathrm{p}$ & $+5.8 \% \mathrm{p}$ & $+5.2 \% \mathrm{p}$ & $+1.5 \% \mathrm{p}$ \\
Open (after 30 years) & $-7.0 \% \mathrm{p}$ & $+7.0 \% \mathrm{p}$ & $+7.7 \% \mathrm{p}$ & $+4.8 \% \mathrm{p}$ \\
Data Estimates (2016) & $-10.0 \% \mathrm{p}$ & $+10.0 \% \mathrm{p}$ & $10.9 \% \mathrm{p}$ & $+8.7 \% \mathrm{p}$ \\
& & & & \\
Open (New Stationary State) & $-13.4 \% \mathrm{p}$ & $+13.4 \% \mathrm{p}$ & $+13.7 \% \mathrm{p}$ & $+8.8 \% \mathrm{p}$ \\
\hline & & & & \\
Equilibrium Prices & $r$ & $s_{1}$ & $r+\sigma_{1} s_{1}$ & $s_{2}$ \\
\hline Autarky & 0.033 & 0.191 & 0.081 & \\
Open (stationary) & 0.023 & 0.399 & 0.073 & 0.43 \\
\hline
\end{tabular}

Notes: This table displays transitional dynamics of the wealth distribution and equilibrium prices. Data estimates are computed from the Survey of Consumer Finances. 
Figure 7: Transitional Dynamics

(a) Wealth Distribution

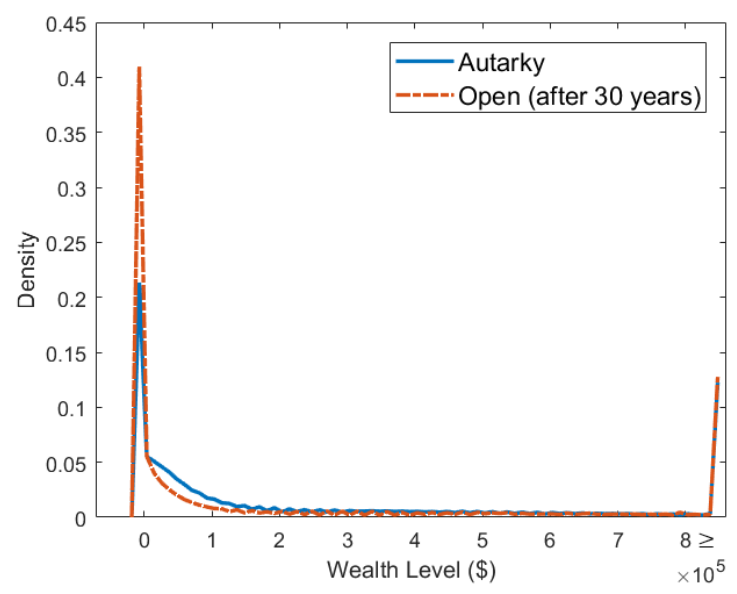

(c) Capital Allocation Line (Autarky)

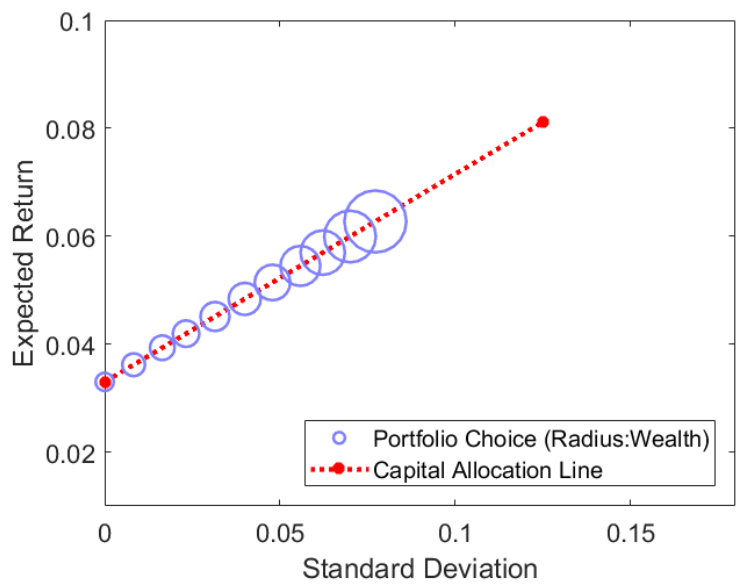

(b) Top Wealth Shares

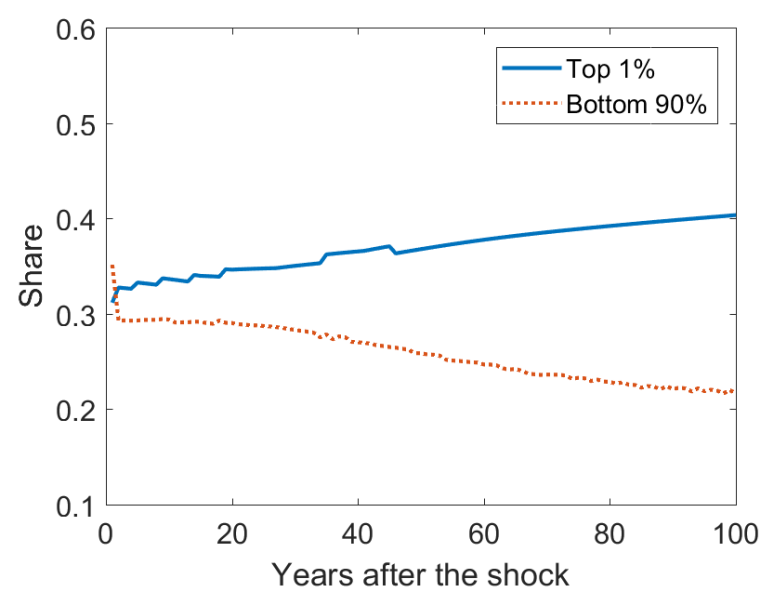

(d) Capital Allocation Line (Open Economy)

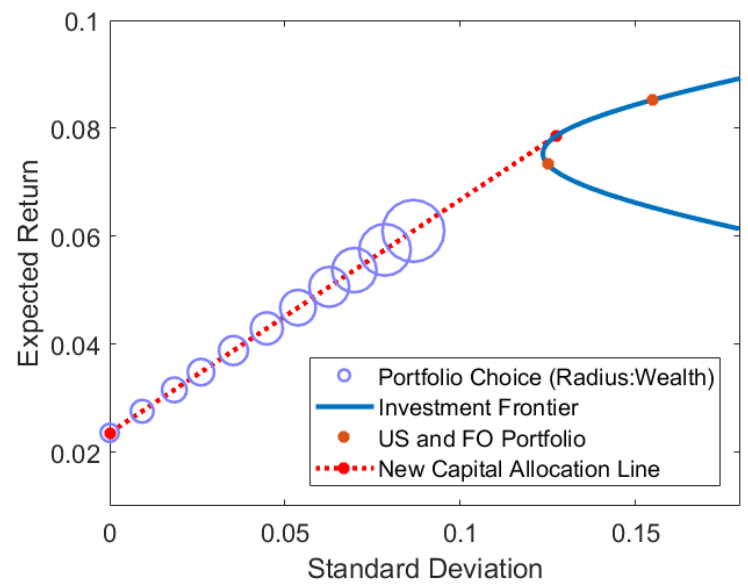

Notes: Panel (a) plots the model-implied wealth distribution prior to the shock and 30 years after the shock. Panel (b) displays transitional dynamics of the wealth distribution. Panel (c) presents capital allocation line in autarky. Panel (d) shows the balance sheet reallocation induced by financial globalization.

no longer provides enough diversification benefit to counteract diminished return on domestic assets. Figure 8 presents one such case. In this exercise, Financial globalization is modeled as two-stage shocks. The first wave of financial globalization is the same as before. In the second wave, the Sharpe ratio of the optimal portfolio is reduced due to a decrease in $\bar{\sigma}^{F O}$. These shocks, as Panel (b) shows, result in an inverse- $U$ shape transitional dynamics of the top one percent wealth share. 
Figure 8: Reversal of the Trend

(a) Wealth Distribution

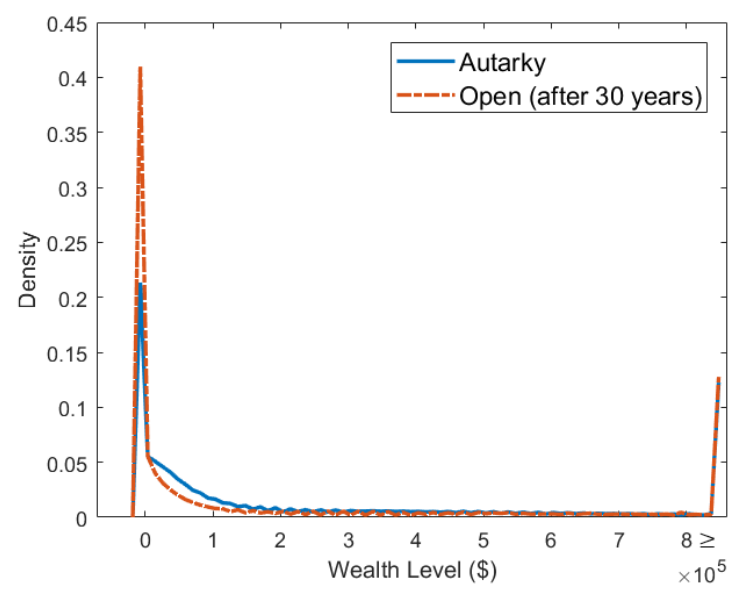

(b) Top Wealth Shares

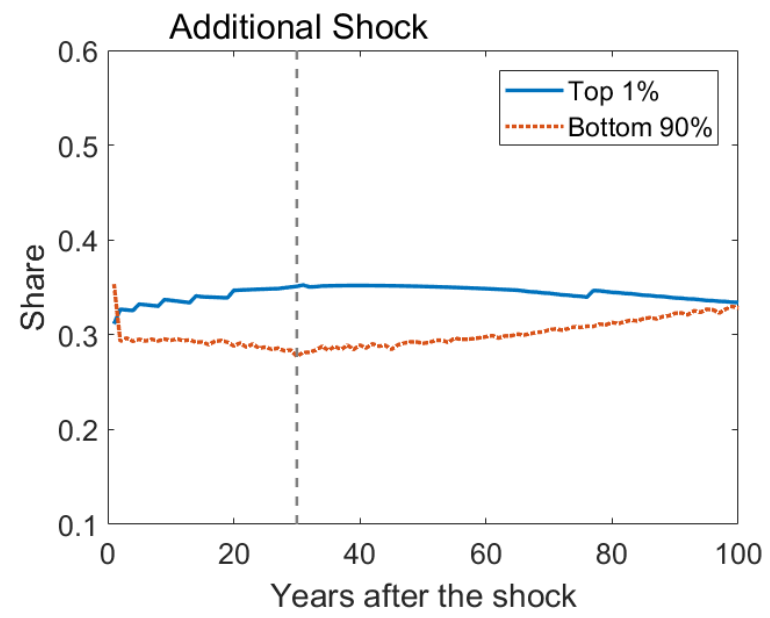

\subsection{Result 3: Factor Decomposition}

Next, we explore different factors that could potentially contribute to rising wealth concentration in the U.S. over the past three decades. Several factors have been proposed to account for the recent change in the wealth distribution in the U.S., including widened wage inequality and tax reforms. In this subsection, we compare the magnitudes of these effects and assess the extent to which global capital flows matter to changes in the U.S. wealth distribution from 1989 to 2016.

The exercise proceeds as follows. In the first scenario, I consider a situation where the economy experiences an increase in wage inequality, with every other parameter held constant. The widened wage inequality is simply captured by an change in the value of $\Sigma_{l l}$. I adjust $\mu_{l}$ to make sure that the total labor supply remains unchanged. These parameters are calibrated such that prior to the shock -- the implied top wage shares are consistent with the observed shares in 1989. The post-shock wage distribution is matched to the 2016 data. In the second scenario, I assume that global capital flows are the only structural change over this period with all else staying the same. This scenario is identical to the one presented in Section 6.2. I also analyze the combined effect between the two factors. Finally, I compute residuals - the portion that is not accounted for by these two factors. I interpret the size of these residuals as the extent to which other factors such as changing taxes contributed to rising wealth concentration.

Table 5 displays the results. The first conclusion is that a change in wage inequality has a relatively small impact on the top wealth holders. This finding is consistent with what Hubmer et al. (2018) reported. A major source of income of the top wealth holders is capital, not labor. The widened wage inequality has limited effects on how these wealth holders reinvest their capital. 
Table 5: Factor Decomposition

\begin{tabular}{|c|c|c|c|c|}
\hline Wealth Shares & Bottom $90 \%$ & Top $10 \%$ & Top 5\% & Top $1 \%$ \\
\hline Autarky & $35.1 \%$ & $64.9 \%$ & $53.7 \%$ & $31.2 \%$ \\
\hline Effect 1: Wage Inequality Only & $-1.3 \% \mathrm{p}$ & $+1.3 \% \mathrm{p}$ & $+1.8 \% \mathrm{p}$ & $+1.0 \% \mathrm{p}$ \\
\hline $\begin{array}{l}\text { Effect } 2 \text { : Global Capital Flows Only } \\
\text { (1 and } 2 \text { combined) }\end{array}$ & $\begin{array}{l}-6.8 \% \mathrm{p} \\
(-8.2 \% \mathrm{p})\end{array}$ & $\begin{array}{l}+6.8 \% \mathrm{p} \\
(+8.2 \% \mathrm{p})\end{array}$ & $\begin{array}{l}+8.2 \% \mathrm{p} \\
(+9.1 \% \mathrm{p})\end{array}$ & $\begin{array}{l}+4.8 \% \mathrm{p} \\
(+4.5 \% \mathrm{p})\end{array}$ \\
\hline Effect 3: Residuals & $-4.0 \% \mathrm{p}$ & $+4.0 \% \mathrm{p}$ & $+2.3 \% \mathrm{p}$ & $+3.0 \% \mathrm{p}$ \\
\hline Data Estimates (2016) & $-12.2 \% \mathrm{p}$ & $+12.2 \% \mathrm{p}$ & $+11.4 \% \mathrm{p}$ & $+7.4 \% \mathrm{p}$ \\
\hline
\end{tabular}

Notes: This table displays changes in the wealth distribution over 30 years under different scenarios. Effect 1 represents a case where the economy experiences changes in wage inequality while other parameters being constant. Effect 2 presents the corresponding estimates in the previous analysis. Numbers in the parenthesis indicate the joint effect. Effect 3 is defined as the gap between Data Estimates (2016) and (1 and 2 combined).

Figure 9: Transitional Dynamics in Different Scenarios

(a) Top $1 \%$ Wealth Shares

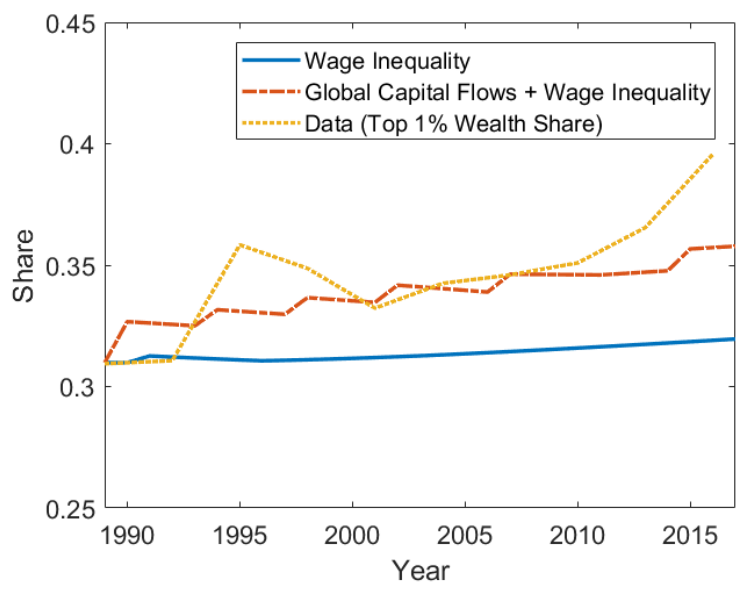

(b) Bottom 90\% Wealth Shares

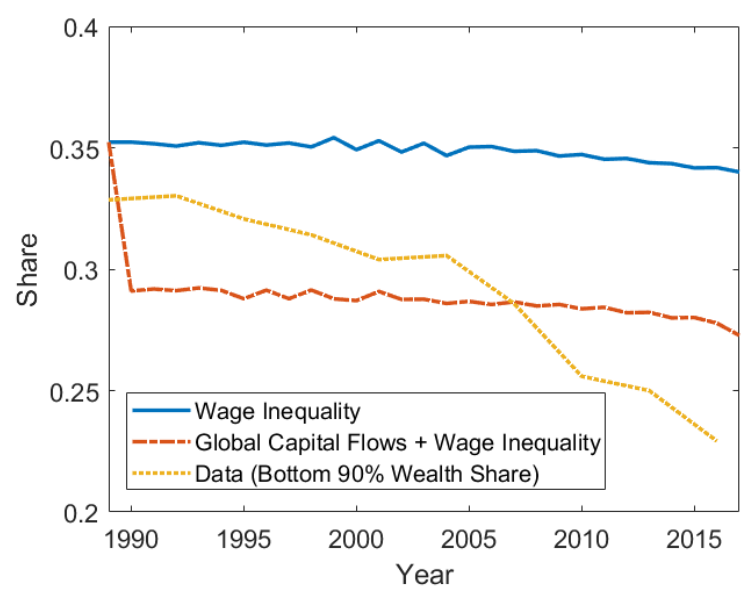

Notes: Panel (a) displays transitional dynamics of the top $1 \%$ wealth shares under different scenarios. Panel (b) plots the corresponding graphs for the bottom $90 \%$ wealth shares. Data estimates are computed from the Survey of Consumer Finances.

By contrast, global financial flows make a more immediate and sizable impact on the wealth distribution. Global capital flows alone can explain a $4.8 \%$ p increase in the top $1 \%$ wealth share out of $7.4 \%$ p and a $-6.8 \%$ p decrease in the bottom $90 \%$ wealth share out of $-12.2 \%$ p. Figure 9 plots the related transitional dynamics. The quantitative analysis here suggests that global capital flows play an outsized role in reshaping the wealth distribution of the U.S. - the central country in global financial architecture. 


\section{Conclusion}

Financial globalization was an important milestone for the US capital market. The US economy has experienced a dramatic increase in capital flows over the past decades, yet the expansion of external balance sheet was asymmetric, owing to the country's special role in the global financial system. On the one hand, American investors gained new access to high-yield risky assets in the form of global equity, and FDI of US multinational firms. On the other hand, an increasingly large proportion of US debt securities is being held by foreign investors seeking safe returns.

This paper developed a model to quantify the contribution of financial globalization to rising wealth concentration in the US. I showed that capital account liberalization around the globe can change the market value of net worth for American households and reshape the way their wealth is subsequently reinvested. Quantitatively, about one-third to one-half of the increase in the top one percent's wealth share could potentially be accounted for by global financial flows between the financial center and peripheral economies. At the same time, the model indicates that a future trajectory of wealth concentration is dependent on the relative magnitudes of the drop in domestic interest rates and the expansion of new risky assets. Declining yields of global and US domestic assets in recent periods suggest that a reversal of the trend in rising wealth inequality is not impossible in the future.

Studying the international dimension of capital market would help us understand the evolution of the wealth distribution and to design distribution policies. This paper takes one step, but the following areas deserve further investigation: First, there is still a computational difficulty in modeling asset prices with heterogeneous agents at a large scale. This paper is no exception, though I provide leeway applicable to a medium-scale model. The literature has room for improvement. Second, I simplify the linkage between housing markets and global financial flows. Third, no active tax policy is explored in this paper. I leave these topics for future research.

\section{References}

[1] Y. Achdou, J. Han, J.-M. Lasry, P.-L. Lions, and B. Moll, "Income and Wealth Distribution in Macroeconomics: A Continuous-Time Approach," National Bureau of Economic Research, Working Paper 23732, August 2017.

[2] S. Ahn, G. Kaplan, B. Moll, T. Winberry, and C. Wolf, "When Inequality Matters for Macro and Macro Matters for Inequality," NBER Macroeconomics Annual, vol. 32, no. 1, pp. 1-75, 2018. 
[3] S. R. Aiyagari, "Uninsured Idiosyncratic Risk and Aggregate Saving," The Quarterly fournal of Economics, vol. 109, no. 3, pp. 659-684, 1994.

[4] P. Antràs and R. J. Caballero, "On the Role of Financial Frictions and the Saving Rate during Trade Liberalizations," Journal of the European Economic Association, vol. 8, no. 2-3, pp. 442455, 2010.

[5] P. Antràs, M. A. Desai, and C. F. Foley, "Multinational Firms, FDI Flows, and Imperfect Capital Markets," The Quarterly fournal of Economics, vol. 124, no. 3, p. 1171, 2009.

[6] L. Bach, L. E. Calvet, and P. Sodini, "Rich Pickings? Risk, Return, and Skill in Household Wealth," Tech. Rep. FIN-2016-1126, 2018.

[7] J. Benhabib and A. Bisin, "Skewed Wealth Distributions: Theory and Empirics," 2018.

[8] T. Bewley, "A Difficulty with the Optimum Quantity of Money," Econometrica, vol. 51, no. 5, pp. 1485-1504, 1983.

[9] O. J. Blanchard, "Debt, Deficits, and Finite Horizons," fournal of Political Economy, vol. 93, no. 2, pp. 223-247, 1985.

[10] R. J. Caballero, E. Farhi, and P.-O. Gourinchas, "An Equilibrium Model of Global Imbalances and Low Interest Rates," American Economic Review, vol. 98, no. 1, pp. 358-93, March 2008.

[11] --, "Rents, Technical Change, and Risk Premia Accounting for Secular Trends in Interest Rates, Returns on Capital, Earning Yields, and Factor Shares," American Economic Review, vol. 107, no. 5, pp. 614-20, May 2017.

[12] M. Cagetti and M. De Nardi, "Entrepreneurship, Frictions, and Wealth," fournal of Political Economy, vol. 114, no. 5, pp. 835-870, 2006.

[13] J. Y. Campbell, "Viewpoint: Estimating the equity premium," Canadian fournal of Economics, vol. 41, no. 1, pp. 1-21, 2008.

[14] J.Y. Campbell and J. H. Cochrane, "By Force of Habit: A ConsumptionfiQuBased Explanation of Aggregate Stock Market Behavior," fournal of Political Economy, vol. 107, no. 2, pp. 205251, 1999.

[15] J. Y. Campbell and S. B. Thompson, "Predicting Excess Stock Returns Out of Sample: Can Anything Beat the Historical Average?” The Review of Financial Studies, vol. 21, no. 4, pp. 1509-1531, 2008. 
[16] D. G. Champernowne, "A Model of Income Distribution,” The Economic fournal, vol. 63, no. 250, pp. 318-351, 1953.

[17] T. Chesnokova, "Immiserizing deindustrialization: A dynamic trade model with credit constraints," Journal of International Economics, vol. 73, no. 2, pp. 407 -420, 2007.

[18] J. C. Cox, J. E. Ingersoll, and S. A. Ross, "An Intertemporal General Equilibrium Model of Asset Prices," Econometrica, vol. 53, no. 2, pp. 363-384, 1985.

[19] S. E. Curcuru, C. P. Thomas, and F. E. Warnock, "On Returns Differentials," National Bureau of Economic Research, Working Paper 18866, March 2013.

[20] W. W. Dou and A. Verdelhan, "The Volatility of International Capital Flows and Foreign Assets," Tech. Rep., 2015.

[21] B. Eichengreen, Exorbitant Privilege: The Rise and Fall of the Dollar and the Future of the International Monetary System, 1st ed. Oxford University Press, 2011.

[22] A. Fagereng, L. Guiso, D. Malacrino, and L. Pistaferri, "Heterogeneity and Persistence in Returns to Wealth," IMF Working Papers, 2018.

[23] E. F. Fama and K. R. French, “The Equity Premium,” The fournal of Finance, vol. 57, no. 2, pp. 637-659, 2002.

[24] J. Fernández-Villaverde, S. Hurtado, and G. Nuno, "Financial Frictions and the Wealth Distribution," 2018.

[25] D. Furceri and P. Loungani, "Capital Account Liberalization and Inequality”, IMF Working Papers, 2015.

[26] D. Furceri, P. Loungani, and J. D. Ostry, "The Aggregate and Distributional Effects of Financial Globalization: Evidence from Macro and Sectoral Data, 2017.

[27] X. Gabaix, "Power Laws in Economics and Finance," Annual Review of Economics, vol. 1, no. 1, pp. 255-294, 2009.

[28] X. Gabaix, J.-M. Lasry, P.-L. Lions, and B. Moll, "The Dynamics of Inequality," Econometrica, vol. 84, no. 6, pp. 2071-2111, 2016.

[29] M. Gomez, “Asset Prices and Wealth Inequality, 2019.

[30] - - "Displacement and the Rise in Top Wealth Inequality, 2019. 
[31] P.-O. Gourinchas and H. Rey, From World Banker to World Venture Capitalist: US External Adjustment and the Exorbitant Privilege. The University of Chicago Press, 2007, pp. 11-15.

[32] --, "Exorbitant Privilege and Exorbitant Duty," IMES Discussion Paper Series, 2010.

[33] C. R. Harvey, "Predictable Risk and Returns in Emerging Markets," The Review of Financial Studies, vol. 8, no. 3, pp. 773-816, 1995.

[34] E. Helpman, Globalization and Inquality. Harvard University Press, 2018.

[35] B. Holmstrom and J. Tirole, "Financial Intermediation, Loanable Funds, and The Real Sector," The Quarterly fournal of Economics, vol. 112, no. 3, pp. 663-691, 1997.

[36] J. Hubmer, P. Krusell, and A. A. Smith Jr, "A Comprehensive Quantitative Theory of the US Wealth Distribution," Working Paper, 2018.

[37] M. Huggett, "The Risk-free Rate in Heterogeneous-agent Incomplete-insurance Economies," Journal of Economic Dynamics and Control, vol. 17, no. 5, pp. 953-969, 1993.

[38] T. L. Hungerford, "Changes in the Distribution of Income Among Tax Filers Between 1996 and 2006: The Role of Labor Income, Capital Income, and Tax Policy," CRS Report for Congres, 2011.

[39] F. Jaumotte, S. Lall, and C. Papageorgiou, "Rising Income Inequality: Technology, or Trade and Financial Globalization?” IMF Working Papers, no. 08/185, 2008.

[40] C. I. Jones, "Pareto and Piketty: The Macroeconomics of Top Income and Wealth Inequality," Journal of Economic Perspectives, vol. 29, no. 1, pp. 29-46, February 2015.

[41] O. Jordà, K. Knoll, D. Kuvshinov, M. Schularick, and A. M. Taylor, "The Rate of Return on Everything, 1870-2015, National Bureau of Economic Research, Working Paper 24112, December 2017.

[42] M. Kacperczyk, J. Nosal, and L. Stevens, "Investor Sophistication and Capital Income Inequality”, Journal of Monetary Economics, 2018.

[43] G. Kaplan, B. Moll, and G. L. Violante, "Monetary Policy According to HANK," American Economic Review, vol. 108, no. 3, pp. 697-743, March 2018.

[44] C. P. Kindleberger, "Balance-of-Payments Deficits and the International Market for Liquidity," Essays in International Finance, vol. 106, no. 46, 1965. 
[45] P. Krusell and A. A. Smith, "Income and Wealth Heterogeneity in the Macroeconomy, fournal of Political Economy, vol. 106, no. 5, pp. 867-896, 1998.

[46] P. R. Lane, "Financial Globalisation and the Crisis," Open Economic Review, vol. 24, no. 3, pp. 555-580, 2013.

[47] P. R. Lane and G. M. Milesi-Ferretti, "The External Wealth of Nations Mark II: Revised and Extended Estimates of Foreign Assets and Liabilities, 1970-2004, Journal of International Economics, vol. 73, no. 2, pp. 223-250, 2007.

[48] R. Litzenberger and M. Rubinstein, "The Strong Case for the Generalized Logarithmic Utility Model as the Premier Model of Financial Markets," The fournal of Finance, vol. 31, no. 2, pp. $551-571,1976$.

[49] M. Maggiori, "Financial Intermediation, International Risk Sharing, and Reserve Currencies," American Economic Review, vol. 107, no. 10, pp. 3038-71, October 2017.

[50] N. G. Mankiw, "Yes, r>g. So What?" American Economic Review: Papers \& Proceedings, vol. 105, no. 5, pp. 43-47, 2015.

[51] E. G. Mendoza, V. Quadrini, and J.-V. Rios-Rull, "Financial Integration, Financial Development, and Global Imbalances," fournal of Political Economy, vol. 117, no. 3, pp. 371-416, 2009.

[52] R. C. Merton, "Lifetime Portfolio Selection under Uncertainty: The Continuous-Time Case," The Review of Economics and Statistics, vol. 51, no. 3, pp. 247-257, 1969.

[53] --, "Optimum Consumption and Portfolio Rules in a Continuous-time Model," fournal of Economic Theory, vol. 3, no. 4, pp. 373-413, 1971.

[54] --, Continuous-Time Finance. Wiley-Blackwell, 1992.

[55] A. Mian, K. Rao, and A. Sufi, "Household Balance Sheets, Consumption, and the Economic Slump," The Quarterly fournal of Economics, vol. 128, no. 4, pp. 1687-1726, 2013.

[56] M. Obstfeld, "Risk-Taking, Global Diversification, and Growth," The American Economic Review, vol. 84, no. 5, pp. 1310-1329, 1994.

[57] M. Ogaki and Q. Zhang, "Decreasing Relative Risk Aversion and Tests of Risk Sharing," Econometrica, vol. 69, no. 2, pp. 515-526, 2001.

[58] T. Piketty, Capital in the Twenty-First Century. Harvard University Press, 2014. 
[59] T. Piketty, E. Saez, and G. Zucman, "Distributional National Accounts: Methods and Estimates for the United States," The Quarterly fournal of Economics, vol. 133, no. 2, pp. 553-609, 2018.

[60] V. Quadrini, "Entrepreneurship, Saving, and Social Mobility," Review of Economic Dynamics, vol. 3, no. 1, pp. 1-40, 2000.

[61] M. Rognlie, “A Note on Piketty and Diminishing Returns,” 2014.

[62] E. Saez and G. Zucman, "Wealth Inequality in the United States since 1913: Evidence from Capitalized Income Tax Data," The Quarterly fournal of Economics, vol. 131, no. 2, p. 519, 2016.

[63] W. F. Sharpe, "Capital Asset Prices: A Theory of Market Equilibrium under Conditions of Risk," The fournal of Finance, vol. 19, no. 3, pp. 425-442, 1964.

[64] J. C. Stein, "Monetary Policy as Financial Stability Regulation,” The Quarterly fournal of Economics, vol. 127, no. 1, pp. 57-95, 2012.

[65] L. H. Summers, "U.S. Economic Prospects: Secular Stagnation, Hysteresis, and the Zero Lower Bound," Business Economics, vol. 49, no. 2, 2014.

[66] M. E. Yaari, "Uncertain Lifetime, Life Insurance, and the Theory of the Consumer," The Review of Economic Studies, vol. 32, no. 2, pp. 137-150, 041965.

\section{Appendix A Detailed Proofs}

\section{A.1 Proof of Proposition 1}

\section{A.1.1 Result 1. $d \log \Omega_{T}$}

It follows from the differential equation (4) that the price of domestic equities rises to $p_{T}=$ $\frac{r^{*}+\sigma_{1} s_{1}^{*}}{r+\sigma_{1} s_{1}}>1$. Using this, we can write $\Omega_{T}$ as

$$
\Omega_{T}=\frac{\int_{a=G^{*-1}(0.99)}^{\infty}\left\{a\left(1-\theta_{1}(a)\right)+\left(\frac{r^{*}+\sigma_{1} s_{1}^{*}}{r+\sigma_{1} s_{1}}\right) a \theta_{1}(a)\right\} g^{*}(a) d a}{\int_{a=\underline{a}}^{\infty}\left\{a\left(1-\theta_{1}(a)\right)+\left(\frac{r^{*}+\sigma_{1} s_{1}^{*}}{r+\sigma_{1} s_{1}}\right) a \theta_{1}(a)\right\} g^{*}(a) d a}
$$

where $G^{*}(\cdot)$ and $g^{*}(\cdot)$ are c.d.f. and p.d.f. of the wealth distribution prior to the shock. The numerator is the average net worth of the top 1 percent households; the cutoff is given by $G^{*-1}(0.99)$. 
The denominator is the average net worth of the entire population. Recall that all households retain their wealth above $\underline{a}$, so no mass exists below this threshold. Multiplying $r+\sigma_{1} s_{1}$ and taking log, one can obtain

$$
\begin{aligned}
\log \Omega_{T}= & \log \left(\int_{a=G^{*-1}(0.99)}^{\infty}\left\{a\left(1-\theta_{1}(a)\right)\left(r+\sigma_{1} s_{1}\right)+a \theta_{1}(a)\left(r^{*}+\sigma_{1} s_{1}^{*}\right)\right\} g^{*}(a) d a\right) \\
& -\log \left(\int_{a=\underline{a}}^{\infty}\left\{a\left(1-\theta_{1}(a)\right)\left(r+\sigma_{1} s_{1}\right)+a \theta_{1}(a)\left(r^{*}+\sigma_{1} s_{1}^{*}\right)\right\} g^{*}(a) d a\right)
\end{aligned}
$$

Differentiating the both sides with respect to $x \equiv r+\sigma_{1} s_{1}$, we have

$$
d \log \Omega_{T}=-\phi_{1} \frac{d\left(r+\sigma_{1} s_{1}\right)}{r+\sigma_{1} s_{1}}=-\phi_{1} d \log \left(r+\sigma_{1} s_{1}\right)
$$

where

$$
\begin{aligned}
\phi_{1}= & -\frac{\left(r+\sigma_{1} s_{1}\right) \int_{a=G^{*-1}(0.99)}^{\infty}\left\{a\left(1-\theta_{1}(a)\right)\right\} g^{*}(a) d a}{\int_{a=G^{*-1}(0.99)}^{\infty}\left\{a\left(1-\theta_{1}(a)\right)\left(r+\sigma_{1} s_{1}\right)+a \theta_{1}(a)\left(r^{*}+\sigma_{1} s_{1}^{*}\right)\right\} g^{*}(a) d a} \\
& +\frac{\left(r+\sigma_{1} s_{1}\right) \int_{a=\underline{a}}^{\infty}\left\{a\left(1-\theta_{1}(a)\right)\right\} g^{*}(a) d a}{\int_{a=\underline{a}}^{\infty}\left\{a\left(1-\theta_{1}(a)\right)\left(r+\sigma_{1} s_{1}\right)+a \theta_{1}(a)\left(r^{*}+\sigma_{1} s_{1}^{*}\right)\right\} g^{*}(a) d a}
\end{aligned}
$$

Dividing each term by its numerator, we can re-write $\phi_{1}$ as

$$
\phi_{1}=-\frac{1}{1+\frac{r^{*}+\sigma_{1} s_{1}^{*}}{r+\sigma_{1} s_{1}} \frac{\int_{a=G^{*-1}(0.99)}^{\infty} a \theta_{1}(a) g^{*}(a) d a}{\int_{a=G^{*-1}(0.99)}^{\infty} a\left(1-\theta_{1}(a)\right) g^{*}(a) d a}}+\frac{1}{1+\frac{r^{*}+\sigma_{1} s_{1}^{*}}{r+\sigma_{1} s_{1}} \frac{\int_{a=\underline{a}}^{\infty} a \theta_{1}(a) g^{*}(a) d a}{\int_{a=\underline{a}}^{\infty} a\left(1-\theta_{1}(a)\right) g^{*}(a) d a}}>0
$$

The positive sign of $\phi_{1}$ follows from Lemma 1 below, which suggests that

$$
\frac{\int_{a=G^{*-1}(0.99)}^{\infty} a \theta_{1}(a) g^{*}(a) d a}{\int_{a=G^{*-1}(0.99)}^{\infty} a\left(1-\theta_{1}(a)\right) g^{*}(a) d a}>\frac{\int_{a=\underline{a}}^{\infty} a \theta_{1}(a) g^{*}(a) d a}{\int_{a=\underline{a}}^{\infty} a\left(1-\theta_{1}(a)\right) g^{*}(a) d a}
$$

This proves the first part of the proposition. Intuitively speaking, the top 1 percent households, on average, invest more heavily in risky assets prior to the shock so they get more revaluation gains than the average population.

Lemma 1. $\frac{d}{d x} \frac{\int_{x}^{\infty} a \theta_{1}(a) g^{*}(a) d a}{\int_{x}^{\infty} a\left(1-\theta_{1}(a)\right) g^{*}(a) d a}>0$ for all $x \geq \underline{a}$.

Proof. It is easy to show

$$
\frac{\int_{a=x}^{\infty} a \theta_{1}(a) g^{*}(a) d a}{\int_{x}^{\infty} a\left(1-\theta_{1}(a)\right) g^{*}(a) d a}=\frac{\int_{x}^{\infty} a \theta_{1}(a) g^{*}(a) d a / \int_{x}^{\infty} a g^{*}(a)}{1-\int_{x}^{\infty} a \theta_{1}(a) g^{*}(a) d a / \int_{a=x}^{\infty} a g^{*}(a)}
$$


So one can see that the sign of $\frac{d}{d x} \frac{\int_{a=x}^{\infty} a \theta_{1}(a) g^{*}(a) d a}{\int_{a=x}^{\infty} a\left(1-\theta_{1}(a)\right) g^{*}(a) d a}$ is identical to the sign of $\frac{d}{d x} \frac{\int_{a=x}^{\infty} a \theta_{1}(a) g^{*}(a) d a}{\int_{a=x}^{\infty} a g^{*}(a)}$. Taking a derivative with respect to $x$, we obtain

$$
\begin{aligned}
& \frac{1}{\left(\int_{x}^{\infty} a g^{*}(a)\right)^{2}}\left[-x \theta_{1}(x) g^{*}(x) \int_{x}^{a} a g^{*}(a) d a+x g^{*}(x) \int_{x}^{a} a \theta_{1}(a) g^{*}(a) d a\right] \\
= & \frac{x g^{*}(x) \theta_{1}(x)}{\left(\int_{x}^{\infty} a g^{*}(a)\right)^{2}}\left[-\int_{x}^{a} a g^{*}(a) d a+\int_{x}^{a} a \frac{\theta_{1}(a)}{\theta_{1}(x)} g^{*}(a) d a\right] \\
> & 0
\end{aligned}
$$

where the last inequality results from $\frac{\theta_{1}(a)}{\theta_{1}(x)}>1$ for all $a \geq x$.

\section{A.1.2 Result 2. $d \log \Omega_{\infty}$}

Next, let me turn to $\Omega_{\infty}$. Let $g(a)$ denote the stationary distribution in closed economy. Substituting $c(a)$ and $\theta_{1}(a)$ from (3), the Kolmogorov Forward equation in (5) can be expressed as

$$
0=-m g_{0}(a)+m g(a)+\frac{d}{d a}\left[\left(r^{*}+\left(s_{1}^{*}\right)^{2}-\delta\right)(a-\underline{a}) g(a)\right]
$$

Arranging the terms, one can restate the differential equation as

$$
\frac{d g(a)}{d a}+\frac{r^{*}+\left(s_{1}^{*}\right)^{2}-\delta+m}{r^{*}+\left(s_{1}^{*}\right)^{2}-\delta} \frac{g(a)}{a-\underline{a}}=\frac{m g_{0}(a)}{\left(r^{*}+\left(s_{1}^{*}\right)^{2}-\delta\right)(a-\underline{a})}
$$

Multiplying the both sides by $(a-\underline{a})^{\frac{r^{*}+\left(s_{1}^{*}\right)^{2}-\delta+m}{r^{*}+\left(s_{1}^{*}\right)^{2}-\delta}}$, we have

$$
\frac{d}{d a}\left[g(a)(a-\underline{a})^{\frac{r^{*}+\left(s_{1}^{*}\right)^{2}-\delta+m}{r^{*}+\left(s_{1}^{*}\right)^{2}-\delta}}\right]=(a-\underline{a})^{\frac{r^{*}+\left(s_{1}^{*}\right)^{2}-\delta+m}{r^{*}+\left(s_{1}^{*}\right)^{2}-\delta}-1} \frac{m g_{0}(a)}{\left(r^{*}+\left(s_{1}^{*}\right)^{2}-\delta\right)}
$$

Taking an integral in terms of $a$, we can obtain

$$
g(a)=\left[\int_{\underline{a}}^{a}(x-\underline{a})^{\frac{r^{*}+\left(s_{1}^{*}\right)^{2}-\delta+m}{r^{*}+\left(s_{1}^{*}\right)^{2}-\delta}} \frac{m g_{0}(x)}{r^{*}+\left(s_{1}^{*}\right)^{2}-\delta} d x+\mathcal{C}\right](a-\underline{a})^{-\frac{r^{*}+\left(s_{1}^{*}\right)^{2}-\delta+m}{r^{*}+\left(s_{1}^{*}\right)^{2}-\delta}}
$$

where $\mathcal{C}$ is the constant of integration. $\mathcal{C}$ is pinned down by the condition $\int_{\underline{a}}^{\infty} g(a) d a=1$. Recall that every k'th moment of $g_{0}$ is finite by assumption, so the limit of the first term in the bracket is finite. That is,

$$
\lim _{a \rightarrow \infty} \int_{\underline{a}}^{a}(x-\underline{a})^{\frac{r^{*}+\left(s_{1}^{*}\right)^{2}-\delta+m}{r^{*}+\left(s_{1}^{*}\right)^{2}-\delta}} \frac{m g_{0}(x)}{r^{*}+\left(s_{1}^{*}\right)^{2}-\delta} d x=\mathcal{C}_{1}<\infty
$$


for some constant $\mathcal{C}_{2}$. Thus, it is easy to show

$$
\left.\lim _{a \rightarrow \infty} \frac{g(\tau a)}{g(a)}=\tau^{-\left(1+\frac{m}{r^{*}+\left(s^{*}\right)^{2}-\delta}\right.}\right)
$$

The Pareto exponent in closed economy is given by $\frac{r^{*}+\left(s_{1}^{*}\right)^{2}-\delta}{m}$.

Next, we turn to the stationary wealth distribution and its Pareto exponent in open economy. To establish an analogous result, we use the following lemma.

Lemma 2. In open economy, household $i$ 's portfolio choice functions, $\theta_{i t}=\left[\theta_{1 i t}, \theta_{2 i t}\right]^{\prime}$, are characterized by

$$
\left[\begin{array}{c}
\theta_{1 i t} \\
\theta_{2 i t}
\end{array}\right]=\Sigma^{-1}\left[\begin{array}{l}
\sigma_{1} s_{1} \\
\sigma_{2} s_{2}
\end{array}\right]\left(1-\frac{\underline{a}}{a_{i t}}\right)
$$

where $\Sigma \equiv\left[\sigma_{1}^{2}, \rho \sigma_{1} \sigma_{2} ; \rho \sigma_{1} \sigma_{2}, \sigma_{2}^{2}\right]$ is the variance-covariance matrix.

Proof. See Appendix B.1.2.

Lemma 2 implies that the relative portfolio weight between the two risky assets are given by

$$
\Sigma^{-1}\left[\begin{array}{l}
\sigma_{1} s_{1} \\
\sigma_{2} s_{2}
\end{array}\right]=\frac{1}{1-\rho^{2}}\left[\begin{array}{l}
\frac{s_{1}}{\sigma_{1}}-\frac{\rho s_{2}}{\sigma_{1}} \\
\frac{s_{2}}{\sigma_{1}}-\frac{\rho s_{1}}{\sigma_{1}}
\end{array}\right]
$$

Again, we only consider cases where the optimal choices of $\theta_{1 i t}$ and $\theta_{2 i t}$ are non-negative. The formula above shows that a sufficient and necessary condition for this is

$$
\rho<\min \left\{\frac{s_{1}}{s_{2}}, \frac{s_{2}}{s_{1}}\right\}
$$

We take this condition as given. Substituting $\theta_{i t}$ from (18) into the Kolmogorov Forward equation, we can obtain

$$
m g(a)+\frac{d}{d a}\left[\left(r+R^{\prime} \Sigma^{-1} R-\delta\right)(a-\underline{a}) g(a)\right]=m g_{0}(a)
$$

where $R=\left[\sigma_{1} s_{1} ; \sigma_{2} s_{2}\right]$. We can then solve for the stationary wealth distribution by following the same procedure as in closed economy. The Pareto exponent in open economy is given by

$$
\begin{aligned}
\frac{1}{\xi} & =\frac{r+R^{\prime} \Sigma^{-1} R-\delta}{m} \\
& =\frac{r+\frac{1}{1-\rho^{2}}\left(s_{1}^{2}-2 \rho s_{1} s_{2}+s_{2}^{2}\right)-\delta}{m}
\end{aligned}
$$


Totally differentiating $\Omega_{\infty}=100^{\frac{1}{\xi}-1}$, we have

$$
d \log \Omega_{\infty}=\phi_{2} d \log \left(r+\sigma_{1} s_{1}\right)+\phi_{3} d \log s_{2}-\phi_{4} d \log \rho
$$

where

$$
\begin{aligned}
\phi_{2} & =\frac{\left(r+\sigma_{1} s_{1}\right) \log 100}{m}>0 \\
\phi_{3} & =\frac{2 s_{2} \log 100}{m\left(1-\rho^{2}\right)}\left(s_{2}-\rho s_{1}\right)>0 \\
\phi_{4} & =\frac{2 \rho \log 100}{m\left(1-\rho^{2}\right)^{2}}\left(\rho^{2} s_{1} s_{2}-\rho\left(s_{1}^{2}+s_{2}^{2}\right)+s_{1} s_{2}\right)>0
\end{aligned}
$$

The second inequality results from (19). The last inequality follows from

$$
-\rho\left(s_{1}^{2}+s_{2}^{2}\right)+s_{1} s_{2}=s_{1} s_{2} \rho\left(-\frac{s_{1}}{s_{2}}-\frac{s_{2}}{s_{1}}+\frac{1}{\rho}\right)>0
$$

in view of the condition in (19).

\section{A.2 More Details on Dynamics}

As time passes by, wealth stock grows and the stationary state level of wealth is affected by various technological parameters. Let me first define the stationary state of this economy. By plugging $\theta_{1 i t}=\frac{s_{1 t}^{*}}{\sigma_{1}}\left(1-\frac{\underline{a}}{a_{i t}}\right)$ and $c_{i t}=(\delta+m) a_{i t}+\left(r_{t}^{*}-\delta-m\right) \underline{a}$ into the households' budget constraint, integrating them with $i$ and incorporating the overlapping generation structure, we can derive the evolution of wealth stock $A_{t}$ as follows

$$
d A_{t}=\left[\left(r^{*}\left(A_{t}\right)+s_{1}^{*}\left(A_{t}\right)^{2}-\delta-m\right)\left(A_{t}-\underline{a}\right)+m\left(A_{t}-A_{0}\right)\right] d t+s_{1}^{*}\left(A_{t}\right) A_{t} d z
$$

where $r(\cdot)$ and $s(\cdot)$ are the solutions given by (14) and (15), and $A_{0}$ is the mean wealth of newborn households. Let $A^{s}$ denote the stock of wealth such that $\mathbb{E}_{t}\left[d A_{t}\right]=0$ and $A^{s}>\underline{a}$. One can interpret $A^{s}$ as the stationary state level of wealth stock in that the expected growth rate is zero. The next proposition states that this feature does little to alter Proposition 2 when $\underline{a}$ is small.

Corollary 2. In the stationary state, a developing country exhibits a smaller wealth stock $A^{s}$, a lower risk-free rate $r^{*}\left(A^{s}\right)$, and a higher Sharpe ratio $s_{1}^{*}\left(A^{s}\right)$, a lower cost of capital $r^{*}\left(A^{s}\right)+\bar{\sigma} s_{1}^{*}\left(A^{s}\right)$ and a lower excess profit $V^{*}\left(A^{s}\right)$ when $\underline{a}=0$ 


\section{A.3 Proof of Collorary 2}

As we discussed in the draft, $A_{t}$ evolves according to a stochastic process

$$
d A_{t}=\left[\left(r\left(A_{t}\right)+s_{1}\left(A_{t}\right)^{2}-\delta-m\right)\left(A_{t}-\underline{a}\right)+m\left(A_{t}-A_{0}\right)\right] d t+s_{1}\left(A_{t}\right) A_{t} d z
$$

where

$$
\begin{aligned}
s_{1}(A) & =\bar{\sigma} A /(A-\underline{a}) \\
r(A) & =\Phi^{\prime}(A)-\bar{\sigma}^{2} A /(A-\underline{a})-\tau+\tau \lambda
\end{aligned}
$$

The stationary wealth stock, $A^{s}$, is pinned down by

$$
r\left(A^{s}\right)+s\left(A^{s}\right)^{2}=\delta+m+\frac{m\left(A_{t}-A_{0}\right)}{A_{t}-\underline{a}}
$$

Substituting $r(A)$ and $s_{1}(A)$ from (21) and (22), one can obtain

$$
\Phi^{\prime}\left(A^{s}\right)+\bar{\sigma}^{2}\left(\left(\frac{A^{s}}{A^{s}-\underline{a}}\right)^{2}-\frac{A^{s}}{A^{s}-\underline{a}}\right)-\tau+\tau \lambda=\delta+m+\frac{m\left(A^{s}-A_{0}\right)}{A^{s}-\underline{a}}
$$

Consider the case where $\underline{a}=0$. One can then write the above expression as

$$
\Phi^{\prime}\left(A^{s}\right)-\tau+\tau \lambda=2 m+\delta-\frac{m A_{0}}{A^{s}}
$$

The left-hand side is decreasing in $A^{s}$, while the right-hand side is increasing in $A^{s}$. So $A^{s}$ is uniquely pinned down by this condition. Invoking the Implicit Function Theorem, we have

$$
\left(\Phi^{\prime \prime}\left(A^{s}\right)-\frac{m A_{0}}{\left(A^{s}\right)^{2}}\right) \frac{\partial A^{s}}{\partial \lambda}+\tau=0
$$

which leads to $\frac{\partial A^{s}}{\partial \lambda}>0$ due to diminishing marginal return. Therefore, FO has a lower $A^{s}$ in autarky. For other variables, it is easy to show that $s_{1}(A)=\bar{\sigma}$ is increasing in $\bar{\sigma}$ and that

$$
r\left(A^{s}\right)=-\bar{\sigma}^{2}-\tau+\tau \lambda
$$

is decreasing in $\bar{\sigma}$ and increasing in $\lambda$. So FO has a higher $s_{1}$ and a lower $r$. Finally, the cost of capital. $r\left(A^{s}\right)+\bar{\sigma}_{1} s\left(A^{s}\right)+\tau-\tau \lambda=\Phi^{\prime}\left(A^{s}\right)$, is higher in a developing country as well. This leads to lower excess profits, $V_{1 t}$. 


\section{A.4 Proof of Proposition 3}

A.4.1 Case 1. $\rho \in(0,1)$

Suppose that $\rho<1$. In Appendix B.2.2, I show that the portfolio choice functions can be written as

$$
\left[\begin{array}{c}
\theta_{1 i t} \\
\theta_{2 i t}
\end{array}\right]=\Sigma^{-1}\left[\begin{array}{l}
\sigma_{1} s_{1 t} \\
\sigma_{2} s_{2 t}
\end{array}\right]\left(1-\frac{\underline{a}}{a_{i t}}\right)
$$

and the market clearing conditions are

$$
\begin{aligned}
r_{t} & =\Phi^{\prime}\left(K_{1 t}\right)-\bar{\sigma}_{1} s_{1 t}-\tau\left(1-\lambda_{1}\right) \\
r_{t} & =\Phi^{\prime}\left(K_{2 t}\right)-\bar{\sigma}_{2} s_{2 t}-\tau\left(1-\lambda_{2}\right) \\
K_{1 t} & =\frac{\left(s_{1 t}-\rho s_{2 t}\right)}{\bar{\sigma}_{1}\left(1-\rho^{2}\right)}\left(2 A-\underline{a}_{1}-\underline{a}_{2}\right) \\
K_{2 t} & =\frac{\left(s_{2 t}-\rho s_{1 t}\right)}{\bar{\sigma}_{2}\left(1-\rho^{2}\right)}\left(2 A-\underline{a}_{1}-\underline{a}_{2}\right) \\
K_{1 t}+K_{2 t} & =2 A
\end{aligned}
$$

conditional on $A_{1 t}=A_{2 t}=A$. Using the system of equations, (25) and (26), we can solve for $s_{1 t}$ as follows

$$
s_{1 t} \equiv \frac{\bar{\sigma}_{1} K_{1 t}+\rho \bar{\sigma}_{2} K_{2 t}}{2 A-\underline{a}_{1}-\underline{a}_{2}}
$$

Substituting $K_{1 t}$ from (27), one can write the above formula as

$$
s_{1 t}=\bar{\sigma}_{1}\left(\frac{2 A-\left(1-\rho \bar{\sigma}_{2} / \bar{\sigma}_{1}\right) K_{2 t}}{2 A-\underline{a}_{1}-\underline{a}_{2}}\right)
$$

Since $\rho \bar{\sigma}_{2}>\bar{\sigma}_{1}$, we have

$$
\begin{aligned}
s_{1 t} & =\bar{\sigma}_{1}\left(\frac{2 A-\left(1-\rho \bar{\sigma}_{2} / \bar{\sigma}_{1}\right) K_{2 t}}{2 A-\underline{a}_{1}-\underline{a}_{2}}\right) \\
& >\bar{\sigma}_{1}\left(\frac{2 A}{2 A-\left(\underline{a}_{1}+\underline{a}_{2}\right)}\right) \\
& >\bar{\sigma}_{1}\left(\frac{A}{A-\underline{a}_{1}}\right) \\
& =s_{1 t}^{*}
\end{aligned}
$$


where the second inequality results from $\underline{a}_{1}<\underline{a}_{2}$.

Next, I compare between $r_{t}$ and $r_{t}^{*}$ conditional on the realization of $A_{1 t}=A_{2 t}=A$. To show that the risk-free interest in financial center country rises after global integration, first note that

$$
\Phi^{\prime-1}\left(r_{t}^{*}+\bar{\sigma}_{1} s_{1 t}^{*}+\tau\left(1-\lambda_{1}\right)\right)=A
$$

Suppose now, to get a contradiction, $r_{t} \geq r_{t}^{*}$. I already showed $s_{1 t}>s_{1 t}^{*}$, so one can obtain

$$
r_{1}+\bar{\sigma}_{1} s_{1 t}+\tau\left(1-\lambda_{1}\right)>r_{1}^{*}+\bar{\sigma}_{1} s_{1 t}^{*}+\tau\left(1-\lambda_{1}\right)
$$

Using the first order condition (29) and $\Phi^{\prime \prime}(\cdot)<0$, it is now straightforward to see that $K_{1 t}<A$. This leads to $K_{2 t}>A$ due to (27). We can then obtain

$$
\begin{aligned}
& \Phi^{\prime}\left(K_{1 t}\right)>\Phi^{\prime}\left(K_{2 t}\right) \\
\Leftrightarrow & r_{t}+\bar{\sigma}_{1} s_{1 t}+\tau\left(1-\lambda_{1}\right)>r_{t}+\bar{\sigma}_{2} s_{2 t}+\tau\left(1-\lambda_{2}\right) \\
\Leftrightarrow & \bar{\sigma}_{2} s_{2 t}<\bar{\sigma}_{1} s_{1 t}-\tau\left(\lambda_{1}-\lambda_{2}\right)
\end{aligned}
$$

in view of (23) and (24). Subtracting $\rho \bar{\sigma}_{2} s_{1 t}$ from the both sides of the last inequality, we have

$$
\begin{aligned}
\bar{\sigma}_{2}\left(s_{2 t}-\rho s_{1 t}\right) & <\bar{\sigma}_{1} s_{1 t}-\rho \bar{\sigma}_{2} s_{1 t}-\tau\left(\lambda_{1}-\lambda_{2}\right) \\
& <0
\end{aligned}
$$

The last inequality follows from $\rho \bar{\sigma}_{2}>\bar{\sigma}_{1}$ and $\lambda_{1}>\lambda_{2}$. This inequality is a contradiction to $K_{2 t}>A$ because it implies

$$
\begin{aligned}
K_{2 t} & =\frac{\left(s_{2 t}-\rho s_{1 t}\right)}{\bar{\sigma}_{2}\left(1-\rho^{2}\right)}\left(2 A-\underline{a}_{1}-\underline{a}_{2}\right) \\
& <0
\end{aligned}
$$

in equilibrium. Thus, $r_{t}<r_{t}^{*}$ must hold when $A_{1 t}=A_{2 t}=A$ is given.

Finally, I turn to proving $r_{t}+\bar{\sigma}_{1} s_{1 t}<r_{t}^{*}+\bar{\sigma}_{1} s_{1 t}^{*}$ and $V_{1 t}>V_{1 t}^{*}$. The first inequality is straightforward to prove because

$$
\begin{aligned}
r_{t}+\bar{\sigma}_{1} s_{1 t} & =\Phi^{\prime}\left(K_{1 t}\right)-\tau\left(1-\lambda_{1}\right) \\
& <\Phi^{\prime}(A)-\tau\left(1-\lambda_{1}\right) \\
& =r_{t}^{*}+\bar{\sigma}_{1} s_{1 t}^{*}
\end{aligned}
$$


The line equality follow from (23). The second line results from $K_{1 t}>A$; recall from (30) that assuming $K_{1 t}<A$ leads to a contradiction as it implies $K_{1 t}<A<K_{2 t}$. The final line is due to (29). Since the cost of capital becomes lower after financial globalization, excess profits to entrepreneurs rise i.e. $V_{1 t}>V_{1 t}^{*}$. This inequality can be analytically proved by applying the Envelope theorem to the firm's profit maximization problem. More specifically, we can write its objective function as

$$
\begin{aligned}
V_{1 t} \equiv \max _{K_{1 t}, D_{1 t}, E_{1 t}}\{ & \Phi\left(K_{1 t}\right)-r_{t} D_{1 t}-\left(r_{t}^{*}+\sigma_{1} s_{1 t}^{*}+\tau\right) E_{1 t} \\
& \left.+\Lambda_{1}\left(K_{1 t}-D_{1 t}-E_{1 t}\right)+\Lambda_{2}\left(\lambda K_{1 t}-D_{1 t}\right)\right\}
\end{aligned}
$$

where $\Lambda_{1}$ and $\Lambda_{2}$ are the Lagrangian multipliers. Also, recall $\sigma_{1}=\frac{\bar{\sigma}_{1}}{1-\lambda}$. So we can restate the problem as

$$
V_{1 t}=\max _{K_{1 t}}\left\{\Phi\left(K_{1 t}\right)-\left(r_{t}+\bar{\sigma}_{1} s_{1 t}\right) K_{1 t}\right\}
$$

Given that the firm is a price taker, let $x \equiv r_{t}+\bar{\sigma} s_{1 t}$. Invoking the Envelope Theorem, we have $\frac{d V_{1 t}}{d x}<0$ for all $x$. Thus, we can see that $V_{1 t}>V_{1 t}^{*}$.

\section{A.4.2 Case 2. $\rho=1$}

Now let me turn to the limit case where $\rho=1$. While the risks per unit of equity are different (i.e. $\sigma_{1}=\frac{\bar{\sigma}_{1}}{1-\lambda_{1}}$ and $\left.\sigma_{2}=\frac{\bar{\sigma}_{2}}{1-\lambda_{2}}\right)$, domestic and foreign risky assets provide identical stochastic returns up to normalization. Essentially, foreign risky assets act as perfect substitutes to domestic risky assets. A single price clears the market for risky assets. I shall use $s_{t} \equiv s_{1 t}=s_{2 t}$ to denote the common Sharpe ratio. Conditional on the realization of $A_{1 t}=A_{2 t}=A$, one can write the market clearing conditions as

$$
\begin{aligned}
& r_{t}=\Phi^{\prime}\left(K_{1 t}\right)-\bar{\sigma}_{1} s_{t}-\tau\left(1-\lambda_{1}\right) \\
& r_{t}=\Phi^{\prime}\left(K_{2 t}\right)-\bar{\sigma}_{2} s_{t}-\tau\left(1-\lambda_{2}\right) \\
& \left(2 A-\underline{a}_{1}-\underline{a}_{2}\right) s_{t}=\bar{\sigma}_{1} K_{1 t}+\bar{\sigma}_{2} K_{2 t} \\
& 2 A=K_{1 t}+K_{2 t}
\end{aligned}
$$

Note here that (25) and (26) are now replaced by (33), which consists of the supply and demand functions for risky assets. The left-hand side of (33) represents the total aggregate amount of risks borne by households, while the right-hand represents the total aggregate amount of risks 
generated by domestic and foreign firms. In fact, we can rewrite condition (33) as

$$
s_{t}=\frac{\omega_{1} \bar{\sigma}_{1}+\omega_{2} \bar{\sigma}_{2}}{1-\left(\underline{a}_{1}+\underline{a}_{2}\right) /(2 A)}
$$

where $\omega_{1} \equiv \frac{K_{1 t}}{2 A}$ and $\omega_{2} \equiv \frac{K_{2 t}}{2 A}$. The sum of $\omega_{1}$ and $\omega_{2}$ equals 1 due to (34). It is then straightforward to see that

$$
\begin{aligned}
s_{t} & =\frac{\omega_{1} \bar{\sigma}_{1}+\omega_{2} \bar{\sigma}_{2}}{1-\left(\underline{a}_{1}+\underline{a}_{2}\right) /(2 A)} \\
& >\frac{\bar{\sigma}_{1}}{1-\underline{a}_{1} / A_{1 t}} \\
& =s_{t}^{*}
\end{aligned}
$$

since $\bar{\sigma}_{2}>\bar{\sigma}_{1}$ and $\underline{a}_{1}<\underline{a}_{2}$. This proves $s_{t}>s_{t}^{*}$. Moving on, it follows from (31) and (32) that $K_{1 t}>K_{2 t}$. This implies that $K_{1 t}>A$ so one obtains

$$
\begin{aligned}
& \Phi\left(K_{1 t}\right)>\Phi(A) \\
\Leftrightarrow & r_{t}+\bar{\sigma}_{1} s_{t}+\tau\left(1-\lambda_{1}\right)<r_{t}^{*}+\bar{\sigma}_{1} s_{t}^{*}+\tau\left(1-\lambda_{1}\right) \\
\Leftrightarrow & r_{t}+\bar{\sigma}_{1} s_{t}<r_{t}^{*}+\bar{\sigma}_{1} s_{t}^{*}
\end{aligned}
$$

Combined with $s_{1 t}>s_{1 t}^{*}$, this leads to $r_{t}<r_{t}^{*}$. Also, invoking the Envelope Theorem as before, one can obtain $V_{1 t}^{*}<V_{1 t}$ when $A_{1 t}=A_{2 t}=A$ is given.

\section{A.5 More Details on Foreign Direct Investment}

Putting all the ingredients in Section 4.2 together, we can state the US firm's problem as maximizing the profit $V_{1 t}+V_{1 t}^{F D I}$ generated in the two countries. $V_{1 t}$ is domestic excess profit defined in (11), while $V_{1 t}^{F D I}$ stems from the optimal contract problem:

$$
V_{1 t}^{F D I} d t \equiv \max _{\substack{\left\{\phi^{L o c a l}, \phi^{F D I}, c, K_{2 t}^{L o c a l}, K_{2 t}^{F D I}\right\}}}\left[\phi^{F D I} \Phi\left(K_{2 t}\right)-R_{1} K_{2 t}^{F D I}-c \Phi\left(K_{2 t}\right)\right] d t
$$


subject to

$$
\begin{aligned}
& K_{2 t}=K_{2 t}^{\text {Local }}+K_{2 t}^{F D I} \\
& \left(1-\pi_{L}\right)\left(1-\phi^{F D I}-\phi^{\text {Local }}\right) \Phi\left(K_{2 t}\right) \geq B(\eta) \Phi\left(K_{2 t}\right) \\
& \left(1-\pi_{L}\right) \phi^{F D I} \Phi\left(K_{2 t}\right) \geq \eta \Phi\left(K_{2 t}\right) \\
& \left(1-\phi^{\text {Local }}-\phi^{F D I}\right) \Phi\left(K_{2 t}\right) \geq 0 \\
& \phi^{\text {Local }} \Phi\left(K_{2 t}\right) \geq R_{2} K_{2 t}^{\text {Local }}
\end{aligned}
$$

where $R_{1} \equiv r_{t}+\bar{\sigma}_{2} s_{2 t}+\tau^{F D I}\left(1-\lambda_{1}\right)$ and $R_{2} \equiv r_{t}+\bar{\sigma}_{2} s_{2 t}+\tau\left(1-\lambda_{2}\right)$ are funding costs per unit of capital in the US and FO respectively. Under this contract, the FO entrepreneur, US firm and local financial intermediary receive $\left(1-\phi^{F D I}-\phi^{\text {Local }}\right), \phi^{F D I}$ and $\phi^{\text {Local }}$ shares of profits at each instantaneous time respectively.

Turning to constraints associated with the contract, the first line represents the balance sheet of the FO firm. It has two funding sources: the U.S. parent firm, $K_{2 t}^{F D I}$, and local financial intermediary, $K_{2 t}^{\text {Local }}$. The second condition is the incentive-compatible constraint for the FO entrepreneur. $\pi_{L}$ is the profit loss from the misbehavior of the FO entrepreneur. Private benefits to the entrepreneur is assumed to be $B(\eta) \Phi\left(K_{2 t}\right)$ where $\eta$ is the monitoring level by the U.S. firm and $B^{\prime}(\eta)<0 .{ }^{39}$ From the FO entrepreneur's viewpoint, increased payoffs from the good behavior should be greater than the private benefit. The third condition represents incentivecompatible constraint to induce the US firm to pay a monitoring cost $\eta \Phi\left(K_{2 t}\right)$. It implies that the benefit of monitoring should outweigh the cost. The fourth condition corresponds to the participation constraint of the FO entrepreneur. The last condition is associated with the funding cost in the FO ; the share of profits allocated to local financial intermediary should be greater than or equal to the equilibrium funding cost. Local financial intermediary breaks even.

Finally, recall that the funding cost for $K_{2 t}^{F D I}$ and $K_{2 t}^{\text {Local }}$ are given by $R_{1} d t$ and $R_{2} d t$ respectively and we can express them as

$$
\begin{aligned}
& R_{1} \equiv r_{t}+\bar{\sigma}_{2} s_{2 t}+\tau^{F D I}\left(1-\lambda_{1}\right) \\
& R_{2} \equiv r_{t}+\bar{\sigma}_{2} s_{2 t}+\tau\left(1-\lambda_{2}\right)
\end{aligned}
$$

One assumption I make here is that $\tau^{F D I}>\tau$ so as to make $R_{1}>R_{2}$ arise. This condition would make local funding preferable when there were no monitoring benefit from FDI. In equilibrium, the firm chooses a mix of $K_{2 t}^{\text {local }}$ and $K_{2 t}^{F D I}$ to equalize the marginal benefit of FDI with its opportunity cost. As it turns out later, this structure leads to the coexistence of foreign portfolio equity

\footnotetext{
${ }^{39}$ To guarantee an interior solution, I assume $B^{\prime \prime}(\eta)>0, \lim _{\eta \rightarrow 0} B^{\prime}(\eta)=0$ and $\lim _{\eta \rightarrow \infty} B(\eta)=\infty$.
} 
and FDI in global capital flows. With this apparatus in place, open economy equilibrium is now defined as follows:

Definition 4. An open economy equilibrium is a stochastic process, $\left\{r_{t},\left(s_{1 t}, \sigma_{1}\right),\left(s_{2 t}, \sigma_{2}\right)\right\}_{t \geq 0}$, which clears global financial markets: $\sum_{k \in\{F O, U S\}}\left(\mathbb{S}_{t}^{k}-\mathbb{I}_{t}^{k}\right)=0, \sum_{k \in\{F O, U S\}} \mathbb{S}_{1 t}^{k}=\mathbb{I}_{1 t}^{U S}$ and $\sum_{k \in\{F O, U S\}} \mathbb{S}_{2 t}^{k}=\mathbb{I}_{2 t}^{F O}$ where $\mathbb{I}_{2 t}^{F O}=K_{2 t}^{\text {Local }}+K_{2 t}^{F D I}$. The rest is same as in Section 4.1.

\section{A.6 Proof of Proposition 4}

I take a similar approach to Antràs et al. (2009). Note here that the participation constraint of the FO entrepreneur, (39), never binds in optimal contract due to some informational rent; if it were to bind, the left-hand side of (37) would become negative so the FO entrepreneur would always shirk. We can then write the Lagrangian associated with the U.S. entrepreneur's problem as

$$
\begin{aligned}
\mathcal{L}= & \phi^{F D I} \Phi\left(K_{2 t}\right)-R_{1} K_{2 t}^{F D I}-\eta \Phi\left(K_{2 t}\right)+\mu_{1}\left[K_{2 t}^{\text {Local }}+K_{2 t}^{F D I}-K_{2 t}\right] \\
& +\mu_{2}\left[\left(1-\pi_{L}\right)\left(1-\phi^{F D I}-\phi^{\text {Local }}\right)-B(\eta)\right] \\
& +\mu_{3}\left[\phi^{F D I}-\eta /\left(1-\pi_{L}\right)\right]+\mu_{5}\left[\phi^{\text {Local }} \Phi\left(K_{2 t}\right)-R_{2} K_{2 t}^{\text {Local }}\right]
\end{aligned}
$$

where $\mu_{k}$ represents the Lagrangian multiplier for the $k^{\prime}$ th constraint. The first order conditions yield

$$
\begin{aligned}
& \frac{\partial \mathcal{L}}{\partial K_{2 t}}=\left(\phi^{F D I}-\eta\right) \Phi^{\prime}\left(K_{2 t}\right)-\mu_{1}+\mu_{5} \phi^{L o c a l} \Phi^{\prime}\left(K_{2 t}\right)=0 \\
& \frac{\partial \mathcal{L}}{\partial K_{2 t}^{F D I}}=-R_{1}+\mu_{1}=0 \\
& \frac{\partial \mathcal{L}}{\partial K_{2 t}^{L o c a l}}=\mu_{1}-R_{2} \mu_{5}=0 \\
& \frac{\partial \mathcal{L}}{\partial \phi^{F D I}}=\Phi\left(K_{2 t}\right)-\mu_{2}\left(1-\pi_{L}\right)+\mu_{3}=0 \\
& \frac{\partial \mathcal{L}}{\partial \phi^{L o c a l}}=-\mu_{2}\left(1-\pi_{L}\right)+\mu_{5} \Phi\left(K_{2 t}\right)=0 \\
& \frac{\partial \mathcal{L}}{\partial \eta}=-\Phi\left(K_{2 t}\right)-\mu_{2} B^{\prime}(\eta)-\frac{\mu_{3}}{1-\pi_{L}}=0
\end{aligned}
$$

Merging these conditions, it is easy to show

$$
\mu_{1}=R_{1}>0, \quad \mu_{5}=\frac{R_{1}}{R_{2}}>0, \quad \mu_{2}=\frac{R_{1}}{R_{2}} \frac{\Phi\left(K_{2 t}\right)}{1-\pi_{L}}>0, \quad \mu_{3}=\Phi\left(K_{2 t}\right)\left(\frac{R_{1}}{R_{2}}-1\right)>0
$$


where the last inequality results from the assumption I made earlier: $R_{1} \equiv r_{t}+\bar{\sigma}_{2} s_{2 t}+\tau^{F D I}(1-$ $\left.\lambda_{1}\right)>r_{t}+\bar{\sigma}_{2} s_{2 t}+\tau\left(1-\lambda_{1}\right) \equiv R_{2}$. These results imply that constraint (36), (37), (38), and (40) must be binding.

Next, substituting $\mu_{2}$ and $\mu_{3}$ from (43), one can convert condition (42) into

$$
B^{\prime}(\eta)=-\frac{R_{2}}{R_{1}}\left(\frac{R_{1}}{R_{2}}-\pi_{L}\right)<0
$$

which pins down the optimal value of monitoring, $\eta$, when the market funding costs are given. Also, the optimal level of investment is determined by condition (41). Substituting $\mu_{1}$ and $\mu_{5}$ from (43), we obtain

$$
\begin{aligned}
\Phi^{\prime}\left(K_{2 t}\right) & =\frac{R_{1}}{\phi^{F D I}-\eta-\frac{R_{1}}{R_{2}} \phi^{\text {Local }}} \\
& =\frac{R_{1}}{\frac{\eta \pi_{L}}{1-\pi_{L}}+\frac{R_{1}}{R_{2}}\left(1-\frac{B(\eta)+\eta}{1-\pi_{L}}\right)}
\end{aligned}
$$

Let $K_{2 t}^{*}$ and $\eta^{*}$ denote the level of investment and monitoring determined by these conditions. The rest of control variables are pinned down by the constraints as follows

$$
\begin{aligned}
\phi^{F D I *} & =\frac{\eta^{*}}{1-\pi_{L}} \\
\phi^{\text {Local* }} & =1-\frac{B\left(\eta^{*}\right)+\eta^{*}}{1-\pi_{L}} \\
K_{2 t}^{\text {Local* }} & =\frac{\phi^{\text {Local* } \Phi\left(K_{2 t}^{*}\right)}}{R_{2}} \\
K_{2 t}^{F D I *} & =K_{2 t}^{*}-K_{2 t}^{\text {Local* }}
\end{aligned}
$$

where the first line follows from (39), the second line from (37), the third line from (40) and the last line from (36). The total payoff obtained by the US entrepreneur is

$$
\begin{aligned}
V_{1 t}^{F D I} & \equiv \phi^{F D I *} \Phi\left(K_{2 t}^{*}\right)-R_{1} K_{2 t}^{F D I *}-\eta^{*} \Phi\left(K_{2 t}^{*}\right) \\
& =\left(\phi^{F D I *}-\eta^{*}\right) \Phi\left(K_{2 t}^{*}\right)-R_{1}\left(K_{2 t}^{*}-K_{2 t}^{L o c a l *}\right) \\
& =\left(\phi^{F D I *}-\eta^{*}\right) \Phi\left(K_{2 t}^{*}\right)-R_{1} K_{2 t}^{*}+\frac{R_{1}}{R_{2}} \phi^{\text {Local* }} \Phi\left(K_{2 t}^{*}\right) \\
& =R_{1}\left(\frac{\Phi\left(K_{2 t}^{*}\right)}{\Phi^{\prime}\left(K_{2 t}^{*}\right)}-K_{2 t}^{*}\right)
\end{aligned}
$$

Next, consider the opposite case: the U.S. firm does not conduct FDI whether by their own 
choice or by investment barriers. (e.g. security market liberalization) Obviously, the US entrepreneur has no incentive to pay monitoring costs any more. It is also clear that the FO entrepreneur receive no share of profits. The optimal contract problem in this case can be simply written as

$$
\max _{\phi^{F D I}, K_{2 t}, K_{2 t}^{F I}, K_{2 t}^{L o}} \phi^{F D I} \pi_{L} \Phi\left(K_{2 t}\right)-R_{1} K_{2 t}^{F D I}
$$

subject to the constraints

$$
\begin{array}{r}
K_{2 t}=K_{2 t}^{F D I}+K_{2 t}^{\text {Local }} \\
\pi_{L}\left(1-\phi^{F D I}\right) \Phi\left(K_{2 t}\right) \geq R_{2} K_{2 t}^{\text {Local }} \\
\phi^{F D I} \leq 0
\end{array}
$$

So we can easily see that $\phi^{\text {Local }}=1$ and $\phi^{F D I}=0$ must hold. The optimal level of investment is determined by the first order condition of the FO entrepreneur:

$$
\Phi^{\prime}\left(K_{2 t}^{* *}\right)=\Phi^{\prime}\left(K_{2 t}^{\text {Local**}}\right)=\frac{R_{2}}{\pi_{L}}
$$

Note that as $\pi_{L} \rightarrow 0, K_{2 t}^{* *}$ converges to zero, while $K_{2 t}^{*}$ converges to a positive value because (44) becomes $\Phi^{\prime}\left(K_{2 t}^{*}\right)=\frac{R_{1}}{\left(1-B\left(\eta^{*}\right)-\eta^{*}\right)}$, provided that $B\left(\eta^{*}\right)+\eta^{*}<1$. I assume that this is taken as given due to the functional form of $B$.

The final step of the proof is to compare equilibrium prices under the full integration, in which $K_{2 t}^{*}$ arises, and under security market liberalization, in which $K_{2 t}^{* *}$ arises. Returning back to the market clearing conditions in Proposition 3, the supply function in (24) is now replaced by

$$
\begin{aligned}
r_{t} & =\pi_{L} \Phi^{\prime}\left(K_{2 t}\right)-\bar{\sigma}_{2} s_{2 t}-\tau\left(1-\lambda_{2}\right) \\
\text { Or, } r_{t} & =\left(1-B\left(\eta^{*}\right)-\eta^{*}\right) \Phi^{\prime}\left(K_{2 t}\right)-\bar{\sigma}_{2} s_{2 t}-\tau\left(1-\lambda_{2}\right)
\end{aligned}
$$

The first line shows up in the case of security market liberalization, while the second line shows up in the case of full integration. In any case, one can derive

$$
s_{1 t}=\bar{\sigma}_{1}\left(\frac{2 A-\left(1-\rho \bar{\sigma}_{2} / \bar{\sigma}_{1}\right) K_{2 t}}{2 A-\underline{a}_{1}-\underline{a}_{2}}\right)
$$

when $\rho<1$ as in (28). Since $K_{2 t}^{*}>K_{2 t}^{* *}>0$ when $\pi_{L}$ is sufficiently small, we have $s_{1 t}^{(i i i)}>$ $s_{1 t}^{(i i)}>s_{1 t}^{(i)}$. This proves the first part of the proposition. Lastly, it is easy to extend the proof of Proposition 3 to show $V_{1 t}^{(i i i)}>V_{1 t}^{(i)}$. Also, $V_{1 t}^{F D I}>0$ follows from (49), (44) and the Inada 
conditions associated with $\Phi(\cdot)$.

\section{A.7 More Details on the Money Premium}

In this subsection, I show that the parameter $\tau$ in Section 3 is equivalent to the money premium that is typically assumed in the banking literature. The household side remains largely unchanged. Households' budget constraints are now given by

$$
d a_{i t}=\left[\left(r_{t}^{*}+\sigma_{1} s_{1 t}^{*} \theta_{1 i t}\right) a_{i t}-c_{i t}\right] d t+\underbrace{\tau\left(1-\theta_{1 i t}\right) a_{i t}}_{\text {Money Premium }}+\sigma_{1} \theta_{1 i t} a_{i t} d z_{1 t}
$$

where $\tau$ is the money premium. One can interpret $\tau$ as the monetary value of banking service (= the creation of completely safe and liquid assets). This assumption plays a similar role to a convenience yield of money-like claims, which has been widely used in the banking literature (e.g. Stein 2012). To give a meaningful role to financial intermediation, a model should deviate from the Modigliani-Miller framework. Here, I do so by distinguishing safe money-like claims from risky dividends.

Define two savings curves, $\mathbb{S}_{t} \equiv A_{t} \equiv \int a_{i t} d i$ and $\mathbb{S}_{1 t} \equiv \int \theta_{1 i t} a_{i t} d i$. Here, $\mathbb{S}_{t}$ represents the total value of assets saved by households, while $\mathbb{S}_{1 t}$ represents savings in domestic risky assets at time $t$. Using $\theta_{1 i t}=\frac{s_{1 t}^{*} \sigma_{1}-\tau}{\sigma_{1}^{2}}\left(1-\frac{\underline{a}}{a_{i t}}\right)$, we can rewrite these savings curves as

$$
\mathbb{S}_{t}=A_{t}, \quad \mathbb{S}_{1 t}=\frac{s_{1 t}^{*} \sigma_{1}-\tau}{\sigma_{1}^{2}}\left(A_{t}-\underline{a}\right)
$$

These two savings curves constitute the demand side for the safe and domestic risky assets. Note that households are restricted only to the two types of assets, the money-like claim and the domestic risky asset. In this framework, one can define two distinct reward-to-risk ratios. One is the conventional Sharpe ratio, $s_{1 t}^{*}$. The other is $\bar{s}_{1 t}^{*} \equiv \frac{s_{1 t}^{*} \sigma_{1}-\tau}{\sigma_{1}}$. The savings in the domestic risky asset can be written as $\mathbb{S}_{1 t}=\frac{\bar{s}_{1 t}^{*}}{\sigma_{1}}\left(A_{t}-\underline{a}\right)$ as in the baseline model.

Given this setup, the bank creates assets by converting its future cash flow into risk-free and risky tranches. The bank simply maximizes contemporaneous residual profits

$$
\underbrace{V_{t}^{*} d t}_{\text {Private Equity Income }} \equiv \max _{K_{t}, D_{t}, E_{t}}\{d \pi_{t}-\underbrace{r_{t}^{*} D_{t} d t}_{\text {Debt Income }}-\underbrace{\left(r_{t}^{*}+\sigma_{1} s_{1 t}^{*}\right) E_{t} d t}_{\text {Public Equity Income }}-\underbrace{\sigma_{1} E_{t} d z_{1 t}}_{\text {Public Equity Volatility }}\}
$$

Equivalently, we can write this as

$$
V_{t}^{*} d t \equiv \max _{K_{t}, D_{t}, E_{t}}\left\{d \pi_{t}-r_{t}^{*} D_{t} d t-\left(r_{t}^{*}+\sigma_{1} \bar{s}_{1 t}^{*}+\tau\right) E_{t} d t-\sigma_{1} E_{t} d z_{1 t}\right\}
$$


which coincides with the bank's optimization problem in Section 3.

\section{Appendix B HJB Equations}

In this section, I elaborate on more details about the Hamiltonian-Jacobian-Bellman equations that are used in various parts of the paper. I begin with a simple case in which financial prices are fixed and given as in Section 2.

\section{B.1 Section 2. Exogenous Prices}

\section{B.1.1 Closed Economy}

Define the value function associated with the maximization problem

$$
J\left(a_{i t}\right)=\max _{\left\{c_{i t}, \theta_{1 i t}\right\}} \mathbb{E}\left[\int_{0}^{\infty} e^{-(\delta+m) t} \log \left(c_{i t}-\kappa\right) d t\right]
$$

subject to the budget constraint (2). We can then restate a household's problem as

$$
(\delta+m) J\left(a_{i t}\right)=\max _{\left\{c_{i t}, \theta_{1 i t}\right\}}\left\{\log \left(c_{i t}-\kappa\right)+J_{a}\left\{\left[r^{*}+\sigma_{1} s_{1}^{*} \theta_{1 i t}\right] a_{i t}-c_{i t}\right\}+\frac{1}{2} J_{a a} \sigma_{1}^{2} \theta_{1 i t}^{2} a_{i t}^{2}\right\}
$$

with the transversality condition

$$
\lim _{t \rightarrow \infty} e^{-(\delta+m) t} J\left(a_{i t}\right)=0
$$

The first order conditions are

$$
\begin{aligned}
c_{i t} & =\left(J_{a}\right)^{-1}+\kappa \\
\theta_{1 i t} & =\frac{-s_{1} J_{a}}{\sigma_{1} a_{i t} J_{a a}}
\end{aligned}
$$

Plugging them into the value function, we obtain

$$
(\delta+m) J\left(a_{i t}\right)=-\log \left(J_{a}\right)+J_{a}\left(r^{*} a_{i t}-\kappa\right)-1-\frac{1}{2} \frac{J_{a}^{2} s_{1}^{* 2}}{J_{a a}}
$$


Pick $J=\frac{1}{\delta+m} \log \left(a_{i t}-\frac{\kappa}{r^{*}}\right)+$ const. as a solution of (54) where const. $\equiv \frac{\log (\delta+m)}{\delta+m}+\frac{r^{*}+m}{(\delta+m)^{2}}-$ $\frac{1}{\delta+m}-\frac{s_{1}^{* 2}}{2(\delta+m)^{2}}$. Then, it is easy to show

$$
J_{a}=\frac{1}{(\delta+m)\left(a_{i t}-\frac{\kappa}{r^{*}}\right)}, \quad J_{a a}=-\frac{1}{(\delta+m)\left(a_{i t}-\frac{\kappa}{r^{*}}\right)^{2}}
$$

Plugging these expressions into (54), we can verify that the right-hand side coincides with the left-hand side. That is,

$$
\begin{aligned}
& \log \left(a_{i t}-\frac{\kappa}{r^{*}}\right)+\log (\delta+m)+\frac{r^{*}+m}{\delta+m}-1+\frac{1}{2} \frac{s_{1}^{* 2}}{(\delta+m)} \\
= & \log (\delta+m)+\log \left(a_{i t}-\frac{\kappa}{r^{*}}\right)+\frac{r^{*}}{\delta+m}-1+\frac{1}{2} \frac{s_{1}^{* 2}}{(\delta+m)}
\end{aligned}
$$

Turning back to the first order conditions, (52) and (53), we can write the final solutions as

$$
\begin{aligned}
c_{i t} & =(\delta+m)\left(a_{i t}-\frac{\kappa}{r^{*}}\right)+\kappa=(\delta+m) a_{i t}+\left(r^{*}-m-\delta\right) \underline{a} \\
\theta_{1 i t} & =\frac{s_{1}^{*}}{\sigma_{1}}\left(1-\frac{\underline{a}}{a_{i t}}\right)
\end{aligned}
$$

where $\underline{a} \equiv \frac{\kappa}{r^{*}}$.

\section{B.1.2 Open Economy}

Now let me turn to open economy. Portfolio frontier is now given by $\left\{r,\left(s_{1}, \sigma_{1}\right),\left(s_{2}, \sigma_{2}\right)\right\}$ with $\rho$ being the correlation between $d z_{1 t}$ and $d z_{2 t}$. The results are summarized as follows

Lemma 2. In open economy, household $i$ 's portfolio choices, $\theta_{i t}=\left[\theta_{1 i t}, \theta_{2 i t}\right]^{\prime}$, are characterized by

$$
\theta_{i t}=\Sigma^{-1}\left[\begin{array}{l}
\sigma_{1} s_{1} \\
\sigma_{2} s_{2}
\end{array}\right]\left(1-\frac{\underline{a}}{a_{i t}}\right)
$$

where $\Sigma \equiv\left[\sigma_{1}^{2}, \rho \sigma_{1} \sigma_{2} ; \rho \sigma_{1} \sigma_{2}, \sigma_{2}^{2}\right]$ is the variance-covariance matrix.

Proof. In open economy, the value function associated with households' problem can be written as

$$
\begin{aligned}
& (\delta+m) J\left(a_{i t}\right)=\max _{\left\{c_{i t}, \theta_{i t}\right\}}\left\{\log \left(c_{i t}-\kappa\right)+J_{a}\left\{\left[\sigma_{1} s_{1} \theta_{1 i t}+\sigma_{2} s_{2} \theta_{2 i t}+r\right] a_{i t}-c_{i t}\right\}\right. \\
& \left.+\frac{1}{2} J_{a a}\left(\left(\sigma_{1} \theta_{1 i t}\right)^{2}+\left(\sigma_{2} \theta_{2 i t}\right)^{2}+2 \rho \sigma_{1} \sigma_{2} \theta_{1 i t} \theta_{2 i t}\right) a_{i t}^{2}\right\}
\end{aligned}
$$


The first order conditions with respect to $\theta_{1 i t}, \theta_{2 i t}$ and $c_{i t}$ are

$$
\begin{aligned}
c_{i t} & =\left(J_{a}\right)^{-1}+\kappa \\
\theta_{i t} & =\Sigma^{-1}\left[\begin{array}{l}
\sigma_{1} s_{1} \\
\sigma_{2} s_{2}
\end{array}\right]\left(-\frac{J_{a}}{a_{i t} J_{a a}}\right)
\end{aligned}
$$

Plugging them back to the value function, we have

$$
(\delta+m) J\left(a_{i t}\right)=-\log \left(J_{a}\right)+J_{a}\left(r a_{i t}-\kappa\right)-1-\frac{1}{2}\left(\frac{s_{1}^{2}+s_{2}^{2}-2 \rho s_{1} s_{2}}{1-\rho^{2}}\right) \frac{J_{a}^{2}}{J_{a a}}
$$

Pick $J=\frac{1}{\delta+m} \log \left(a_{i t}-\frac{\kappa}{r}\right)+$ const. with const. $\equiv \frac{\log (\delta+m)}{\delta+m}+\frac{r+m}{(\delta+m)^{2}}-\frac{1}{\delta+m}-\frac{1}{2(\delta+m)^{2}}\left(\frac{s_{1}^{2}+s_{2}^{2}-2 \rho s_{1} s_{2}}{1-\rho^{2}}\right)$. As before, it is easy to verify that this is a solution to equation (55). So we have

$$
\theta_{i t}=\Sigma^{-1}\left[\begin{array}{l}
\sigma_{1} s_{1} \\
\sigma_{2} s_{2}
\end{array}\right]\left(1-\frac{\underline{a}}{a_{i t}}\right)
$$

If $\Omega$ is positive definite (i.e. $1>\rho>0$ ), the second order condition holds.

\section{B.2 Section 3: Endogenous Prices}

\section{B.2.1 Closed Economy}

Let me begin with closed economy. Households maximize $\max _{\theta_{1 i t}, c_{i t}} \mathbb{E}_{0}\left[\int_{0}^{\infty} e^{-(\delta+m) t} \log \left(c_{i t}-\kappa\right) d t\right]$ subject to the budget constraint $d a_{i t}=\left[\left(r_{t}^{*}+\sigma s_{1 t}^{*} \theta_{1 i t}\right) a_{i t}-c_{i t}\right] d t+\sigma_{1} \theta_{1 i t} a_{i t} d z$. The problem is equivalent to solving

$$
\max _{\theta_{1 i t}, c_{i t}} \mathbb{E}_{0}\left[\int_{0}^{\infty} e^{-(\delta+m) t} \log c_{i t} d t\right]
$$

subject to

$$
d a_{i t}=\left[\left(r_{t}^{*}+\sigma_{1} s_{1 t}^{*} \theta_{1 i t}\right) a_{i t}-c_{i t}-\kappa\right] d t+\sigma_{1} \theta_{1 i t} a_{i t} d z
$$

Recall that $\kappa$ is assumed to be $\kappa=r_{t}^{*} \underline{a}$ where $\underline{a}$ is constant.

The key difference from Section 2 is that $r_{t}^{*} \equiv r^{*}\left(A_{t}\right)$ and $s_{1 t}^{*} \equiv s_{1}^{*}\left(A_{t}\right)$ are now functions of the aggregate state variables $A_{t}$. We solve the household's problem by guessing and verifying an equilibrium. First, assume that households save according to

$$
c_{i t}=(\delta+m) a_{i t}-(\delta+m) \bar{a}, \quad \theta_{1 i t}=\frac{s_{1 t}^{*}}{\sigma_{1}}\left(1-\frac{\underline{a}}{a_{i t}}\right)
$$

Substituting them into the households' budget constraint and integrating them with $i$, we can 
derive the evolution of wealth stock $A_{t}$ as follows

$$
\begin{aligned}
d A_{t} & =\left[\left(r^{*}\left(A_{t}\right)+s_{1}^{*}\left(A_{t}\right)^{2}-\delta-m\right)\left(A_{t}-\underline{a}\right)+m\left(A_{t}-A_{0}\right)\right] d t+s_{1}^{*}\left(A_{t}\right) A_{t} d z_{1 t} \\
& \equiv \mu_{A} d t+\sigma_{A} d z_{1 t}
\end{aligned}
$$

where $r^{*}\left(A_{t}\right)$ and $s_{1}^{*}\left(A_{t}\right)$ are given by (14) and (15) in the main text. Thus, the state variables for households' decision makings are $A_{t}$ and $a_{i t}$. Let $J\left(a_{i t}, A_{t}\right)$ be the value function associated with the household's problem. We can then state the HJB equation as

$$
\begin{gathered}
(\delta+m) J d t=\max _{c_{i t}, \theta_{1, i t}}\left\{\log c_{i t}\right. \\
+J_{a}\left\{\left(r_{t}^{*}+\sigma_{1} s_{1 t}^{*} \theta_{1, i t}\right) a_{i t}-c_{i t}-r_{t}^{*} \underline{a}\right\}+\frac{1}{2} J_{a a} \sigma_{1}^{2} \theta_{1 i t}^{2} a_{i t}^{2} \\
\left.+J_{A} \mu_{A}+\frac{1}{2} J_{A A} \sigma_{A}^{2}+J_{A a} \sigma_{1} \theta_{1 i t} a_{i t} \sigma_{A}\right\} d t
\end{gathered}
$$

where $\mu_{A}$ and $\sigma_{A}$ come from (57). The transversality condition is given by $\lim _{t \rightarrow \infty} e^{-\delta t} J\left(a_{i t}, A_{t}\right) \stackrel{p}{\rightarrow}$ 0 . Notice that the last three terms are added to the standard Merton's model. The first order conditions yield

$$
\begin{aligned}
c_{i t} & =\left(J_{a}\right)^{-1} \\
\theta_{1 i t} & =\frac{-s_{1 t}^{*} J_{a}}{\sigma_{1} a_{i t} J_{a a}+J_{A a} \sigma_{1} a_{i t} \sigma_{A}}
\end{aligned}
$$

Let $J\left(a_{i t}, A_{t}\right) \equiv \frac{1}{\delta+m} \log \left(a_{i t}-\underline{a}\right)+\mathcal{C}\left(A_{t}\right)$ be a candidate value function where $\mathcal{C}(\cdot)$ is implicitly defined by an ordinary differential equation

$$
(\delta+m) \mathcal{C}\left(A_{t}\right)=\log (\delta+m)+\frac{r^{*}\left(A_{t}\right)-\delta-m}{\delta+m}-\frac{1}{2} \frac{\left(s_{1}\left(A_{t}\right)\right)^{2}}{\delta+m}+\mathcal{C}^{\prime}\left(A_{t}\right) \mu_{A}+\frac{1}{2} \mathcal{C}^{\prime \prime}\left(A_{t}\right) \sigma_{A}^{2}
$$

with suitable boundary conditions. This makes $\theta_{1 i t}=\frac{-s_{1 t}^{*} J_{a}}{\sigma_{1} a_{i t} J_{a a}}$. Substituting $c_{i t}, \theta_{1 i t}$ and $J$ into the HJB equation, (58), we can verify that the left-hand side equals

$$
\log \left(a_{i t}-\underline{a}\right)+(\delta+m) \mathcal{C}\left(A_{t}\right)
$$

and the right-hand side equals

$$
\log \left(a_{i t}-\underline{a}\right)+\log (\delta+m)+\frac{r_{t}^{*}-\delta-m}{\delta+m}-\frac{1}{2} \frac{s_{1 t}^{2}}{\delta+m}+\mathcal{C}^{\prime}\left(A_{t}\right) \mu_{A}+\frac{1}{2} \mathcal{C}^{\prime \prime}\left(A_{t}\right) \sigma_{A}^{2}
$$

Therefore, we can confirm that the following solutions, along with the market clearing conditions, 
constitute an equilibrium.

$$
\begin{aligned}
c_{i t} & =(\delta+m)\left(a_{i t}-\underline{a}\right) \\
\theta_{1 i t} & =\frac{s_{1 t}^{*}}{\sigma_{1}}\left(1-\frac{\underline{a}}{a_{i t}}\right) \\
J\left(a_{i t}, A_{t}\right) & =\frac{1}{\delta+m} \log \left(a_{i t}-\underline{a}\right)+\mathcal{C}\left(A_{t}\right)
\end{aligned}
$$

The transversality condition holds. The simplification comes from a property of log utility. It allows to decompose $J\left(a_{i t}, A_{t}\right)$ into two additively separable terms.

\section{B.2.2 Open Economy}

We again solve for an equilibrium by guessing and verifying. First, assume that the solutions of the households problem are given by

$$
\begin{aligned}
& c_{i t}=(\delta+m)\left(a_{i t}-\underline{a}\right) \\
& \theta_{1 i t}=\frac{\left(s_{1 t}-\rho s_{2 t}\right)}{\sigma_{1}\left(1-\rho^{2}\right)}\left(1-\frac{\underline{a}}{a_{i t}}\right) \\
& \theta_{2 i t}=\frac{\left(s_{2 t}-\rho s_{1 t}\right)}{\sigma_{2}\left(1-\rho^{2}\right)}\left(1-\frac{\underline{a}}{a_{i t}}\right)
\end{aligned}
$$

Then we can write the market clearing conditions as

$$
\begin{aligned}
\Phi^{\prime}\left(K_{1 t}\right)-\bar{\sigma}_{1} s_{1 t}-\tau_{1}\left(1-\lambda_{1}\right) & =r_{t} \\
\Phi^{\prime}\left(K_{2 t}\right)-\bar{\sigma}_{2} s_{2 t}-\tau_{2}\left(1-\lambda_{2}\right) & =r_{t} \\
\frac{s_{1 t}-\rho s_{2 t}}{\sigma_{1}\left(1-\rho^{2}\right)}\left(A_{1 t}+A_{2 t}-2 \underline{a}\right) & =K_{1 t} \\
\frac{s_{2 t}-\rho s_{1 t}}{\sigma_{2}\left(1-\rho^{2}\right)}\left(A_{1 t}+A_{2 t}-2 \underline{a}\right) & =K_{2 t} \\
K_{1 t}+K_{2 t} & =A_{1 t}+A_{2 t}
\end{aligned}
$$

It follows from the market clearing conditions that the state variable in the economy is $\bar{A}_{1 t} \equiv$ $A_{1 t}+A_{2 t}$. Let $r\left(\bar{A}_{t}\right), s_{1}\left(\bar{A}_{t}\right)$ and $s_{2}\left(\bar{A}_{t}\right)$ denote the market clearing prices pinned down by the above system of equations. Plug them into the budget constraints and integrate across households. We can then see that the aggregate state variable evolves according to

$$
d \bar{A}_{t}=\mu_{\bar{A}} d t+\sigma_{\bar{A}, 1} d z_{1 t}+\sigma_{\bar{A}, 2} d z_{2 t}
$$


where

$$
\begin{aligned}
\mu_{\bar{A}}= & \left.\left(\frac{\bar{A}_{t}-2 \underline{a}}{1-\rho^{2}}\right)\left[s_{1}\left(\bar{A}_{t}\right)^{2}+s_{2}\left(\bar{A}_{t}\right)^{2}-2 \rho s_{1}\left(\bar{A}_{t}\right) s_{2}\left(\bar{A}_{t}\right)\right)+r\left(\bar{A}_{t}\right)-\delta-m\right] \\
& +m\left(A_{t}-A_{0}\right) \\
\sigma_{\bar{A}, 1}= & \frac{s_{1}\left(\bar{A}_{t}\right)-\rho s_{2}\left(\bar{A}_{t}\right)}{1-\rho^{2}} \bar{A}_{t} \\
\sigma_{\bar{A}, 2}= & \frac{s_{2}\left(\bar{A}_{t}\right)-\rho s_{1}\left(\bar{A}_{t}\right)}{1-\rho^{2}} \bar{A}_{t}
\end{aligned}
$$

Let $J\left(a_{i t}, \bar{A}_{t}\right)$ denote the value function of households' problem. In open economy, the HJB equation is given by

$$
\begin{aligned}
(\delta+m) J d t=\max _{c_{i t}, \theta_{i t}}\left\{\log c_{i t}\right. & +J_{a}\left\{\left[\sigma_{1} s_{1 t} \theta_{1, i t}+\sigma_{2} s_{2 t} \theta_{2 i t}+r_{t}\right] a_{i t}-c_{i t}-r_{t} \underline{a}\right\} \\
& +\frac{1}{2} J_{a a}\left(\left(\sigma_{1} \theta_{1, i t}\right)^{2}+\left(\sigma_{2} \theta_{2 i t}\right)^{2}+2 \rho \sigma_{1} \sigma_{2} \theta_{1 i t} \theta_{2 i t}\right) a_{i t}^{2} \\
& +J_{\bar{A}} \mu_{\bar{A}}+\frac{1}{2} J_{\bar{A} \bar{A}}\left(\sigma_{\bar{A}, 1}^{2}+\sigma_{\bar{A}, 2}^{2}+2 \rho \sigma_{\bar{A}, 1} \sigma_{\bar{A}, 2}\right) \\
& \left.+J_{\bar{A} a}\left(\sigma_{1} \theta_{1 i t} a_{i t}\left(\sigma_{\bar{A}, 1}+\rho \sigma_{\bar{A}, 2}\right)+\sigma_{2} \theta_{2 i t} a_{i t}\left(\sigma_{\bar{A}, 2}+\rho \sigma_{\bar{A}, 1}\right)\right)\right\} d t
\end{aligned}
$$

Pick

$$
J\left(a_{i t}, \bar{A}_{t}\right) \equiv \frac{1}{\delta+m} \log \left(a_{i t}-\underline{a}\right)+\mathcal{C}\left(\bar{A}_{t}\right)
$$

where $\mathcal{C}\left(\bar{A}_{t}\right)$ is a solution of the following differential equation

$$
(\delta+m) \mathcal{C}\left(A_{t}\right)=\log (\delta+m)+\frac{r_{t}-\delta-m}{\delta+m}-\frac{1}{2} \frac{s_{1}^{2}+s_{2}^{2}-2 \rho s_{1} s_{2}}{(\delta+m)\left(1-\rho^{2}\right)}+\mathcal{C}^{\prime}\left(\bar{A}_{t}\right) \mu_{\bar{A}}+\frac{1}{2} \mathcal{C}^{\prime \prime}\left(\bar{A}_{t}\right) \sigma_{\bar{A}}^{2}
$$

with suitable boundary conditions. Note that the value function is consistent with consumption and portfolio choices given by (59), (60) and (61). Substituting them into the HJB equation, the left-hand side equals

$$
\log \left(a_{i t}-\underline{a}\right)+(\delta+m) \mathcal{C}\left(\bar{A}_{t}\right)
$$

while the right-hand side equals

$$
\log \left(a_{i t}-\underline{a}\right)+\log (\delta+m)+\frac{r_{t}-\delta-m}{\delta+m}-\frac{1}{2} \frac{s_{1}^{2}+s_{2}^{2}-2 \rho s_{1} s_{2}}{(\delta+m)\left(1-\rho^{2}\right)}+\mathcal{C}^{\prime}\left(\bar{A}_{t}\right) \mu_{\bar{A}}+\frac{1}{2} \mathcal{C}^{\prime \prime}\left(\bar{A}_{t}\right) \sigma_{\bar{A}}^{2}
$$


The transverality condition also holds. Therefore, the proposed solutions and market clearing conditions constitute an equilibrium.

\section{Appendix C Quantitative Analysis}

In this section, I elaborate on more details about numerical simulations presented in Section 5.

\section{C.1 Closed Economy}

(i) Households' Problem The utility function is given by $u\left(c_{i t}\right)=\frac{c_{i t}^{1-\gamma}}{1-\gamma}$. Households' problem is now replaced by

$$
\max _{c_{i t}} \mathbb{E}_{0}\left[\int_{0}^{\infty} e^{-(\delta+m) t} u\left(c_{i t}\right) d t\right]
$$

subject to

$$
\begin{aligned}
d a_{i t} & =\left[\left(r_{t}^{*}+\sigma_{1} s_{1 t}^{*} \theta_{1 i t}+m\right) a_{i t}+w_{1 t}^{*} l_{i t}+r^{h} h_{i t}-c_{i t}-\kappa r_{t}^{*}\right] d t+\sigma_{1} \theta_{1 i t} a_{i t} d z_{1 t} \\
\theta_{1 i t} & =\max \left\{\frac{s_{1 t}^{*}}{\chi_{1} \sigma_{1}}\left(1-\frac{\chi_{2}}{a_{i t}}-\frac{\chi_{3}}{a_{i t} l_{i t}}\right), 0\right\}
\end{aligned}
$$

Unlike the baseline model, the portfolio choice function is taken as given. The functional form in (62) is an approximation to the actual solution in a sense that $\chi_{1}=\gamma, \chi_{2}=\kappa$, and $\chi_{3}=0$ would arise if the model dispensed with labor income and housing assets. ${ }^{40}$

(ii) Market Clearing Conditions One key advantage of Assumption 1 is that the market clearing conditions are now characterized by a finite number of aggregate variables. Let me first turn to the market clearing conditions in a closed economy.

$$
\begin{aligned}
r_{t}^{*} & =\alpha Z A_{1 t}^{\alpha-1} L^{1-\alpha}-\bar{\sigma}_{1} s_{1 t}^{*}-\tau\left(1-\lambda_{1}\right) \\
(1-\lambda) A_{1 t} & =\int_{i} a_{i t} \theta_{1 i t} d i \\
w_{1 t}^{*} & =(1-\alpha) Z A_{1 t}^{\alpha} L^{-\alpha}
\end{aligned}
$$

The first and second lines imply that financial markets for the domestic safe and risky assets are cleared. The last line is associated with the labor market clearing condition. Note that the second

\footnotetext{
${ }^{40}$ One can confirm this by applying the method in Appendix B.2.1 with $u\left(c_{i t}\right)=\frac{c_{i t}^{1-\gamma}}{1-\gamma}$.
} 
line can be written as

$$
\begin{aligned}
(1-\lambda) A_{1 t} & =\int_{a_{i t} \geq \chi_{2}+\chi_{3} / l_{i}} a_{i t} \frac{s_{1 t}}{\sigma_{1} \chi_{1}}\left(1-\frac{\chi_{2}}{a_{i t}}-\frac{\chi_{3}}{a_{i t} \ell_{i}}\right) d i \\
& =\frac{s_{1 t}}{\bar{\sigma} \chi_{1}}\left(A_{1 t}-F_{1 t}^{a}-F_{i}\right)
\end{aligned}
$$

where $F_{1 t}^{a}=\int_{a_{i t}<\chi_{2}+\chi_{3} / l_{i}} a_{i t} d i$ and $F_{i}=\int_{a_{i t} \geq \chi_{2}+\chi_{3} / \ell_{i}}\left(\chi_{2}+\chi_{3} / \ell_{i}\right) d i$. Here, $F_{i}$ is a time-invariant variable as, due to the setting of this model, the measure of households whose wealth levels are below the threshold $\chi_{2}+\chi_{3} / l_{i}$ is constant. This is because when their wealth levels are close to this threshold they only invest in safe assets to retain their wealth. In actual simulations, it is convenient to express these market clearing conditions as

$$
\begin{aligned}
r_{t}^{*} & \equiv r^{*}\left(A_{1 t}, F_{1 t}^{a}\right)=\alpha Z A_{1 t}^{\alpha-1} L^{1-\alpha}-\bar{\sigma}_{1} s_{1}^{*}\left(A_{1 t}\right)-\tau\left(1-\lambda_{1}\right) \\
s_{1 t}^{*} & \equiv s_{1}^{*}\left(A_{1 t}, F_{1 t}^{a}\right)=\frac{\bar{\sigma}_{1} \chi_{1} A_{1 t}}{A_{1 t}-F_{1 t}^{a}-F_{i}} \\
w_{1 t}^{*} \equiv w_{1}^{*}\left(A_{1 t}, F_{1 t}^{a}\right) & =(1-\alpha) Z A_{1 t}^{\alpha} L^{-\alpha}
\end{aligned}
$$

(iii) Simulation Algorithm Numerical simulations for closed economy proceed in four steps. First, I begin with a guess for the law of motion for the state variables. In the model where all households retain wealth $\chi_{2}+\chi_{3} / \ell_{i}, A_{1 t}$ acts as a sufficient statistics for current prices. The following law of motion fits the model well:

$$
\frac{d A_{1 t}}{A_{1 t}}=\left(\left(\psi_{2}-1\right) \log A_{1 t}+\psi_{1}\right) d t+\bar{\sigma}_{1} d z_{1 t}
$$

where $\psi_{1}$ and $\psi_{2}$ are constants. It is worth noting that (63) corresponds to $\log A_{1, t+1}=\psi_{2} \log A_{1, t}+$ $\psi_{1}+\bar{\sigma}_{1} \epsilon_{t}$ in the discrete-time setting. This functional form is identical to the one used by Krusell and Smith (1998). On the other hand, in the model where some households are indebted, one may also consider the law of motion for $F_{1 t}^{a}$. In practice, $d F_{1 t}^{a}=0$ worked well around the stationary state.

Second, given an initial guess for $\psi_{1}$ and $\psi_{2}$, I solve differential equations that characterize saving decisions of households and evolution of the wealth distribution. Let $J_{t} \equiv J\left(a, \ell, \varepsilon, A_{t}\right)$ denote the value function associated with households' optimization problem. $g_{t}(a, \ell, \epsilon)$ represents 
probability density distribution across households at time $t$. They are pinned down by

$$
\begin{aligned}
(\delta+m) J_{t} d t=\max _{c, \theta_{1}}\{u(c) & +\frac{\partial J_{t}}{\partial a} v_{t}(a, \ell, \epsilon)+\frac{1}{2} \frac{\partial^{2} J_{t}}{\partial a^{2}}\left(\sigma_{1} \theta_{1} a\right)^{2}+\frac{\partial J_{t}}{\partial \epsilon}(-\beta \epsilon) \\
& \left.+\zeta \int_{-\infty}^{\infty}\left(J_{t}(a, \ell, x)-J_{t}(a, \ell, \epsilon)\right) \phi(x) d x+\frac{1}{d t} \mathbb{E}_{t}\left[d J_{t}\right]\right\} d t \\
\frac{d}{d t} g_{t}(a, \ell, \epsilon)=-m g_{t}(a, \ell, \epsilon) & +m g_{0}(a, \ell, \varepsilon)-\frac{d}{d a}\left[v_{t}(a, \ell, \epsilon) g_{t}(a, \ell, \epsilon)\right] \\
& -\zeta g_{t}(a, \ell, \epsilon)+\zeta \phi(\epsilon) \int_{-\infty}^{\infty} g_{t}(a, \ell, x) d x d \ell
\end{aligned}
$$

where $v_{t}(a, l, \epsilon) \equiv\left[\left(r_{t}^{*}+\sigma_{1} s_{1 t}^{*} \theta_{1}+m\right) a_{i t}+w_{1 t}^{*} l+r^{h} h-c-\kappa\left(r_{t}^{*}+m\right)\right]$ indicate individual savings. To find a numerical approximation to the solution, I turn to a finite difference method called "Upwind Scheme". More details are referred to the next subsection.

The third step is to check if the initial guess for $\psi_{1}$ and $\psi_{2}$ is consistent with the ones derived from the Kolmogorov Forward Equation. Set the simulation period, say $t=0$ to $t=T$. Starting from $g_{0}$, I compute $g_{1}, \ldots, g_{T}$ sequentially by applying the Kolmogorov Forward Equation. It is then easy to compute the mean of each distribution, $A_{1,0}, \ldots, A_{1, T}$. The model-implied estimates, $\hat{\psi}_{1}$ and $\hat{\psi}_{2}$, are obtained by running ordinary least squares over the series. If the distance between $\left(\psi_{1}, \psi_{2}\right)$ and $\left(\hat{\psi}_{1}, \hat{\psi}_{2}\right)$ is sufficiently small, terminate the process. Otherwise, start with another guess for $\psi_{1}$ and $\psi_{2}$ and repeat the above steps. ${ }^{41}$

Finally, once the model converges, I compute the fit of the model to the observed data. I use 1989 as the benchmark year due to data availability of the Survey of Consumer Finances. I calibrate parameter values such that the stationary wealth distribution implied by the model fits the actual wealth distribution in the data.

(cf) Unwind Scheme Here, I briefly summarize the core idea to approximately solve the HJB equation and Kolmogorov Forward Equation. Achdou et al. (2017) provides a nice introduction to this method and applications. I follow their notation and exposition throughout this chapter. Let $a_{i}, \ell_{j}$ and $A_{k}$ denote $i$ 'th, $j$ 'th and $k$ 'th coordinates of each variable; there are $I, J$ and $K$ discrete points along each dimension of the space. Let's first consider the case $\epsilon=0$ for all $t$.

\footnotetext{
${ }^{41}$ In actual practice, one can recursively update $\psi_{1}^{k}$ and $\psi_{2}^{k}$ to find a fixed point faster. The initial guess is denoted by $\psi_{1}^{0}$ and $\psi_{1}^{0}$. I can then derive $\hat{\psi}_{1}$ and $\hat{\psi}_{2}$ from the Kolmogorov Forward Equation. Update $\psi_{1}^{1}=\hat{\psi}_{1}$ and $\psi_{2}^{1}=\hat{\psi}_{2}$ and solve the model again. Repeat this process until the distance between $\left(\psi_{1}^{k}, \psi_{2}^{k}\right)$ and $\left(\psi_{1}^{k+1}, \psi_{2}^{k+1}\right)$ becomes sufficiently small. This method appears to work well in simulation although there is no established result for this.
} 
With this apparatus in place, it is natural to express other variables as

$$
\begin{aligned}
\theta_{1, i, j, k} & =\max \left\{\frac{s_{1}^{*}\left(A_{k}\right)}{\chi_{1} \sigma_{1}}\left(1-\frac{\chi_{2}}{a_{i}}-\frac{\chi_{3}}{a_{i} \ell_{j}}\right), 0\right\} \\
I_{i, j, k} & =\left(r^{*}\left(A_{k}\right)+\sigma_{1} s_{1}^{*}\left(A_{k}\right) \theta_{1, i, j, k}+m\right) a_{i}+\ell_{j} w_{1}^{*}\left(A_{k}\right)+r^{h} h_{i, j, k}-\kappa\left(r^{*}\left(A_{k}\right)+m\right)
\end{aligned}
$$

where $I_{i, j, k}$ is gross income of individual households and $h_{i, j, k}$ is the holding of housing assets corresponding to $a_{i, j, k}$

The value function is defined over these points so I shall use the short-hand notation $J_{i, j, k} \equiv$ $J\left(a_{i}, \ell_{j}, A_{k}\right)$. Starting with an initial guess of $J_{i, j, k}^{0}$, the aim of this exercise is to iteratively update $J_{i, j, k}^{n}$ until it converges to a certain function. A natural initial guess is $J_{i, j, k}^{0} \equiv \frac{u\left(I_{i, j, k}\right)}{\delta+m}$. Let $n$ denote a current iteration. The second step of this exercise is to compute a first difference, $\left(J_{i, j, k}^{n}\right)^{\prime}$, using

$$
\begin{aligned}
s_{i, j, k}^{n, F} & \equiv I_{i, j, k}-\left(u^{\prime}\right)^{-1}\left(\frac{J_{i+1, j, k}^{n}-J_{i, j, k}^{n}}{\Delta a}\right) \\
s_{i, j, k}^{n, B} & \equiv I_{i, j, k}-\left(u^{\prime}\right)^{-1}\left(\frac{J_{i, j, k}^{n}-J_{i-1, j, k}^{n}}{\Delta a}\right) \\
\left(J_{i, j, k}^{n}\right)^{\prime} & \equiv\left(\frac{J_{i+1, j, k}^{n}-J_{i, j, k}^{n}}{\Delta a}\right) \mathbb{I}_{s_{i, j, k}^{n, F}>0}+\left(\frac{J_{i, j, k}^{n}-J_{i-1, j, k}^{n}}{\Delta a}\right) \mathbb{I}_{s_{i, j, k}^{n, F}<0}+u^{\prime}\left(I_{i, j, k}\right) \mathbb{I}_{s_{i, j, k}^{n, F} \leq 0 \leq s_{i, j, k}^{n, B}}
\end{aligned}
$$

The third step is to convert $c_{i, j, k}^{n}=\left(u^{\prime}\right)^{-1}\left(\left(J_{i, j, k}^{n}\right)^{\prime}\right)$. The forth step is to update $J_{i, j, k}^{n}, n=1,2, \ldots$ according to

$$
\begin{aligned}
& \frac{J_{i, j, k}^{n+1}-J_{i, j, k}^{n}}{\Delta}+(\delta+m) J_{i, j, k}^{n+1} \\
= & u\left(c_{i, j, k}^{n}\right)+\frac{J_{i+1, j, k}^{n+1}-J_{i, j, k}^{n+1}}{\Delta a} v_{i, j, k}^{+}+\frac{J_{i, j, k}^{n+1}-J_{i-1, j, k}^{n+1}}{\Delta a} v_{i, j, k}^{-} \\
& +\frac{\left(\sigma_{1} \theta_{1, i, j, k} a_{i}\right)^{2}}{2} \frac{J_{i, j, k+1}-2 J_{i, j, k}-J_{i, j, k-1}}{\Delta a^{2}}+\frac{\bar{\sigma}_{1}^{2}}{2} \frac{J_{i, j, k+1}-2 J_{i, j, k}-J_{i, j, k-1}}{\Delta A^{2}} \\
& +\left(\sigma_{1} \theta_{1, i, j, k} a_{i}\right) \bar{\sigma}_{1} \frac{J_{i+1, j, k+1}-J_{i, j, k+1}-J_{i+1, j, k}+J_{i, j, k}}{\Delta a \Delta A}
\end{aligned}
$$

where $\Delta$ is the iteration step size, $\Delta a$ is the gap between two points in asset grid and $\Delta A$ is the gap in the state variable grid. $v_{i, j k}^{+}$and $v_{i, j, k}^{-}$represent saving functions given by

$$
v_{i, j, k}^{+} \equiv \max \left\{0, I_{i, j, k}-c_{i, j, k}^{n, F}\right\} \quad \text { and } \quad v_{i, j, k}^{-} \equiv \min \left\{0, I_{i, j, k}-c_{i, j, k}^{n, B}\right\}
$$


where

$$
\begin{gathered}
c_{i, j, k}^{n, F} \equiv\left(u^{\prime}\right)^{-1}\left(\frac{J_{i+1, j, k}-J_{i, j, k}}{\Delta a}\right) \\
c_{i, j, k}^{n, B} \equiv\left(u^{\prime}\right)^{-1}\left(\frac{J_{i, j, k}-J_{i-1, j, k}}{\Delta a}\right)
\end{gathered}
$$

$J_{i, j, k}^{n}$ is updated until $\left\|J_{i, j, k}^{n}-J_{i, j, k}^{n-1}\right\|$ becomes sufficiently small. See the discussion in Section 5 of Achdou et al. (2017) for the convergence property. The method is called 'Upwind Scheme' because it uses a forward difference approximation whenever the drift of the state variable is positive; a backward difference is used whenever the drift is negative.

A byproduct of this exercise is a numerical approximation to the Kolmogorov Forward Equation. Let $t_{1}, \ldots, t_{n}$ denote grid points over evenly-spaced time intervals. Let $g_{i, j}^{n} \equiv g_{t_{n}}\left(a_{i}, \ell_{j}\right)$ be wealth-labor distribution over grid points. For every $n$, one has to find the nearest $k$ such that $A_{k} \approx \sum_{i, j} g_{i, j}^{n} a_{i}$. Starting from $g_{i, j}^{0}$, one has to update $g_{i, j}^{n}$ iteratively according to a difference equation:

$$
\frac{g_{i, j}^{n+1}-g_{i, j}^{n}}{\Delta t}=-\frac{\left(s_{i, j, k}^{n, F}\right)^{+} g_{i, j}^{n}-\left(s_{i-1, j, k}^{n, F}\right)^{+} g_{i-1, j}^{n}}{\Delta a}-\frac{\left(s_{i+1, j, k}^{n, B}\right)^{-} g_{i+1, j}^{n}-\left(s_{i, j, k}^{n, B}\right)^{-} g_{i, j}^{n}}{\Delta a}
$$

where $s_{i, j, k}^{n, F}$ and $s_{i, j, k}^{n, F}$ are the values computed from (66) and (67). Here, I use $(x)^{+} \equiv \max \{x, 0\}$ and $(x)^{-} \equiv \min \{x, 0\}$ to simplify notations. I use this updating process to compute the series $A_{1,1}, A_{1,2}$ and $A_{1, n}$ in autarky. The stationary wealth distribution can be computed by replacing the left-hand side with zero.

\section{C.2 Open Economy}

(i) Households' Problem In open economy, the budget constraint and portfolio choice functions are now replaced by

$$
\begin{aligned}
d a_{i t}= & {\left[\left(r_{t}+\sigma_{1} s_{1 t} \theta_{1 i t}+\sigma_{2} s_{2 t} \theta_{2 i t}+m\right) a_{i t}+w_{1 t} l_{i t}+r^{h} h_{i t}-c_{i t}-\kappa\left(r_{t}+m\right)\right] d t } \\
& +\sigma_{1} \theta_{1 i t} a_{i t} d z_{1 t}+\sigma_{2} \theta_{2 i t} a_{i t} d z_{2 t} \\
\theta_{1 i t}= & \max \left\{\frac{s_{1 t}-\rho s_{2 t}}{\chi_{1} \sigma_{1}\left(1-\rho^{2}\right)}\left(1-\frac{\chi_{2}}{a_{i t}}-\frac{\chi_{3}}{a_{i t} l_{i t}}\right), 0\right\} \\
\theta_{2 i t}= & \max \left\{\frac{s_{2 t}-\rho s_{1 t}}{\chi_{1} \sigma_{1}\left(1-\rho^{2}\right)}\left(1-\frac{\chi_{2}}{a_{i t}}-\frac{\chi_{3}}{a_{i t} l_{i t}}\right), 0\right\}
\end{aligned}
$$

from time $T$ onward. 
(ii) Market Clearing Conditions Under this setting, the market clearing conditions can be stated as

$$
\begin{aligned}
\alpha Z K_{1 t}^{\alpha-1} L_{1}^{1-\alpha}-\bar{\sigma}_{1} s_{1 t}-\tau_{1}\left(1-\lambda_{1}\right) & =r_{t} \\
\alpha Z K_{2 t}^{\alpha-1} L_{2}^{1-\alpha}-\bar{\sigma}_{2} s_{2 t}-\tau_{2}\left(1-\lambda_{2}\right) & =r_{t} \\
\frac{s_{1 t}-\rho s_{2 t}}{\bar{\sigma}_{1}\left(1-\rho^{2}\right) \chi_{1}}\left(A_{1 t}+A_{2 t}-F_{1 t}^{a}-F_{2 t}^{a}-2 F_{i}\right) & =K_{1 t} \\
\frac{s_{2 t}-\rho s_{1 t}}{\bar{\sigma}_{2}\left(1-\rho^{2}\right) \chi_{1}}\left(A_{1 t}+A_{2 t}-F_{1 t}^{a}-F_{2 t}^{a}-2 F_{i}\right) & =K_{2 t} \\
K_{1 t}+K_{2 t} & =A_{1 t}+A_{2 t} \\
(1-\alpha) Z K_{1 t}^{\alpha} L_{1}^{-\alpha} & =w_{1 t}
\end{aligned}
$$

when $A_{1 t}$ and $A_{2 t}$ are given. Let $\bar{A}_{t} \equiv A_{1 t}+A_{2 t}$ and $\zeta\left(\bar{A}_{t}\right) \equiv A_{1 t}+A_{2 t}-2 F_{1 t}^{a}-2 F_{i}$ to simplify notation. We can merge some of these equations and write them as

$$
\begin{aligned}
& \left(\frac{s_{1 t}-\rho s_{2 t}}{\bar{\sigma}_{1}\left(1-\rho^{2}\right) \chi_{1}}+\frac{s_{2 t}-\rho s_{1 t}}{\bar{\sigma}_{2}\left(1-\rho^{2}\right) \chi_{1}}\right) \zeta\left(\bar{A}_{t}\right)=\bar{A}_{t} \\
& \alpha Z\left(\frac{s_{1 t}-\rho s_{2 t}}{\bar{\sigma}_{1}\left(1-\rho^{2}\right) \chi_{1}} \zeta\left(\bar{A}_{t}\right)\right)^{\alpha-1} L_{1}^{1-\alpha}-\bar{\sigma}_{1} s_{1 t}-\tau_{1}\left(1-\lambda_{1}\right) \\
= & \alpha Z\left(\frac{s_{2 t}-\rho s_{1 t}}{\bar{\sigma}_{1}\left(1-\rho^{2}\right) \chi_{1}} \zeta\left(\bar{A}_{t}\right)\right)^{\alpha-1} L_{2}^{1-\alpha}-\bar{\sigma}_{2} s_{2 t}-\tau_{2}\left(1-\lambda_{2}\right)
\end{aligned}
$$

where the first equation follows from (70), (71) and (72), and the second equation results from (68), (69), (70) and (71). It follows from these equations that $s_{1 t}$ and $s_{2 t}$ are functions of $\bar{A}_{t}$ so I denote them by $s_{1 t} \equiv s_{1}\left(\bar{A}_{t}\right)$ and $s_{2 t} \equiv s_{2}\left(\bar{A}_{t}\right)$. Substituting them back into (68) and (73), we can express $r_{t}$ and $w_{1 t}$ as

$$
\begin{gathered}
r_{t} \equiv r\left(\bar{A}_{t}\right)=\alpha Z\left(\frac{s_{1}\left(\bar{A}_{t}\right)-\rho s_{2}\left(\bar{A}_{t}\right)}{\bar{\sigma}_{1}\left(1-\rho^{2}\right) \chi_{1}} \zeta\left(\bar{A}_{t}\right)\right)^{\alpha-1} L_{1}^{1-\alpha}-\bar{\sigma}_{1} s_{1}\left(\bar{A}_{t}\right)-\tau_{1}\left(1-\lambda_{1}\right) \\
w_{1 t} \equiv w_{1}\left(\bar{A}_{t}\right)=(1-\alpha) Z\left(\frac{s_{1}\left(\bar{A}_{t}\right)-\rho s_{2}\left(\bar{A}_{t}\right)}{\bar{\sigma}_{1}\left(1-\rho^{2}\right) \chi_{1}} \zeta\left(\bar{A}_{t}\right)\right)^{\alpha} L_{1}^{-\alpha}
\end{gathered}
$$

Therefore, we can regard $\bar{A}_{t}$ as the sole state variable associated with the market clearing conditions.

(iii) Simulation Algorithm Let me describe a simulation algorithm for open economy. For expository purposes, I first consider the case that the initial state of the economy is open while setting aside transition from autarky to open economy. The simulation begins by guessing the law 
of motion for the state variables. In the simple case where all households retain $a_{i t} \geq \chi_{2}+\chi_{3} / \ell_{i}$, the following functional form works well in simulations:

$$
\frac{d \bar{A}_{t}}{\bar{A}_{1 t}}=\left(\left(\psi_{2}-1\right) \log \bar{A}_{t}+\psi_{1}\right) d t+\sigma_{\bar{A}, 1} d z_{1 t}+\sigma_{\bar{A}, 1} d z_{1 t}
$$

where

$$
\begin{aligned}
\sigma_{\bar{A}, 1} & =\frac{s_{1}\left(\bar{A}_{t}\right)-\rho s_{2}\left(\bar{A}_{t}\right)}{1-\rho^{2}} \bar{A}_{t} \\
\sigma_{\bar{A}, 2} & =\frac{s_{2}\left(\bar{A}_{t}\right)-\rho s_{1}\left(\bar{A}_{t}\right)}{1-\rho^{2}} \bar{A}_{t}
\end{aligned}
$$

$s_{1}\left(\bar{A}_{t}\right)$ and $s_{2}\left(\bar{A}_{t}\right)$ are solutions of the system of equations, (74) and (75). Households take this motion into account when they make investment decisions. Again, in the model where some households are indebted, one may also consider the law of motion for $F_{1 t}^{a}$ and. In practice, $d F_{1 t}^{a}=0$ worked well around the stationary state.

Second, given an initial guess for $\psi_{1}$ and $\psi_{2}$, I solve differential equations that characterize saving decisions of households and evolution of the wealth distribution. This step is similar to that of closed economy. Let $J_{t} \equiv J\left(a, \ell, \varepsilon, A_{t}\right)$ denote the value function associated with households' optimization problem. $g_{t}(a, \ell, \epsilon)$ represents probability density distribution across households at time $t$. They are characterized by the HJB equation and the Kolmogorov Forward Equation shown in (64) and (65), but now the saving function, $v_{t}$, is replaced by

$$
v_{t}(a, l, \epsilon) \equiv\left[\left(r_{t}+\sigma_{1} s_{1 t} \theta_{1}+\sigma_{2} s_{2 t} \theta_{2}+m\right) a_{i t}+w_{1 t} l+r^{h} h-c-\kappa\left(r_{t}+m\right)\right]
$$

The market clearing conditions are (74), (75), (76) and (77). To find a numerical approximation to the solution, I again turn to a finite difference method ("Upwind Scheme") as in closed economy.

The third step is to check if the initial guess for $\psi_{1}$ and $\psi_{2}$ is consistent with the ones derived from the Kolmogorov Forward Equation. I again set the simulation period, say $t=T$ to $t=2 T$. The procedure is similar to that of closed economy. Starting from $g_{T}$, I compute $g_{T+1}, \ldots, g_{2 T}$ sequentially by applying the Kolmogorov Forward Equation. It is then easy to compute the mean of each distribution, $A_{1,0}, \ldots, A_{1, T}$. The model-implied estimates, $\hat{\psi}_{1}$ and $\hat{\psi}_{2}$, are obtained by running ordinary least squares over the series. If the distance between $\left(\psi_{1}, \psi_{2}\right)$ and $\left(\hat{\psi}_{1}, \hat{\psi}_{2}\right)$ is sufficiently small, terminate the process. Otherwise, start with another guess for $\psi_{1}$ and $\psi_{2}$ and repeat the above steps. 
(iv) Transition to open economy Once the model converges, I turn back to transitional dynamics from autarky to open economy. The first thing to consider is to incorporate capital gains stemming from unanticipated changes in the economy. Let $p_{t}$ denote the price of a unit of equity for taking a $\sigma_{1} d z_{1 t}$. No arbitrage condition implies that, immediately after the shock, the price movement is dictated by

$$
\frac{d p_{t}}{p_{t}}+\frac{\left(r_{t}^{*}+\sigma_{1} s_{1 t}^{*}\right) d t}{p_{t}}=\left(r_{t}+\sigma_{1} s_{1 t}\right) d t
$$

In the numerical simulation, I approximate the path of $p_{t}$ by turning to a discrete-time version

$$
\mathbb{E}_{t}\left[\frac{p_{t+1}-p_{t}+r_{t}^{*}+\sigma_{1} s_{1 t}^{*}}{p_{t}}\right]=r_{t}+\sigma_{1} s_{1 t}
$$

Since $p_{t}=1$ for all $t<T$, we have

$$
\begin{aligned}
p_{T}^{\text {new }} & \approx \mathbb{E}_{T}\left[\sum_{t=T}^{\infty} \frac{\left(r_{t}^{*}+\sigma s_{t}^{*}\right)}{\left(1+r_{t}+\sigma s_{1 t}\right)^{t}}\right] \\
& \equiv \mathbb{E}_{T}\left[\sum_{t=T}^{\infty} \frac{\left(r^{*}\left(A_{1 t}\right)+\sigma s_{1}^{*}\left(A_{1 t}\right)\right)}{\left(1+r\left(A_{1 t}+A_{2 t}\right)+\sigma s_{1}\left(A_{1 t}+A_{2 t}\right)\right)^{t}}\right]
\end{aligned}
$$

I then simulate the stochastic processes of $A_{1 t}$ and $A_{2 t}$ according to (78) in discrete time. I run Monte Carlo simulations to compute the expected value numerically.

Let $g_{i, j, k}^{n}$ denote the wealth distribution prior to financial globalization, and $g_{i, j, k}^{n+1}$ denote the wealth distribution immediately after capital gains are realized. $g_{i, j, k}^{n+1}$ is updated according to a difference equation

$$
\frac{g_{i, j}^{n+1}-g_{i, j}^{n}}{\Delta t}=-\frac{\left(s_{i, j, k}^{n, F}\right)^{+} g_{i, j}^{n}-\left(s_{i-1, j, k}^{n, F}\right)^{+} g_{i-1, j}^{n}}{\Delta a}-\frac{\left(s_{i+1, j, k}^{n, B}\right)^{-} g_{i+1, j}^{n}-\left(s_{i, j, k}^{n, B}\right)^{-} g_{i, j}^{n}}{\Delta a}
$$

But now $I_{i, j, k}$ in $s_{i, j, k}^{n, F}$ and $s_{i, j, k}^{n, B}$, which are computed from (66) and (67), is replaced by

$$
\left(r^{*}\left(A_{k}\right)+\sigma_{1} s_{1}^{*}\left(A_{k}\right) \theta_{1, i, j, k}+m+p_{T}^{n e w}\right) a_{i}+\ell_{j} w_{1}^{*}\left(A_{k}\right)+r^{h} h_{i, j, k}-\kappa\left(r^{*}\left(A_{k}\right)+m\right)
$$

Essentially, households receive unanticipated capital gains and these incomes show up in the budget constraint in period $T=t_{n}$. Starting from $g_{i, j, k}^{n+1}$, I again use the difference equation without capital gains to compute $g_{i, j, k}^{n+2} \ldots ., g_{i, j, k}^{2 n}$. 


\section{Appendix D Additional Details}

\section{D.1 Estimation of the Risk Premium}

To illustrate the point, let $d_{t+1}$ denote the dividend for year $t+1, P_{t}$ denote the price at the end of year $t$ and $R_{t+1}$ denote the return for year $t+1$. The return is then measured as the dividend yield $\frac{d_{t+1}}{P_{t}}$ plus the rate of capital gains.

$$
R_{t+1}=\frac{d_{t+1}}{P_{t}}+\frac{P_{t+1}-P_{t}}{P_{t}}
$$

What we aim to estimate here is $\mathbb{E}_{t}\left[R_{t+1}\right]$. The key identifying assumption is the stationarity of the valuation ratios. Fama and French (2002) proposes that the dividend growth rate $\left(d_{t+1}-\right.$ $\left.d_{t}\right) / d_{t}$ can be an estimate of the expected capital gains under the assumption that the dividendprice ratio $d_{t} / P_{t}$ is stationary i.e. mean reverting. In the same manner, the earning growth rate $\left(E_{t+1}-E_{t}\right) / E_{t}$ can be an alternative estimate of the expected capital gains if the earning-price ratio is a stationary process. Furthermore, Campbell and Thompson (2008) combines this formula with the steady-state relation between dividend growth and accounting return on equity. The return for year $t+1$ can be expressed as

$$
R_{t+1}=\frac{d_{t+1}}{e_{t+1}} \frac{e_{t+1}}{P_{t}}+\left(1-\frac{d_{t+1}}{e_{t+1}}\right) \frac{e_{t+1}}{B_{t}}
$$

where $B_{t}$ is the book value of equity. Campbell (2008) then uses three-year smoothed return on equity, dividend yields, and payout ratios to estimate the time varying equity premium. In the analysis that follows, I consider these three approaches and denote them by FF Dividends, FF Earnings and CT RoE respectively. I use five-year smoothed dividend growth rates and earnings growth rates for the first two cases. These methods are well suited to judging whether the average realized return is high or low relative to the expected return implied by fundamentals.

\section{D.2 Kolmogorov Forward Equation (Section 2)}

We have seen that the wealth of individual $i$, conditional on being alive, evolves according to an Itô diffusion process

$$
d a_{t}=\left[\left(r^{*}+s_{1}^{* 2}-\delta-m\right)\left(a_{i t}-\underline{a}\right)\right] d t+s_{1}^{*} a_{t} d z_{1 t}
$$


in the case of autarky. Subscript $i$ is repressed. Let $(\Omega, \mathcal{F}, \mathbb{P})$ represent a probability space on which the above diffusion process is defined. Note that (81) can be expressed as an integral form

$$
a_{t}(\omega)=a_{0}+\int_{0}^{t}\left[\left(r^{*}+s_{1}^{* 2}-\delta-m\right)\left(a_{\tau}(\omega)-\underline{a}\right)\right] d \tau+\int_{0}^{t} s a_{\tau}(\omega) d z_{1 \tau}(\omega)
$$

for $\omega \in \mathcal{F}$. The last term on the right-hand side expression is the Ito integral defined by

$$
\int_{0}^{t} s_{1}^{*} a_{\tau}(\omega) d z_{1 \tau}(\omega)=\lim _{n \rightarrow \infty} \int \zeta_{n}(t, w) d z_{1 t}(\omega)
$$

where $\left\{\zeta_{n}\right\}$ is a sequence of elementary functions

$$
\begin{aligned}
& \zeta_{n}(t, \omega)=\sum_{j=0}^{n-1} s_{1}^{*} a_{t_{j}}(\omega) \mathbb{I}_{\left[t_{j}, t_{j+1}\right)}(t) \\
& \mathbb{I}_{\left[t_{j}, t_{j+1}\right)}(t)= \begin{cases}1 & \text { if } t \in\left[t_{j}, t_{j+1}\right) \\
0 & \text { otherwise }\end{cases}
\end{aligned}
$$

over evenly spaced intervals i.e. $t_{j}=t j / n$. Pick any $\bar{\omega} \in \mathcal{F}$ such that $z_{1 t_{1}}(\bar{\omega})=z_{1 t_{2}}(\bar{\omega})=\ldots=$ $z_{1 t_{k}}(\bar{\omega})=z_{0}$ for all $t_{1}, \ldots, t_{k}$ and any $k$. Such a trajectory always exists because a random vector $\left(z_{1 t_{1}}, \ldots, z_{1 t_{k}}\right)$ is Gaussian. In this case, we can see that

$$
\zeta_{n}(t, \bar{w})=\sum_{j=0}^{n-1} s_{1}^{*} a_{t_{j}}(\bar{\omega})\left(z_{1 t_{j}}-z_{1 t_{j+1}}\right)=0
$$

for all $n$. Thus, along this trajectory, we have

$$
a_{t}(\bar{\omega})=a_{0}+\int_{0}^{t}\left[\left(r^{*}+s_{1}^{* 2}-\delta-m\right)\left(a_{\tau}(\bar{\omega})-\underline{a}\right)\right] d \tau
$$

From this point on, we denote by $a_{t} \equiv a_{t}(\bar{\omega})$ the solution of the differential equation (83). Reviving the subscript $i$, we can write its dynamics as $d a_{i t}=\left[\left(r^{*}+s_{1}^{* 2}-\delta-m\right)\left(a_{i t}-\underline{a}\right)\right] d t$

Along this trajectory, we can define a cross-sectional wealth distribution $G_{t}(a)$ in period $t$ as $G_{t}(a)=\int_{[0,1]} \mathbb{I}_{\left\{i \in[0,1]: a_{i t} \leq a\right\}}(i) d i$. I denote by $g_{t}(a)=\frac{\partial G_{t}(a)}{\partial a}$ its density distribution. Take a small interval $[t, t+d t)$. A $m d t$ measure of households drop out and replaced with the newborn households. Those who remain accumulate (or deccumulate) their wealth from $a_{i t}$ to $a_{i, t+d t}=$ $a_{i t}+\left[\left(r^{*}+s_{1}^{* 2}-\delta-m\right)\left(a_{i t}-\underline{a}\right)\right] d t$. In view of this dynamics, the period $t+d t$ wealth distribution 
can be written as

$$
G_{t+d t}(a)=(1-m d t) G_{t}\left(a-\left[\left(r+s^{2}-\delta-m\right)(a-\underline{a})\right] d t\right)+m d t G_{0}(a)
$$

which leads to

$$
\frac{G_{t+d t}(a)-G_{t}(a)}{d t}=-m G_{t}(a)+m G_{0}(a)+(1-m d t) \frac{G_{t}\left(a-\left[\left(r+s^{2}-\delta\right)(a-\kappa)\right] d t\right)-G_{t}(a)}{d t}
$$

Taking $d t \rightarrow 0$, we have

$$
\frac{d G_{t}(a)}{d t}=-m G_{t}(a)+m G_{0}(a)-\left[\left(r^{*}+s^{* 2}-\delta-m\right)(a-\underline{a})\right] g_{t}(a)
$$

Differentiating the both sides with respect to $a$, we can derive

$$
\frac{d}{d t} g_{t}(a)=-m g_{t}(a)+m g_{0}(a)-\frac{d}{d a}\left[\left(r^{*}+\sigma_{1} s_{1}^{*} \theta_{1}(a)\right) a-c(a)\right] g_{t}(a)
$$

where $\theta_{1}(a)=\frac{s_{1}^{*}}{\sigma_{1}}\left(1-\frac{\underline{a}}{a_{i t}}\right)$ and $c(a)=(\delta+m) a+\left(r^{*}-\delta-m\right) \underline{a}$. We can analogously derive the case for the open economy.

\section{D.3 Convergence of the Wealth Distribution}

In autarky, the stationary wealth distribution is the unique solution of the following ordinary differential equation

$$
0=-m g(a)+m g_{0}(a)-\frac{\partial\left[\left(r^{*}+s_{1}^{* 2}-\delta-m\right)(a-\underline{a})\right] g(a)}{\partial a}
$$

subject to the condition $\int_{\underline{a}}^{\infty} g(a)=1$. The aim of this subsection is to show that

$$
\int_{\kappa}^{\infty}\left|g_{t}(a)-g(a)\right| d a \leq e^{-m t}
$$

I follow a similar strategy to Gabaix et al. (2016) to prove this inequality.

Lemma 3. For any twice continuously differentiable function $q(a, t)$, the following inequality holds

$$
\frac{\partial|q(a, t)|}{\partial t} \leq-m|q(a, t)|+m\left|g_{0}(a)\right|-\left(r^{*}+s_{1}^{* 2}-\delta-m\right) \frac{\partial|(a-\underline{a}) q(a, t)|}{\partial a}
$$

Proof. Let $z(q(a, t))=\sqrt{\epsilon^{2}+q(a, t)^{2}}$. This mapping has property: $\lim _{\epsilon \rightarrow 0} z(q(a, t))=|q(a, t)|$. 
Next, one can show that

$$
\begin{aligned}
& \frac{\partial z(q(a, t))}{\partial t}-\left(-m z(q(a, t))+m g_{0}(a)-\frac{\partial\left[\left(r^{*}+s_{1}^{* 2}-\delta-m\right)(a-\underline{a})\right] z(q(a, t))}{\partial a}\right) \\
= & z^{\prime}(q)\left(\frac{\partial q(a, t)}{\partial t}+\frac{\partial q(a, t)}{\partial a}\left(r^{*}+s_{1}^{* 2}-\delta-m\right)(a-\underline{a})\right)+m z(q(a, t))-m g_{0}(a) \\
= & z^{\prime}(q)\left(-m q(a, t)+m g_{0}(a)\right)+m z(q(a, t))-m g_{0}(a) \\
= & \underbrace{m\left(z^{\prime}(q) q(a, t)+z(q(a, t))\right)}_{\text {Term (i) }}+\underbrace{m g_{0}(a)\left(z^{\prime}(q)-1\right)}_{\text {Term (ii) }}
\end{aligned}
$$

Term (i) and Term (ii) vanish to zero as $\epsilon \rightarrow 0$, because

$$
\begin{aligned}
& \operatorname{Term}(\mathrm{i})=m\left(-\frac{q^{2}}{\sqrt{\epsilon^{2}+q^{2}}}+\sqrt{\epsilon^{2}+q^{2}}\right)=m\left(\frac{\epsilon^{2}}{\sqrt{\epsilon^{2}+q^{2}}}\right) \\
& \operatorname{Term}\left(\text { ii) }=m g_{0}(a)\left(\frac{q}{\sqrt{\epsilon^{2}+q^{2}}}-1\right)\right.
\end{aligned}
$$

On the other hand, the left-hand side becomes

$$
\frac{\partial|q(a, t)|}{\partial t}-\left(-m|q(a, t)|+m\left|g_{0}(a)\right|-\left(r^{*}+s^{* 2}-\delta-m\right) \frac{\partial|(a-\underline{a}) q(a, t)|}{\partial a}\right)
$$

since $\lim _{\epsilon \rightarrow 0} z(q(a, t))=|q(a, t)|$. This completes the proof.

Using this lemma and substituting $q(a, t)=g_{t}(a)-g(a)$, it is straightforward to show that

$$
\begin{aligned}
\int_{\kappa}^{\infty} \frac{\partial\left|g_{t}(a)-g(a)\right|}{\partial t} d a & \leq \int_{\kappa}^{\infty}\left\{-m\left|g_{t}(a)-g(a)\right|-\left(r^{*}+s_{1}^{* 2}-\delta-m\right) \frac{\partial|(a-\underline{a}) q(a, t)|}{\partial a}\right\} d a \\
& =\int_{\kappa}^{\infty}\left\{-m\left|g_{t}(a)-g(a)\right|\right\} d a
\end{aligned}
$$

Then, Gronwell's lemma leads to

$$
\int_{\kappa}^{\infty}\left|g_{t}(a)-g(a)\right| d a \leq e^{-m t}
$$

So the wealth distribution converges to $g(a)$ as $t \rightarrow \infty$

\section{D.4 Discrete Time Model}

In this subsection, I follow Merton (1992) to construct a diffusion process in the households' problem. I use the standard $\mathrm{O}$ notations to describe asymptotic properties. That is, $f_{1}(h)=$ 
$O\left[f_{2}(h)\right]$ if $\lim _{h \rightarrow 0} f_{1}(h) / f_{2}(h)$ is bounded and $f_{1}(h)=o\left[f_{2}(h)\right]$ if $\lim _{h \rightarrow 0} f_{1}(h) / f_{2}(h)=0$. Also, $f_{1}(h) \sim f_{2}(h)$ if $f_{1}(h)=O\left[f_{2}(h)\right]$ but $f_{1}(h) \neq o\left[f_{2}(h)\right]$.

Consider a finite time interval $[0, T)$ prior to a structural change in period $T \equiv n h$. Financial markets are cleared at time $0, h, 2 h, \ldots$ and $n h$ respectively. Here, $h$ denotes the minimum length of time between the successive clearings of markets. By investing the $K_{t}$ units of goods in period $t \equiv k h$, the representative firm generates new goods

$$
\Phi\left(K_{t}\right) h+\bar{\sigma} K_{t} \epsilon_{t+h}
$$

in period $t+h$ where $\epsilon_{t+h}$ is the unanticipated productivity change between period $t$ and period $t+h$. The following assumptions are made on $\epsilon_{t+h}$.

(A1) $\epsilon_{t+h}$ can take on any one of $n_{\epsilon}$ distinct values. For $k=1, \ldots, n_{\epsilon}$, let $\epsilon(k)$ denote one of its values and $p(k)$ represent probability that $\epsilon_{t+h}=\epsilon(k)$ occurs conditional on all information in period $t$. Assume that $\epsilon(k)$ is a sufficiently well behaved function of $h$ such that $\epsilon(k) \sim$ $h^{1 / 2}$ and $p(k)=O(1)$

(A2) $\mathbb{E}_{t}\left[\epsilon_{t+h}\right]=0$ and $\lim _{h \rightarrow 0} \sum_{k=1}^{n_{\epsilon}} p(k) \epsilon(k)^{2} / h=1$

(A3) $\left\{\epsilon_{k h}\right\}_{k=1}^{n}$ are independent and identically distributed across times $k=1,2, \ldots, n$

A market equilibrium price is given by $\left\{r\left(\mathcal{S}_{t}\right),\left(s\left(\mathcal{S}_{t}\right), \sigma\right)\right\}$, which is a function of the aggregate state variables $\mathcal{S}_{t}$. The firm's problem can be stated as maximizing

$$
V_{t} h \equiv \max _{K_{t}, D_{t}, E_{t}}\left\{\Phi\left(K_{t}\right)-r^{*}\left(\mathcal{S}_{t}\right) D_{t}-\left(r^{*}\left(\mathcal{S}_{t}\right)+\sigma_{1} s_{1}^{*}\left(\mathcal{S}_{t}\right)+\tau\right) E_{t}\right\} h
$$

subject to the following constraints:

$$
K_{t}=D_{t}+E_{t}, \quad \sigma_{1}=\frac{\bar{\sigma} K_{t}}{E_{t}}, \quad D_{t} \leq \lambda K_{t}
$$

The equilibrium value of $r^{*}\left(\mathcal{S}_{t}\right)$ and $s_{1}^{*}\left(\mathcal{S}_{t}\right)$ are pinned down by the market clearing conditions that I will specify later.

Turning back to the budget constraint, household $i$ comes into period $t$ with wealth $a_{i t}$. We can write $a_{i t}$ as

$$
a_{i t}=n_{i t} p_{t}+n_{i t}^{D}
$$

where $n_{i t}$ is the number of stock shares, $p_{t}$ is the stock price and $n_{i t}^{D}$ is the number of deposits owned by individual $i$ in period $t$. The portfolio weight on risky assets is $\theta_{1 i t}=n_{i t} p_{t} / a_{i t}$. Each 
deposit pays $r_{t} h$ in period $t+h$ with no uncertainty. Each equity share pays $x\left(\mathcal{S}_{t}\right) h+\sigma_{1} p_{t} \epsilon_{t+h}$ in period $t+h$ and it also pledges future payoffs $x\left(\mathcal{S}_{t+k h}\right) h+\sigma_{1} p_{t+k h} \epsilon_{t+(k+1) h}$ for all future periods $k=1,2, \ldots$ Ex post return of equity shares, $\frac{x\left(\mathcal{S}_{t}\right) h}{p_{t}}+\sigma_{1} \epsilon_{t+h}$, depends on the realization of $\epsilon_{t+h}$. After the dice are rolled up, $\epsilon_{t+h}$ is determined, interest rates are paid and households rebalance their portfolio. All trades are made at known current prices. Households also receive annuity $m h$ for their wealth holdings. We can then obtain

$$
\begin{aligned}
& \left(n_{i t} \pi\left(\mathcal{S}_{t}\right)+n_{i t}^{D} r\left(\mathcal{S}_{t}\right)-c_{i, t+h}\right) h+n_{i t} p_{t} \sigma \epsilon_{t+h} \\
= & \left(n_{i, t+h}-n_{i t}\right) p_{t+h}+\left(n_{i, t+h}^{D}-n_{i t}^{D}\right)
\end{aligned}
$$

Merging (84) and (85), we have

$$
\begin{aligned}
a_{i, t+h}-a_{i t} & =n_{i, t+h} p_{t+h}-n_{i t} p_{t}+n_{i, t+h}^{D}-n_{i t}^{D} \\
& =\left(n_{i, t+h}-n_{i t}\right) p_{t+h}+n_{i t}\left(p_{t+h}-p_{t}\right)+n_{i, t+h}^{D}-n_{i t}^{D} \\
& =\left(\left(r^{*}\left(\mathcal{S}_{t}\right)+\theta_{1 i t}\left(\frac{x\left(\mathcal{S}_{t}\right)}{p_{t}}-r^{*}\left(\mathcal{S}_{t}\right)\right)\right) a_{t}-c_{t+h}\right) h+\frac{p_{t+h}-p_{t}}{p_{t}} a_{i t}+\sigma_{1} \theta_{1 i t} a_{i t} \epsilon_{t+h}
\end{aligned}
$$

Finally, the equilibrium value of $r^{*}\left(\mathcal{S}_{t}\right)$ and $s^{*}\left(\mathcal{S}_{t}\right)$ are pinned down by the market clearing conditions.

$$
E_{t}=\int_{i \in[0,1]} p_{t} n_{i t} d i \quad \text { and } \quad D_{t}=\int_{i \in[0,1]} n_{i t}^{D} d i
$$

In equilibrium, the financial intermediary equalizes

$$
\frac{p_{t+h}-p_{t}}{p_{t}}+\frac{x\left(\mathcal{S}_{t}\right) h}{p_{t}}+\sigma \epsilon_{t+h}=\left(r\left(\mathcal{S}_{t}\right)+\sigma s\left(\mathcal{S}_{t}\right)\right) h+\sigma \epsilon_{t+h}
$$

since, otherwise, they can make profits by taking long-short strategies. I assume that $x\left(\mathcal{S}_{t}\right)=$ $r^{*}\left(\mathcal{S}_{t}\right)+\sigma_{1} s_{1}^{*}\left(\mathcal{S}_{t}\right)$, so have $p_{t}=1$ for all $t$ as long as there is no unanticipated change. Let $r_{t}^{*} \equiv r^{*}\left(\mathcal{S}_{t}\right)$ and $s_{t} \equiv s_{1}\left(\mathcal{S}_{t}\right)$. Plugging this into the household's budget constraint and taking a limit $h \rightarrow 0$, we can see that $a_{i, t}$ follows a diffusion process

$$
d a_{i t}=\left(\left(r_{t}^{*}+\sigma s_{1 t}^{*} \theta_{i t}\right) a_{i t}-c_{i t}\right) d t+\sigma_{1} \theta_{1 i t} a_{i t} d z_{1 t}
$$

in view of (A1), (A2), and (A3). 